\title{
La blessure créatrice entre poterie et sculpture
}

Ou Yagi Kazuo entre la tradition japonaise et l'avant-garde occidentale

\section{Shigemi Inaga}

\section{(2) OpenEdition}

\section{Journals}

Édition électronique

URL : http://journals.openedition.org/imagesrevues/156

DOI : 10.4000/imagesrevues. 156

ISSN : 1778-3801

Éditeur :

Centre d'Histoire et Théorie des Arts, Groupe d'Anthropologie Historique de l'Occident Médiéval, Laboratoire d'Anthropologie Sociale, UMR 8210 Anthropologie et Histoire des Mondes Antiques

\section{Référence électronique}

Shigemi Inaga, "La blessure créatrice entre poterie et sculpture », Images Re-vues [En ligne], 4 | 2007, document 11, mis en ligne le 01 janvier 2007, consulté le 30 janvier 2021. URL : http://

journals.openedition.org/imagesrevues/156 ; DOI : https://doi.org/10.4000/imagesrevues. 156

Ce document a été généré automatiquement le 30 janvier 2021.

\section{(c) (1) (8)}

Images Re-vues est mise à disposition selon les termes de la Licence Creative Commons Attribution Pas d'Utilisation Commerciale 4.0 International. 


\section{La blessure créatrice entre poterie et sculpture}

Ou Yagi Kazuo entre la tradition japonaise et l'avant-garde occidentale

\section{Shigemi Inaga}

\section{NOTE DE L'ÉDITEUR}

Le texte en français est une traduction libre de mon texte rédigé en japonais, publié comme « Furukizu ni yadoru Hikari » (La Lumière qui demeure dans la vieille plaie), dans le mensuel Aida, $n^{\circ}$ 109, 20 janvier 2005. Une autre version abrégée est lue dans le colloque tenu en Alsace 8-10 Décembre, 2005 sur le thème de « La rencontre du Japon et de l'Europe : images d'une découverte ". Un texte légèrement différent est publié dans le Japan Review, International Research Center for Japanese Studies $N^{\circ} 18$ (2007). Nous présentons ici une version modifiée pour convenir à la publication dans un périodique scientifique en langue française.

\section{Préliminaire $^{1}$}


1 Un des pionniers de la poterie avantgardiste au Japon, YAGI Kazuo (1918-1979), traça un chemin sans précédent dans l'art du $\mathrm{XX}^{\mathrm{e}}$ siècle de l'archipel en se détournant de la tradition de la poterie nippone. Considéré comme un génie représentatif de l'avant-garde dans le travail de la céramique, Yagi ne paraît pas encore jouir d'une légitimité

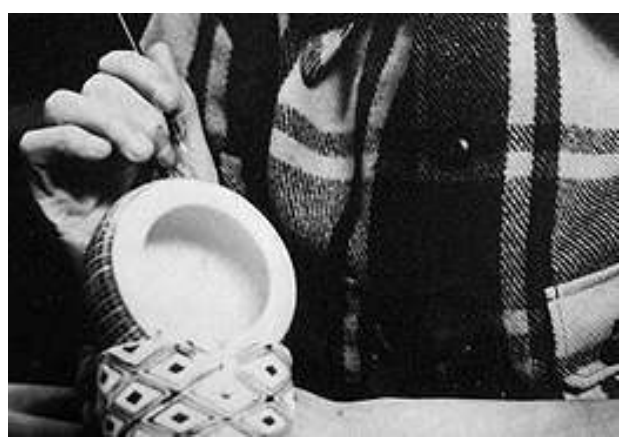
d'artiste au sens occidental du terme. Nous voudrions jeter une nouvelle lumière sur son activité de créateur en comparant son parcours avec celui de sculpteurs et de peintres contemporains tant en Occident qu'en Orient, afin de faire ressortir les spécificités de son œuvre, qui se situe aux confins de la sculpture occidentale et la poterie orientale.

2 Si la sculpture peut s'exprimer par elle-même à travers les matériaux assemblés ou ciselés dans la masse au gré de la volonté de son auteur, la poterie contient un vide en son sein, et c'est autour de ce vide que s'accumule la terre qui va se transformer au contact du feu. Au cours de ce processus le potier est à l'écoute des matériaux, en collaboration avec la nature.

3 S'opposant à la fois à la notion de l'art et à celle des "arts et métiers ", la pensée plastique de Yagi Kazuo synthétise la confrontation inhérente à la rencontre entre l'Europe et le Japon, et scrute la marge étroite entre les deux. Notre but sera de sonder le secret de sa création qui se traduirait par la cicatrice due à la confrontation entre la vocation d'un art conceptuel et autonome à venir, et la conception passéiste d'un récipient utilitaire. Dépourvu de sa fonction primaire, le vase extériorise chez Yagi Kazuo son potentiel propre.

4 En se concentrant sur le cas de Yagi Kazuo, nous nous proposons d'éclaircir les influences mutuelles qui sont en jeu dans la communication artistique entre Est et Ouest. Nous souhaiterions aussi mesurer les dimensions philosophiques qui y sont concomitantes. Les images découvertes dans ce processus recèlent la clef d'une découverte réciproque.

\section{« Être en butte à soi-même »}

5 Le caractère chinois pour 'créer' veut aussi dire « blessure » et " ouverture ». Dans son essai intitulé « Être en butte à soi-même » (en 1976) Yagi Kazuo s'amuse de ce double sens : la création comme blessure. Causer une blessure à la liberté pour la contraindre, et se confronter au cadre imposé de force par la volonté même de l'artiste afin de le surmonter (p.131) ${ }^{2}$. Tel fut le cheminement de la création plastique de Yagi dans ses dernières années. Nous voudrions retracer quelques-unes de ces blessures que subit l'artiste-potier japonais dans son tâtonnement créateur. Les traces que laisse le processus créateur sont autant de blessures d'amour propre qui marquent l'ontogenèse d'un créateur. Loin d'être personnelle, cette ontogenèse résume à elle seule toute l'histoire de la phylogenèse de la rencontre du Japon et de l'Europe dans le langage 
plastique. En effet la création de Yagi Kazuo s'articule comme le chiasme ou la fissure creusée entre la poterie japonaise et la sculpture occidentale.

\section{Tanuki - jijii ou Joan Miro déguisé ?}

Fig.1.

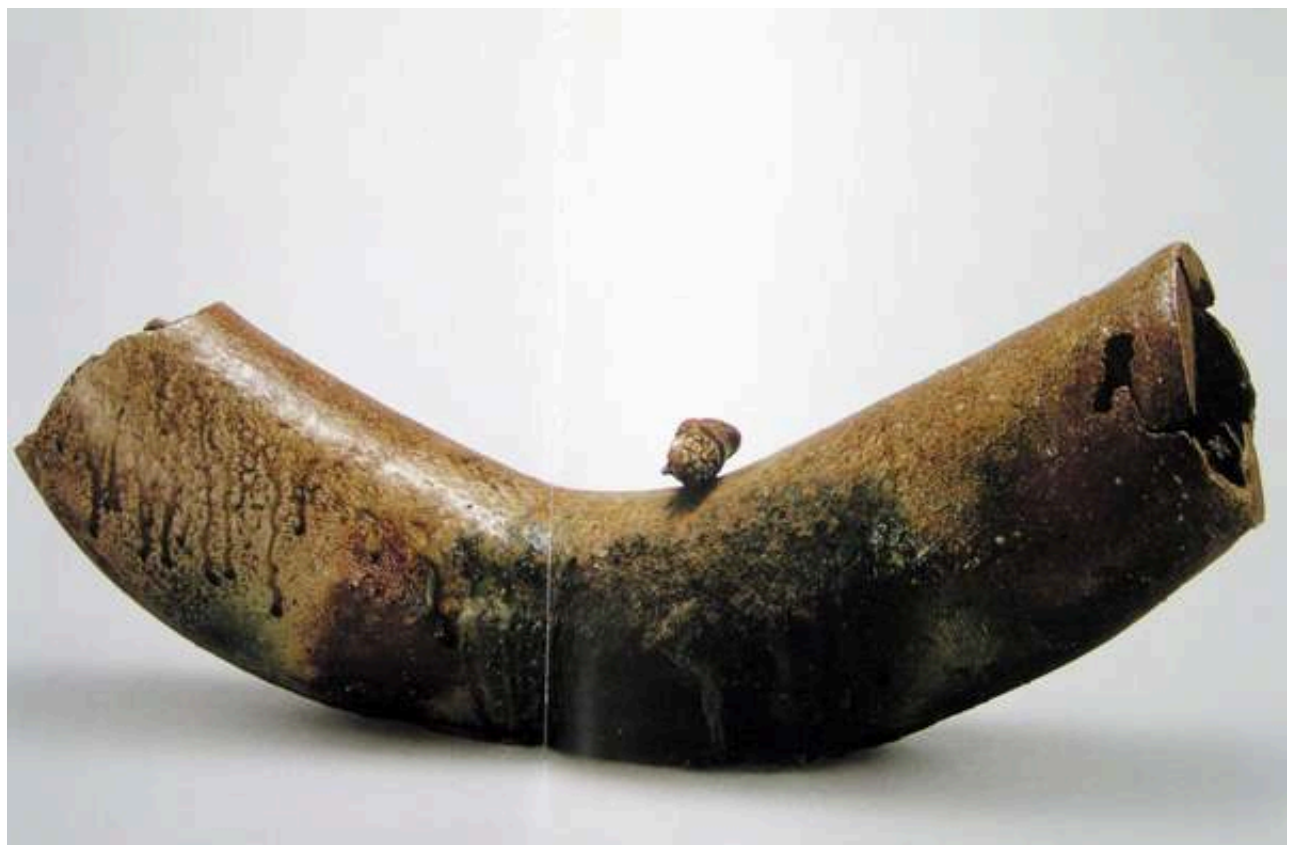

Yagi Kazuo, Earthen Pipe, Shigaraki Ware, 1966. Dans Yagi 2004, p. 94 
Fig.2.

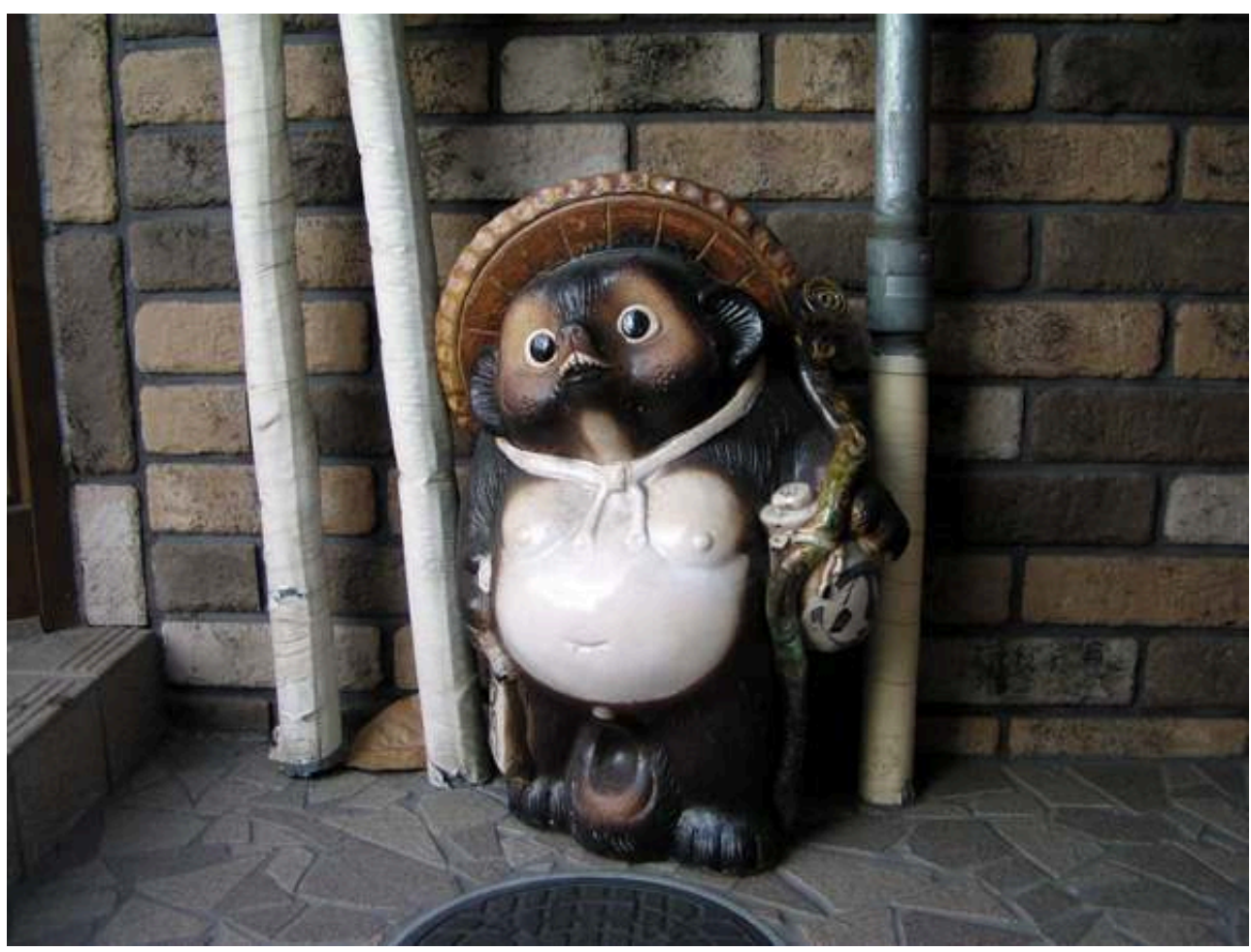

Anonyme, Shigaraki tanuki fabrication artisanale en terre cuite à Shigaraki. @o Shigemi Inaga

En ce sens, «Tuyau de terre cuite à Shigaraki» (1966: 94) (fig.1) est révélateur³. D'un bout à l'autre, le tuyau mesure $80 \mathrm{~cm}$ de longueur et le diamètre est d'environ $30 \mathrm{~cm}$. Le tube de terre est rompu au milieu et les deux extrémités, surélevées, sont coupées en l'air de façon irrégulière, ouvrant leurs bouches comme des blessures béantes. Sur la courbure convexe, se trouve attaché un petit chien viverrin (tanuki) en terre cuite de Shigaraki (fig.2) et un autre se cache près de l'une des ouvertures du tuyau, comme si les deux animaux en terre jouaient à cache-cache. Ces rajouts animaliers, accessoires et ludiques sont en fait un clin d'oeil ironique de Yagi aux céramistes qui ont coutume de se réjouir, comme d'une grâce inattendue, de la réunion accidentelle de deux pièces ayant chutées l'une sur l'autre à la cuisson. En effet, ces rajouts chez Yagi ne sont pas accidentels mais bien intentionnels. Et nous voudrions y voir la trace de la blessure que fut pour Yagi sa rencontre avec Joan Miro en 1966 (fig.3). Lors du séjour que fit à Kyoto l'artiste espagnol de 73 ans, Yagi Kazuo, alors âgé de 48 ans, fut son accompagnateur pour le voyage à Shigaraki. 
Fig.3.

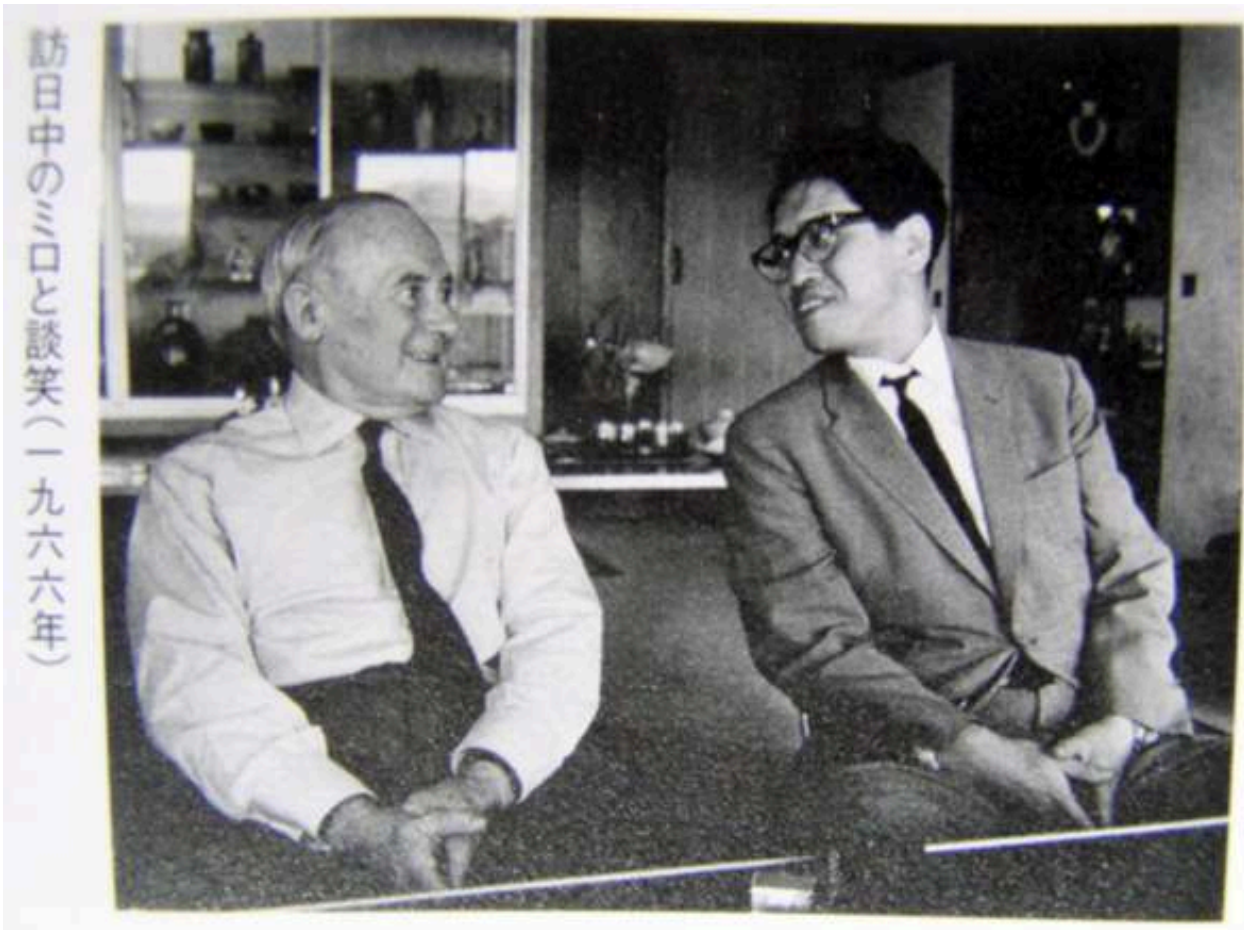

Photo de Yagi Kazuo avec Joan Miro prise en 1966. Dans Yagi 2004, p. 297.

7 Joan Miro (1893-1983) s'intéressait alors à la peinture sur poterie de Majorque et à la sculpture en terre cuite. Yagi remarquait chez le maître espagnol « un talent toujours juvénile et plein de poésie, qui ne cessait de dépeindre un paysage où les étoiles et les jeunes femmes se rencontrent en des couleurs primaires retentissantes ». Yagi avait prévu un itinéraire qui plairait à son hôte, incarnation de la Méditerranée et dont le pas léger et dansant, l'instant d'une photo prise sur le trottoir parisien, était resté gravé dans sa mémoire. Pourtant le Miro qui apparut au Japon n'était plus celui que Yagi avait vu sur la photo. Le vieillard au geste lent et au pas lourd rendit Yagi perplexe. Le décalage entre l'attente et la réalité plongeait l'accompagnateur japonais dans la confusion. Yagi était presque déçu de ce Miro vieilli, qui montait, complètement épuisé, à la Villa impériale de Katsura et admirait une oeuvre japonaise représentant le soleil levant que Yagi trouvait médiocre et sans intérêt artistique aucun, quand Yagi fut assailli comme par un coup de foudre. Avec une agilité et une perspicacité inattendues, le vieillard découvrit dans le jardin, et de sa propre initiative, une statue de Tanuki du style Shigaraki que Yagi voulait lui présenter plus tard. Ce fut une immense surprise et Yagi se sentit presque dupé par Miro. Il fut devancé par ce vieux malin (tanuki-jijii en japonais) qu'il avait pris, à tort, pour sénile et maladroit (« Une promenade avec Miro » (1966: pp. 49-57)).

8 Cette anecdote d'apparence anodine nous aidera à mieux comprendre la présence des deux petits animaux parasites qui se trouvent fixés sur le tuyau exécuté l'année même du séjour de Miro à Kyoto. Dans la tradition populaire, les tanukis sont célèbres pour leur espièglerie et l'espèce humaine est souvent le jouet de cet animal rusé. Ces deux bêtes qui jouent à cache-cache peuvent être les figures déguisées de ces deux artistes. Leur dialogue (ou plutôt tentative de tromperie) entre l'extérieur et l'intérieur d'un tuyau peut être considéré comme une métonymie: qui de Yagi (qui se cache dans le 
vide intérieur) ou de Joan Miro (qui s'exhibe à l'extérieur), se laisse tromper au croisement de la poterie et de la sculpture ? Par son ton aussi ironique que ludique, la pièce pourrait être interprétée comme un exemple historique d'autoportrait de l'auteur faisant face au génie occidental. Cristallisant l'autodérision d'un guide local qui se laissait tromper par un invité étranger, la pièce montre la prise de position d'un céramiste japonais, celui qui essayait de communiquer avec le monde extérieur des artistes et sculpteurs de renommée mondiale tout en demeurant au sein de la tradition artisanale de la poterie enracinée dans la ville de Kyoto dont il est issu. Le fléchissement du tuyau traduirait le fléchissement mental de Yagi Kazuo lui-même dont l'esprit fort complexe se trouvait « en butte à soi-même ».

\section{Signes et physiologie}

La poterie est classée en France dans la catégorie des arts et métiers et n'est pas considérée comme faisant partie intégrante des Beaux-Arts. Au titre de maîtres incontestables, un Joan Miro ou un Pablo Picasso (1881-1973) ont le privilège de pouvoir s'essayer librement à la poterie, comme extension de leur création plastique, mais quelqu'un qui commença sa carrière professionnelle comme artisan ne peut que difficilement se faire reconnaître comme artiste. D'après Isabelle Charrier, Yagi ne peut pas être considéré en France comme un sculpteur à part entière, tant qu'il (et dans la mesure où il) reste réputé en tant que potier distingué4. Face à cette différenciation à la fois axiologique et institutionnelle entre Beaux-Arts et arts et métiers, Yagi Kazuo a dû essayer de combler l'écart ontologique entre poterie et sculpture.

Fig.4.

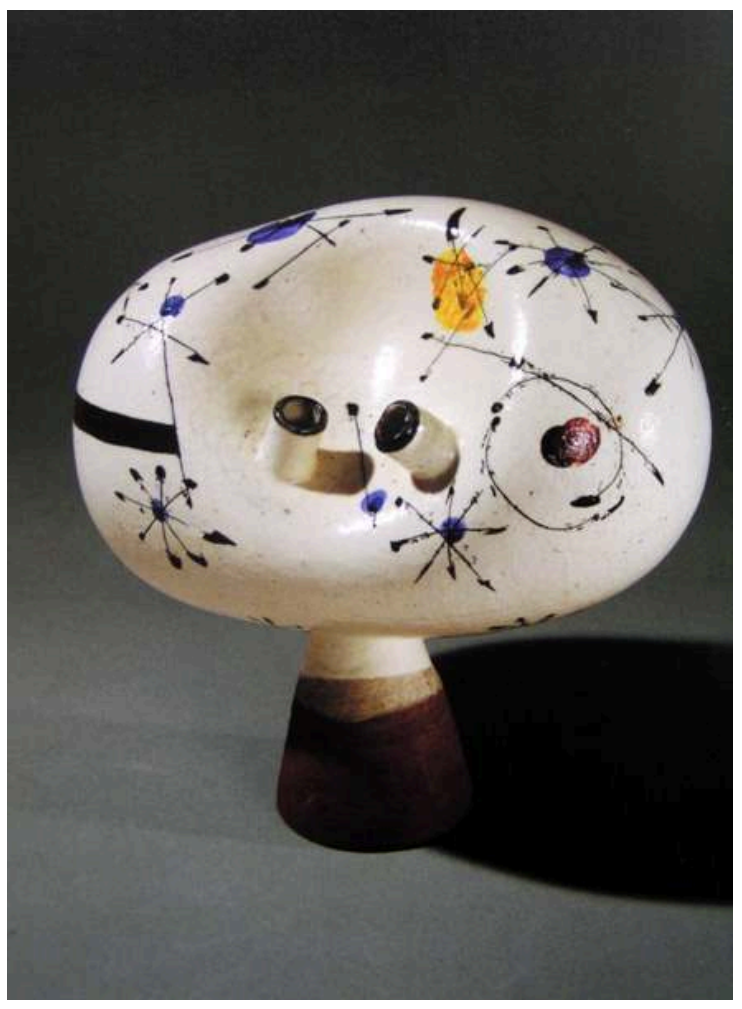

Yagi Kazuo, Vase with Two Small Mouths, 1950. Dans Yagi 2004, p. 13. 
Fig.5.

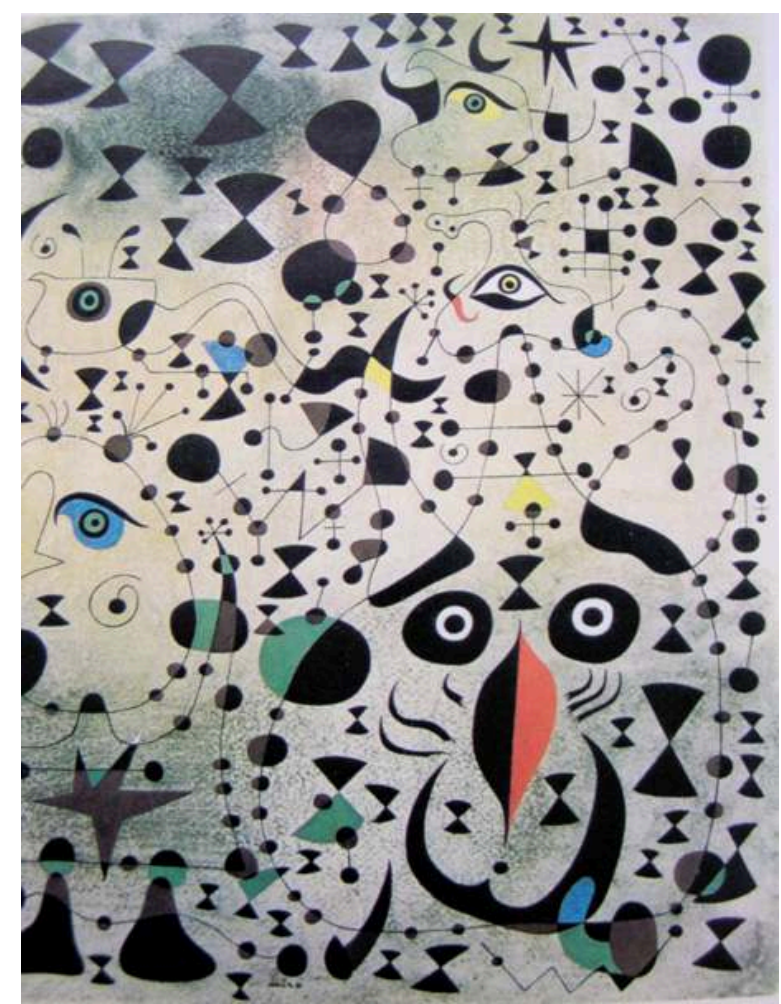

Joan Miro, Un bel oiseau dévoilant le monde inconnu aux amoureux, 1941 Museum of Modern Art, New York. Dans Asahi No 70, vol. 7 : p. 262.

http://www.moma.org

Dès sa jeunesse Yagi a été attiré par les signes plastiques inventés par Joan Miro, et essaya de les appliquer sur sa céramique, comme en témoigne le "Vase à deux bouches " (1950: 13) (fig.4) et (fig.5). À propos des objets en faïence italienne, Yagi remarqua en 1970 le peu de contraintes techniques qui pèsent sur les Italiens. Si la céramique japonaise présente une physionomie sérieuse résultant $\mathrm{du}$ compromis nécessaire avec les matériaux, un tel souci pratique fait défaut à la faïence italienne donnant libre cours à une aisance typiquement latine. Ce furent la nonchalance et la liberté dont jouissaient les Italiens dans leur rapport à la terre qui frappèrent le céramiste japonais. L'aridité et la franchise d'esprit qu'il observa dans la recherche plastique en Méditerranée restaient inconnues aux artisans de l'archipel extrêmeOriental.

Pourtant Yagi a également bien compris que la création chez Miro n'était guère une improvisation ni une application autonome de ses signes personnels aux objets choisis. Les propos de Miro, recueillis par Yagi, attestent en effet le contraire. Tout en confessant la forte impression que lui a faite la visite à Shigaraki, Miro reconnaît aussi qu'il lui faudrait prendre le temps de re-examiner tant la technique que les matériaux avant de faire réellement sienne cette expérience, et de la transformer en signes plastiques personnels. Ce message de Miro, rapporté par Yagi, suggère bien que ce dernier a pu trouver une confirmation de sa conviction personnelle en écoutant ce vieillard laconique. 
Fig.6.

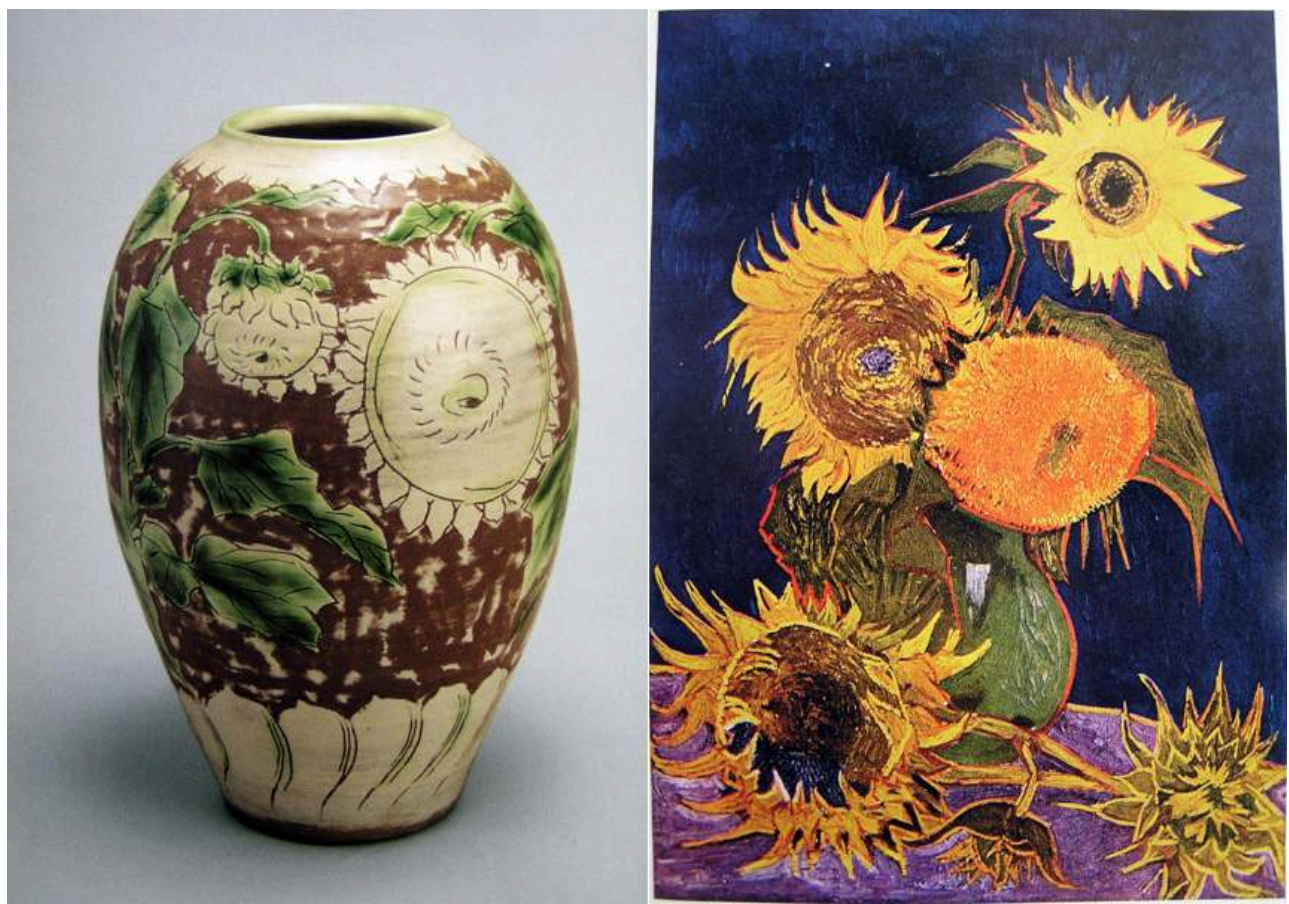

Yagi Kazuo, Pot with Sunflower Design, 1947. Dans Yagi 2004, p. 6; Vincent van Gogh, Sunflowers, 1888. Ancienne collection Yamamoto (F.459), pièce détruite à la fin de la Deuxième Guerre mondiale à Ashiya.

Comment ciseler des signes picturaux sur une surface de terre? Quel serait le rapport entre le support et le motif? Commençons par analyser ces problèmes. "Le vase à tournesol » (1947: 6) (fig.6a) emprunte clairement le motif favori de Vincent van Gogh (fig.6b) afin d'en fixer l'expressivité sur la céramique. A ce stade le support de terre reste neutre, mais au bout de quelques années, Yagi ne se contente plus d'un traitement aussi superficiel. «Le plat avec la scène de revue au café concert » (1949: 10) (fig.7a) rappelle la peinture à l'huile de MIGISHI Kôtarô (1903-1934) représentant «L'Orchestre » (en 1933) (fig.7b). Si Migishi dessina la scène en grattant au couteau les pigments collés sur la palette pour dévoiler le fond noir du bois qui sert de support au dessin, Yagi profite du fond mou de la terre crue pour y ciseler les dessins au pigment de fer. Une fois le plat cuit, le noir apparaît incrusté dans le fond. Le dessin n'est pas collé sur la surface du support mais il fait, au sens propre, corps avec la terre, modifiant son rapport avec le support. Avec le «Vase au motif floral " (1953-4 : 17) (fig.8), Yagi fait encore un pas de plus. Le dessin ciselé constitue maintenant une intrusion littéralement physique dans la matérialité du vase, laissant voir une intention violente et insolite de briser le vase par la force même du dessin gravé. Ici, le motif floral n'est plus un accessoire parasite et décoratif du support, mais il en menace la stabilité sans laquelle, pourtant, il ne peut exister. La fleur dessinée s'enracine dans la vase avec une telle force qu'elle court le risque de commettre ce qui serait un double suicide, détruisant le terrain sur lequel elle est implantée. 
Fig.7.

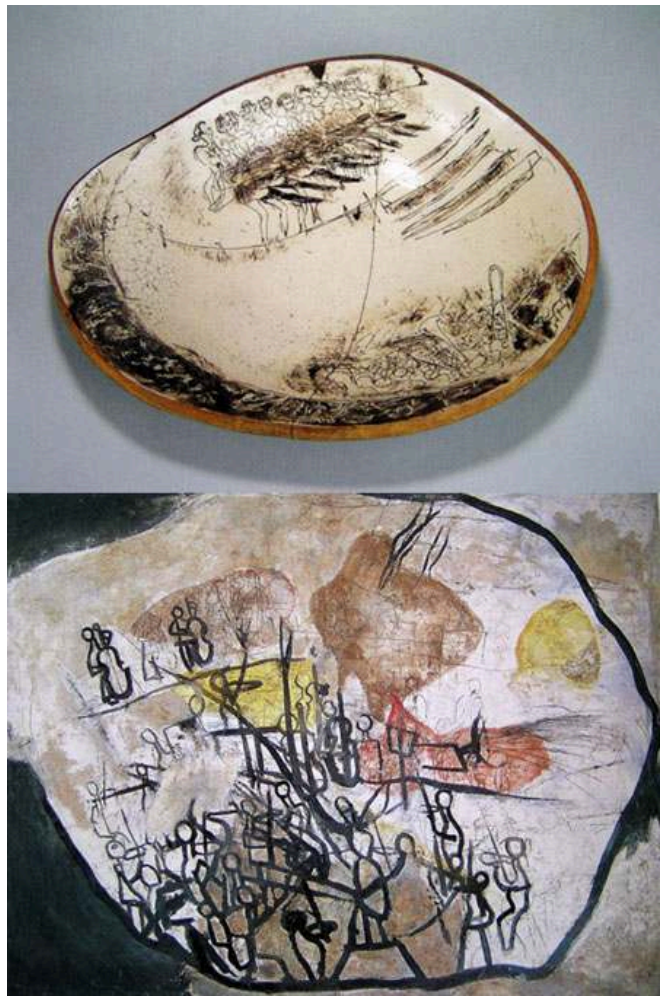

Yagi Kazuo, Large Bowl, with glaze, â€ Review', 1949. Dans Yagi 2004, p. 10; Migishi KÃ'tarÃ', Orchestra,

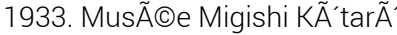

Fig.8.

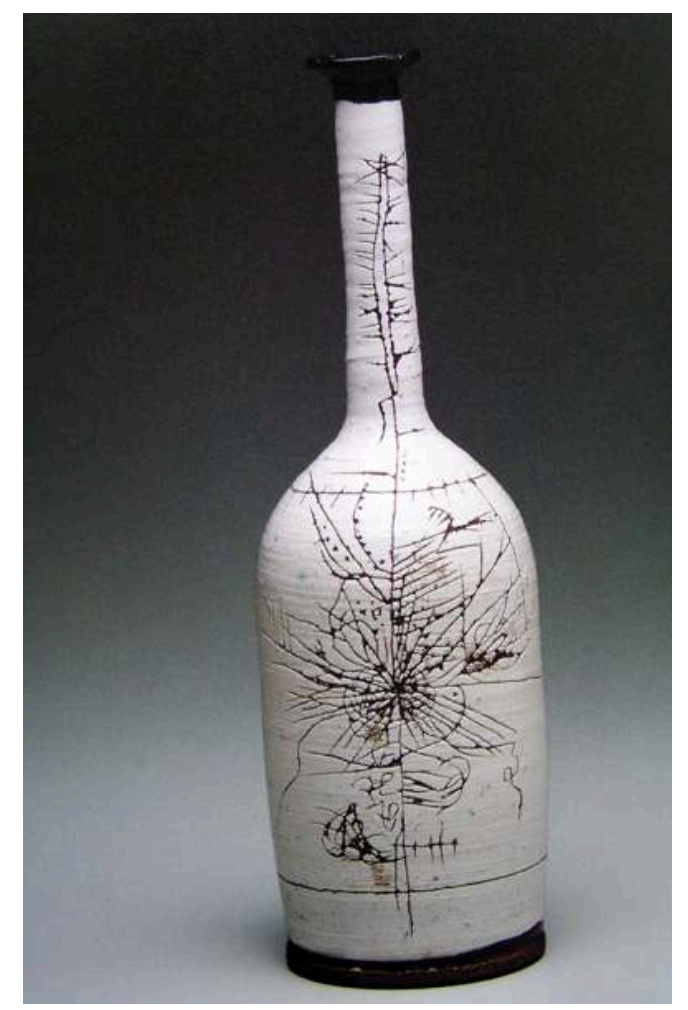

Yagi Kazuo, Vase, Floral Design. Dans Yagi 2004, p. 17. 
Comment expliquer une telle transgression radicale? Une des hypothèses envisageables serait un rejet, de la part du jeune Yagi, de Tomimoto Kenkichi (1886-1963) (fig.9). Grand classique de la céramique moderne, Tomimoto était particulièrement strict concernant la peinture sur céramique (fig.10). Yagi remarque une sorte d' » ivresse à dessiner » chez Tomimoto ; elle l'aurait empêché de pousser la recherche plastique jusqu'à la fissure fatale, à force d'incrustation de peinture («Sur Monsieur Tomimoto"(1974: pp.61-70)). Être potier consistait pour Yagi non pas à obéir à ce bon sens de Tomimoto mais à essayer au contraire de trouver la limite à la fois matérielle et conceptuelle du métier, et ceci quitte à rendre impossible la coexistence de la peinture et de la poterie.

Fig.9.

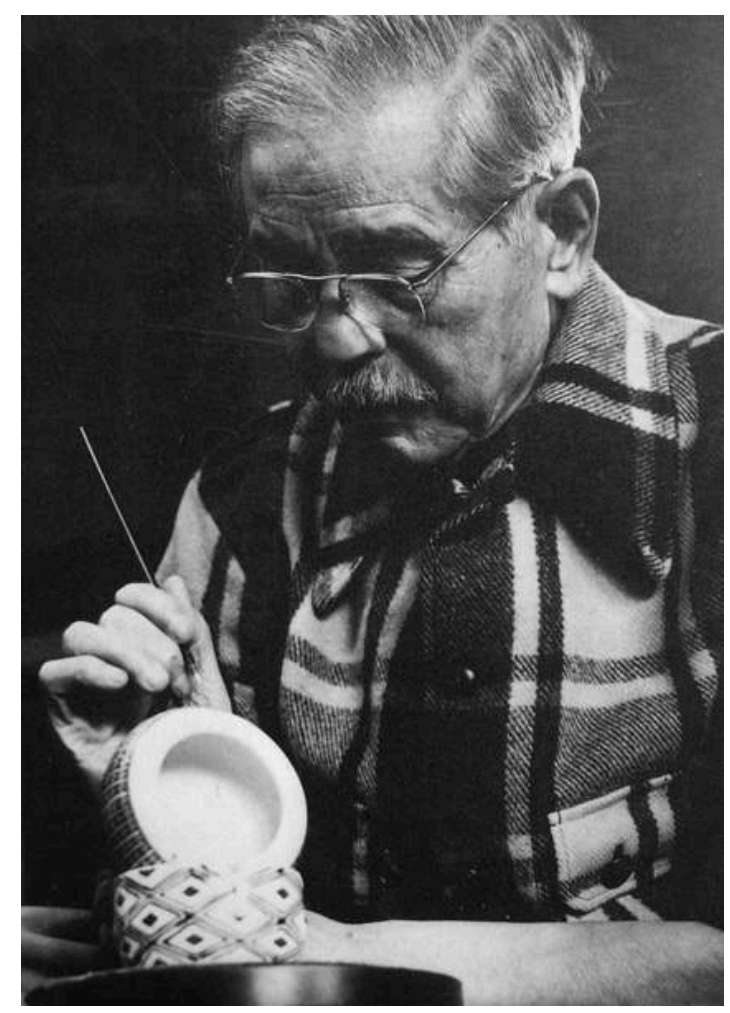

Photo de Tomimoto Kenkichi. Dans NANAKNODÔ Isshin ed., TOMIMOTO Kenkichi, Odakyû Museum, Daimaru Museum Kyoto ; The Asahi Shinbun, 1995, couverture. 
Fig.10.

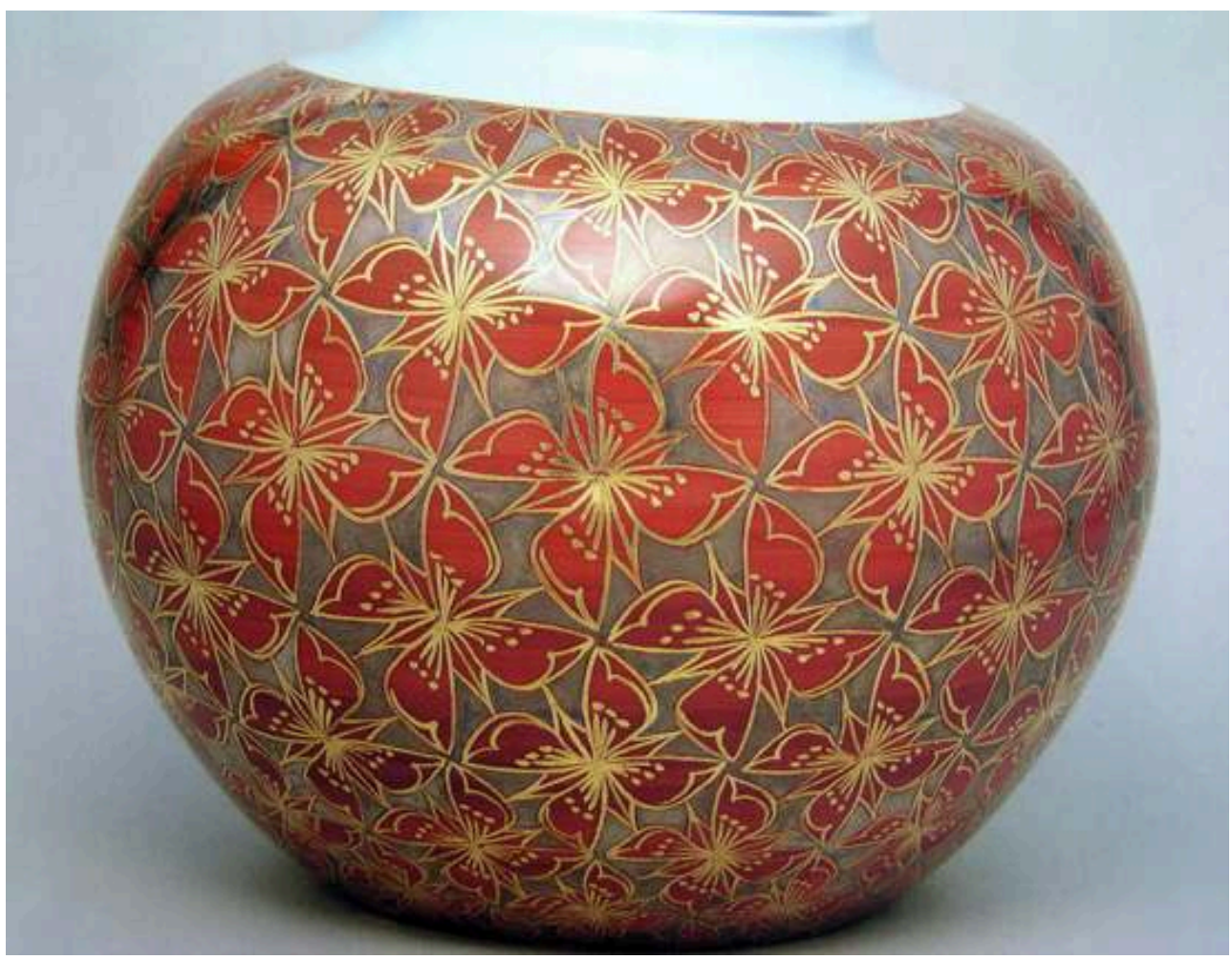

Tomimoto Kenkichi, Vase à motif peint de fleurs à quatre pétales en or, 1960. Dans NANAKNODÔ Isshin ed., TOMIMOTO Kenkichi, Odakyû Museum, Daimaru Museum Kyoto ; The Asahi Shinbun, 1995, p. 126.

Le « Vase à deux bouches » paré des signes à la Miro présente cette autre particularité qu'il est doté de deux trous. Ces trous figurent des fosses nasales ou des orbites oculaires. Mais leur fonction reste énigmatique du point de vue de l'usage quotidien. De même, « le vase blanc avec des fleurs incrustées en noir » (1952-3:15) (fig.11a) possède aussi deux cheminées dont les bouches noires font écho aux signes noirs, eux aussi, de Paul Klee (1879-1940) (fig.11b). Pourquoi les deux trous? Dans sa jeunesse Yagi a eu l'occasion de critiquer le brûle-parfum en forme d'oiseau confectionné par son maître Numata Ichiga (1873-1954), spécialiste de «céramique ciselée ». N'ayant qu'un seul trou, ce brûle-parfum ne permet pas la circulation de la fumée et ne fonctionne pas correctement. Yagi se rappelle de cette critique audacieuse qu'il osa lancer à son maître, au désarroi de leur entourage (« Le Maître inoubliable, Numata Ichiga » (1968: pp. 58-60). «Le traumatisme de cette expérience me revenait régulièrement à l'esprit comme une fièvre périodique ». Est-on autorisé à y détecter une clef psychanalytique pour expliquer cette obsession particulière de Yagi pour les doubles trous? 
Fig. 11.

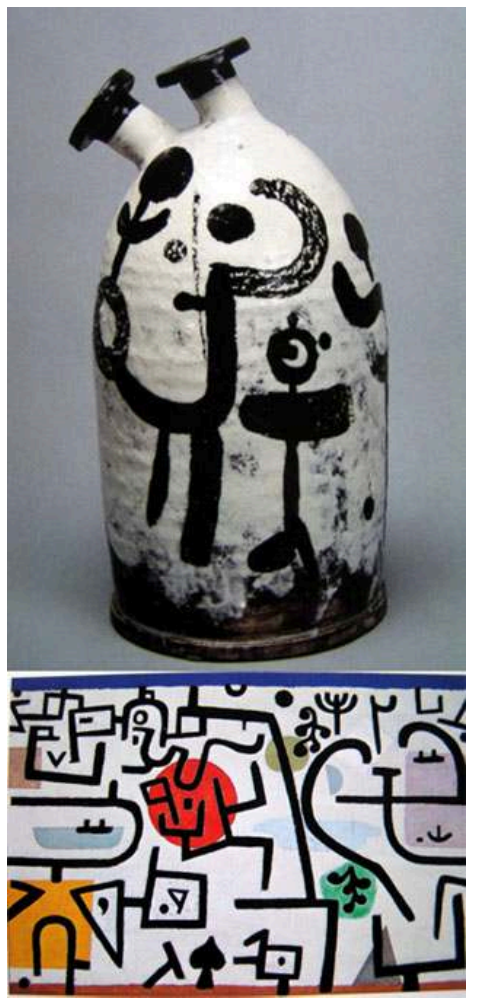

Yagi Kazuo, Vase, Black Inlay on Brushmark Pattern, 1952-53. Dans Yagi 2004, p. 15 ; Paul Klee, La porte joyeuse,1938. Musée des Beaux-Arts, Bâle.

http://www.kunstmuseumbasel.ch/ 
Fig.12.

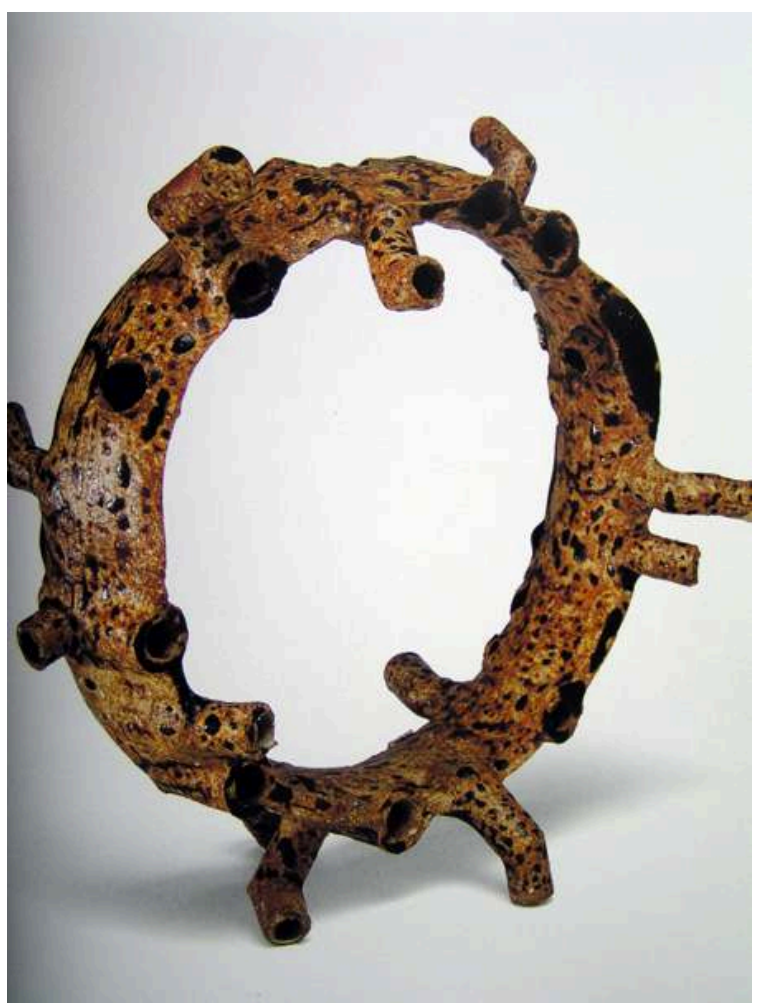

Yagi Kazuo, The Walk of Mr. Samsa, 1954. Dans Yagi 2004, p. 19.

Bientôt ces tuyaux sans fonction définie commencent à se multiplier et s'attachent comme des parasites au cercle détaché du tour (rokuro). Ni les trous, ni le cercle ne servent plus à rien du point de vue pratique. Et le cercle cesse d'être horizontal mais se dresse verticalement en s'appuyant sur ces tuyaux qui servent maintenant de pieds. Voici qu'apparaît la «Promenade de M. Samsa» (1954: 19) (fig. 12), qui marque la naissance de la céramique avant-gardiste au Japon.

\section{Entre l'artiste et l'artisan}

En se servant d'une tournure intentionnellement péjorative, Yagi insista durant toute sa vie sur son identité de «chawanya » ou fabricant du bol de riz ${ }^{5}$. En tant que potier, Yagi s'attachait à perfectionner son maniement du tour. La nouveauté particulière de la «Promenade de M. Samsa » consistait à s'être délivré de la règle pratique dans laquelle il s'était enfermé, sans sacrifier pour autant le métier du tour. D'après Yagi, le bon maniement du tour réside dans un équilibre fluide et presque nécessaire que l'artisan doit maintenir entre sa main et la terre glaise. Entre la force centrifuge du tour et la force d'agrégation inhérente à la terre kaolinique, il y a un état de repos parfait qu'un bon travail artisanal ne cesse de chercher au détriment d'une volonté égoïste de créateur. Une déviation par rapport à cet équilibre idéal ne peut que signifier la disqualification en tant qu'artisan, honte insupportable pour Yagi. Ce souci du métier artisanal se conjugue chez lui avec des sentiments ambivalents par rapport à l'innocence ingénue d'un Tomimoto Kenkichi (fig.13); la manière dont ce dernier maniait le tour ne méritait pas de compliments, mais sa nonchalance candide ne cessait de susciter l'envie compliquée de Yagi (fig.14a). Cet amour-propre blessé rendrait sans 
doute compte de la psychologie profonde de Yagi et jetterait une lumière sur le mécanisme mental qui l'a conduit à la métamorphose, à l'instar de M. Samsa transformé en bête dans l'imagination de Franz Kafka.

Fig.13.

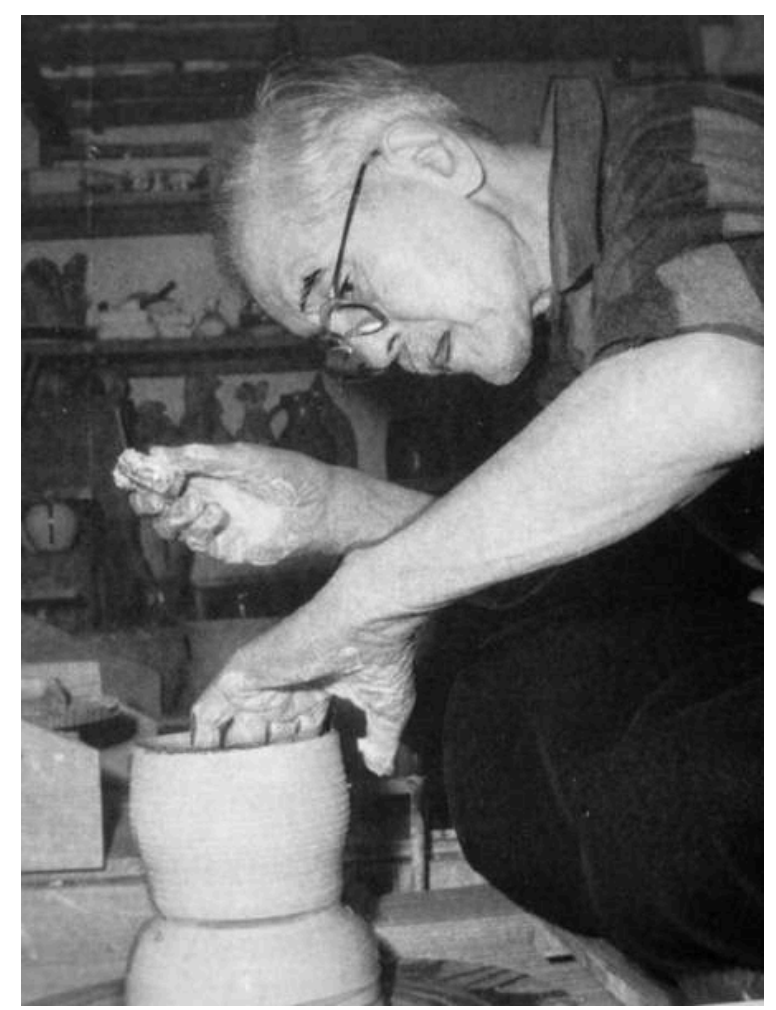

Photo de Tomimoto Kenkichi maniant le tournant. Dans NANAKNODÔ Isshin ed., TOMIMOTO Kenkichi, Odakyû Museum, Daimaru Museum Kyoto; The Asahi Shinbun, 1995, p. 101. 
Fig.14.

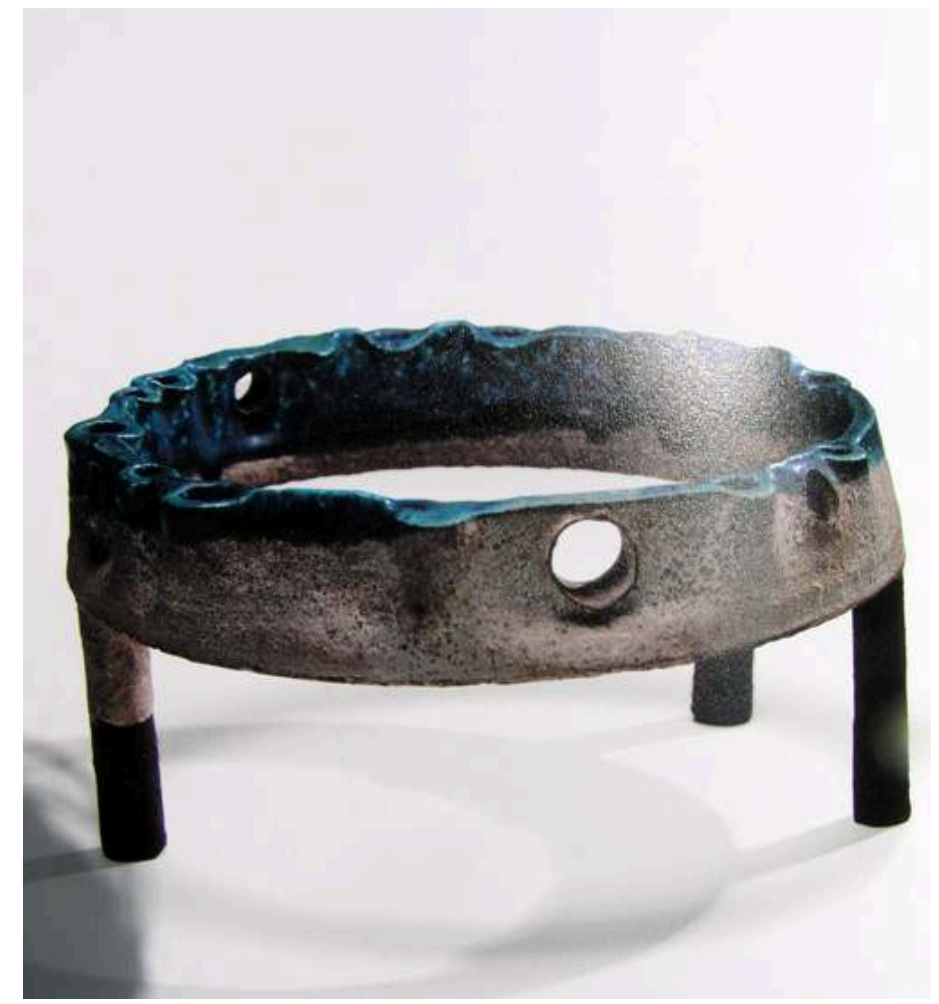

Yagi Kazuo, Vase, Circular Tube, 1954. Dans Yagi 2004, p. 18.

17 Pour comprendre la métamorphose de Yagi en 1954, il faudrait aussi tenir compte de l'impact qu'a eu sur lui l'exposition consacrée à Isamu NOGUCHI (1904-1988) au Musée municipal d'art moderne de Kanazawa en 1952 (fig.14b). Dans son compte rendu, TAKIGUCHI Shûzô (1903-1979), critique et poète surréaliste, remarqua que les Japonais d'autrefois ont eu autant de liberté qu'en a montré Noguchi dans leur création, sans se soucier de la distinction entre sculpture et poterie. « Les Japonais d'antan savaient faire respirer plus librement les formes dans leur vie sans les contraindre aux normes d'une sculpture ou d'une poterie » («Sur Isamu Noguchi ou un voyage fantastique » 1952). Ce texte aurait pu être pour Yagi un catalyseur afin de s'affranchir du joug du métier traditionnel. Révélateur également est le fait que Takiguchi parle dans le même texte de «sensation de volume spatial propre à la poterie qui s'appuie sur le vide» qui se cache à l'intérieur. 
Fig.15.

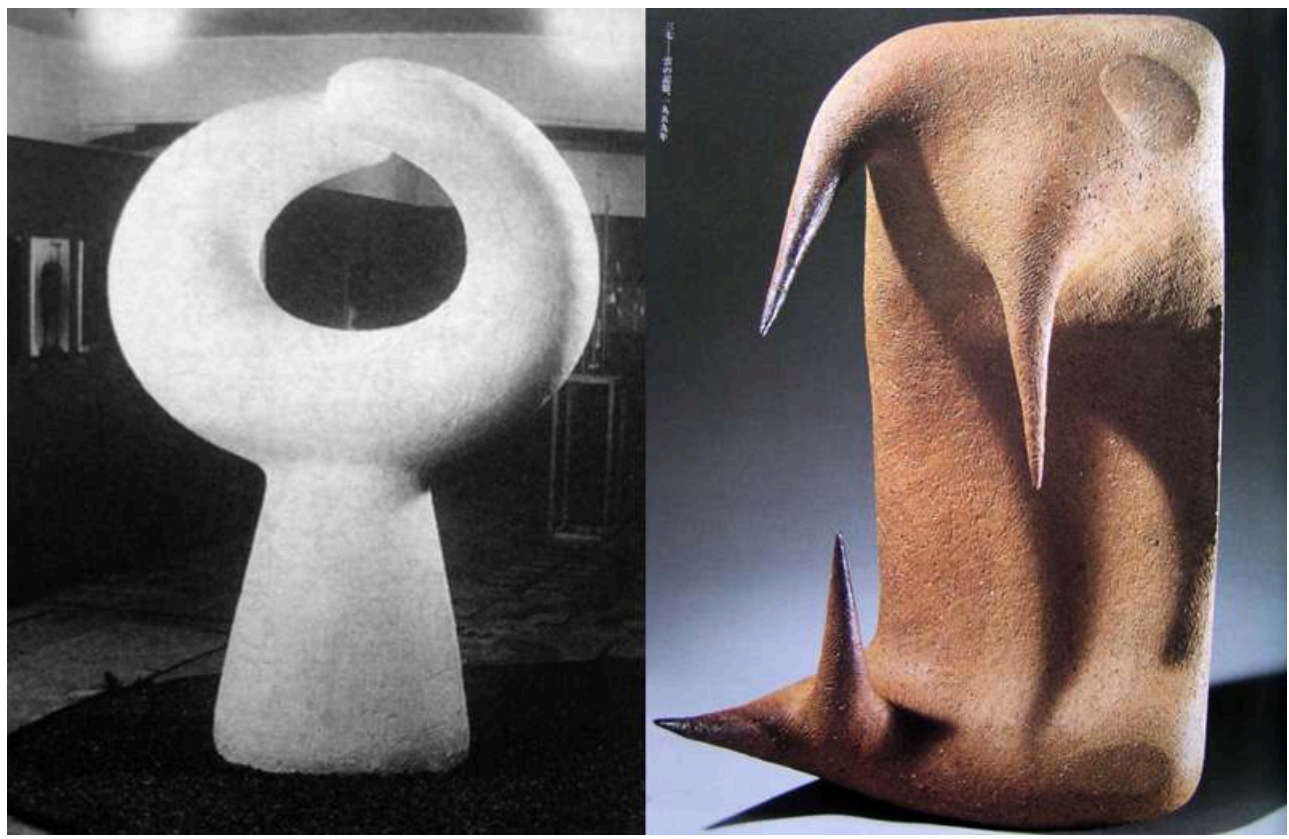

Isamu Noguchi, Nothingness, 1950. Université de Keiô, Tokyo ; Yagi Kazuo, A Cloud Remenbered 1959. Dans Yagi 2004, p. 37.

Fig.16.
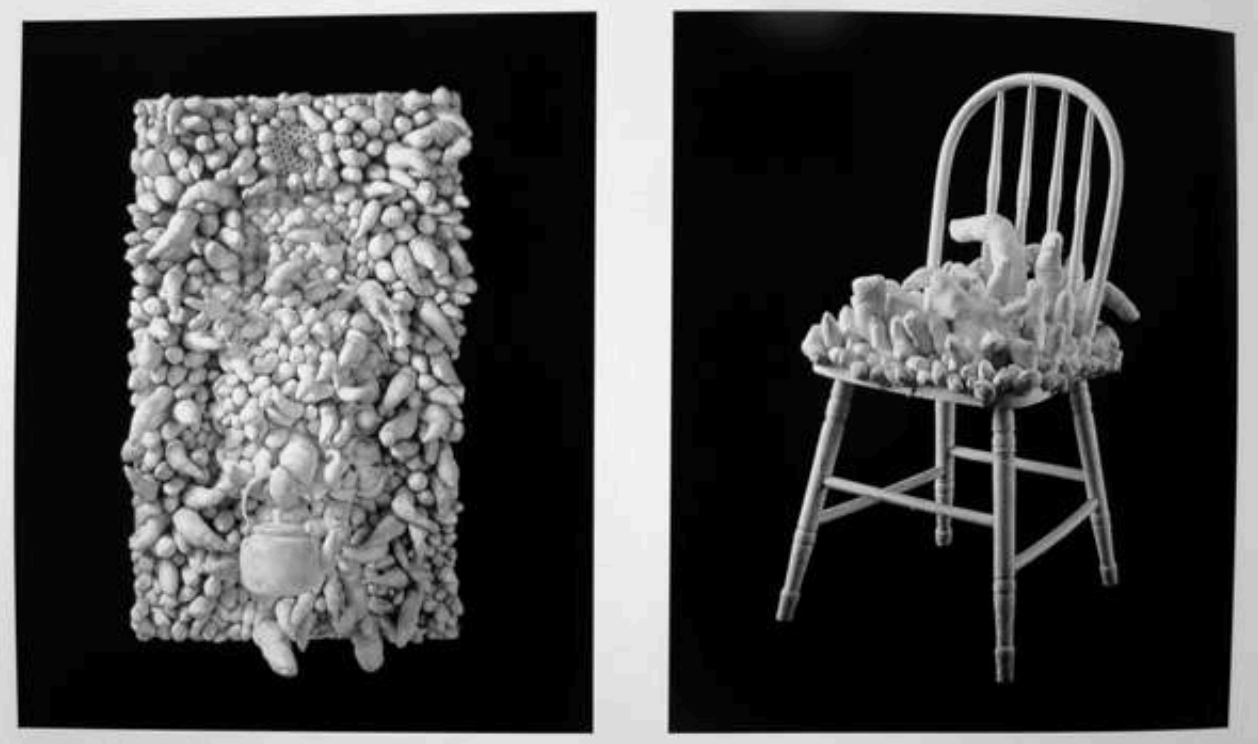

Kusama Yayoi, The Man, 1963; Untitled (Chair). Dans KUSAMA Yayoi, MATSUMOTO Tôru, SHIBUTAMI Akira, DEHARA Hitoshi, Yayoi KUSAMA, Eternity-Modernity, The National Museum of Modern Art, Tokyo, Kyoto, 2004-2005, p. 56.

18 En effet, la question du vide que contient la cavité d'un vase sera essentielle dans les discussions du groupe Sôdeisha fondé par Yagi et ses camarades. C'est la cavité enfermée à l'intérieur d'un vase qui permet à la poterie de se distinguer par rapport à la sculpture. Dans son célèbre Livre du thé (1906), OKAKURA Kakuzô (1863-1913) avait déjà saisi que l'essence d'un vase est dans sa cavité. « La Mémoire d'un nuage » (1959 : 
37) (fig.15) avec sa forme qui suggère l'air contenu en son sein en est certainement l'exemple typique à l'état sublimé. Et si on en retrace la généalogie descendante, on peut rencontrer la "soft sculpture » (fig.16) conçue et réalisée par KUSAMA Yayoi (1929-). Se composant d'un assemblage de tissu épidermique rempli d'air, la «soft sculpture » fait partie d'une stratégie féministe, puisque le concept de cette sculpture molle consiste à greffer d'innombrables formes phalliques sur la peau constitutive des produits artisanaux des arts appliqués (mobilier, comme féminité incarnée). Kusama a intentionnellement transplanté le symbole du principe masculin (mais gonflé par l'air) afin de transformer l'objet en « une sculpture » classable dans la hiérarchie masculine des Beaux-Arts. Il est vrai qu'une volonté de transgression aussi provocante faisait encore défaut à Yagi, mais il n'en est pas moins indéniable que «La Mémoire d'un nuage » participe d'une stratégie pour faire passer la céramique de la catégorie des arts mineurs à celle de la sculpture. Il s'agissait de donner la parole à la céramique dans le monde des Beaux-Arts sans sacrifier pour autant sa spécificité en tant qu'englobant du vide.

\section{La Surface et l'intériorité}

19 Tant que ses flancs n'enveloppent que du vide, le vase reste passif, car le contenant ne se définit qu'en fonction du contenu. Comment le vase passif par nature peut-il endosser un rôle d'objet autonome dans le monde à trois dimensions? Telle fut une des préoccupations majeures de Yagi Kazuo dans les années 60. Pour affronter ces problèmes, le céramiste a recours d'un côté à la confrontation complémentaire des formes mâle et femelle et d'un autre côté à l'inversion de l'intérieur et de l'extérieur. La dialectique du contenant et du contenu - question rarement posée dans la sculpture - est en jeu. La faïence noire ('black ware') y joue un rôle important. 
Fig.17.

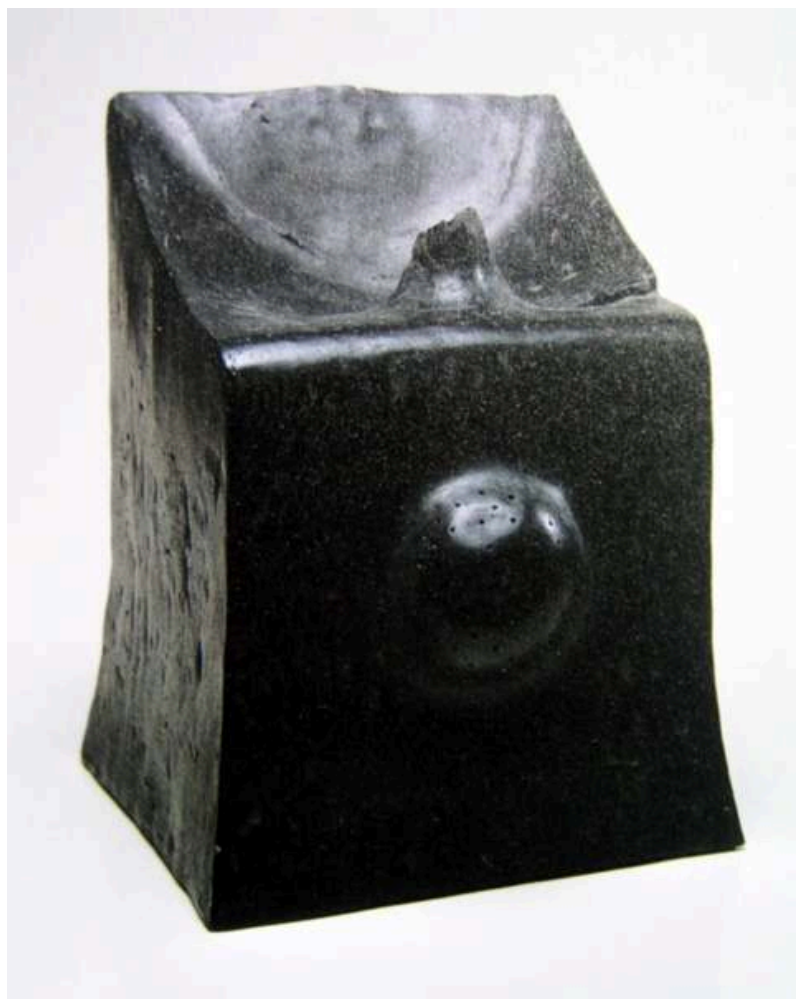

Yagi Kazuo, Garment, Black Ware, 1963. Dans Yagi 2004, p. 49.

Le « Vêtement » (1963 : 49) (fig.17) est une boîte noire, couverte d'un drap noir. Telle un coussin en cuir noir, la partaie supérieure montre une courbure concave; donnant l'impression qu'une femme voluptueuse était assise dessus et l'a quitté en y laissant l'empreinte de la sinuosité de son corps. La forme qui en résulte n'est pas autonome mais assujettie au moule absent et subordonnée à la loi de la gravitation. Une telle subordination féminine à la forme extérieure s'oppose au principe du modelage occidental (fig.18a), comme le rappelle le scandale d'une statue d'Auguste RODIN (1840-1917) dont on a soupçonné le moulage d'après un corps humain vivant (fig. 18b). Dans le cas de Yagi, ce n'est pas le torse mais un moule femelle du torse qui se déguise subrepticement en la pièce achevée. S'arrogeant ainsi le titre et le statut d'une oeuvre d'art, la forme, à l'origine subordonnée et passive, s'affiche avec l'insolence triomphante d'une autonomie plastique. 
Fig.18.
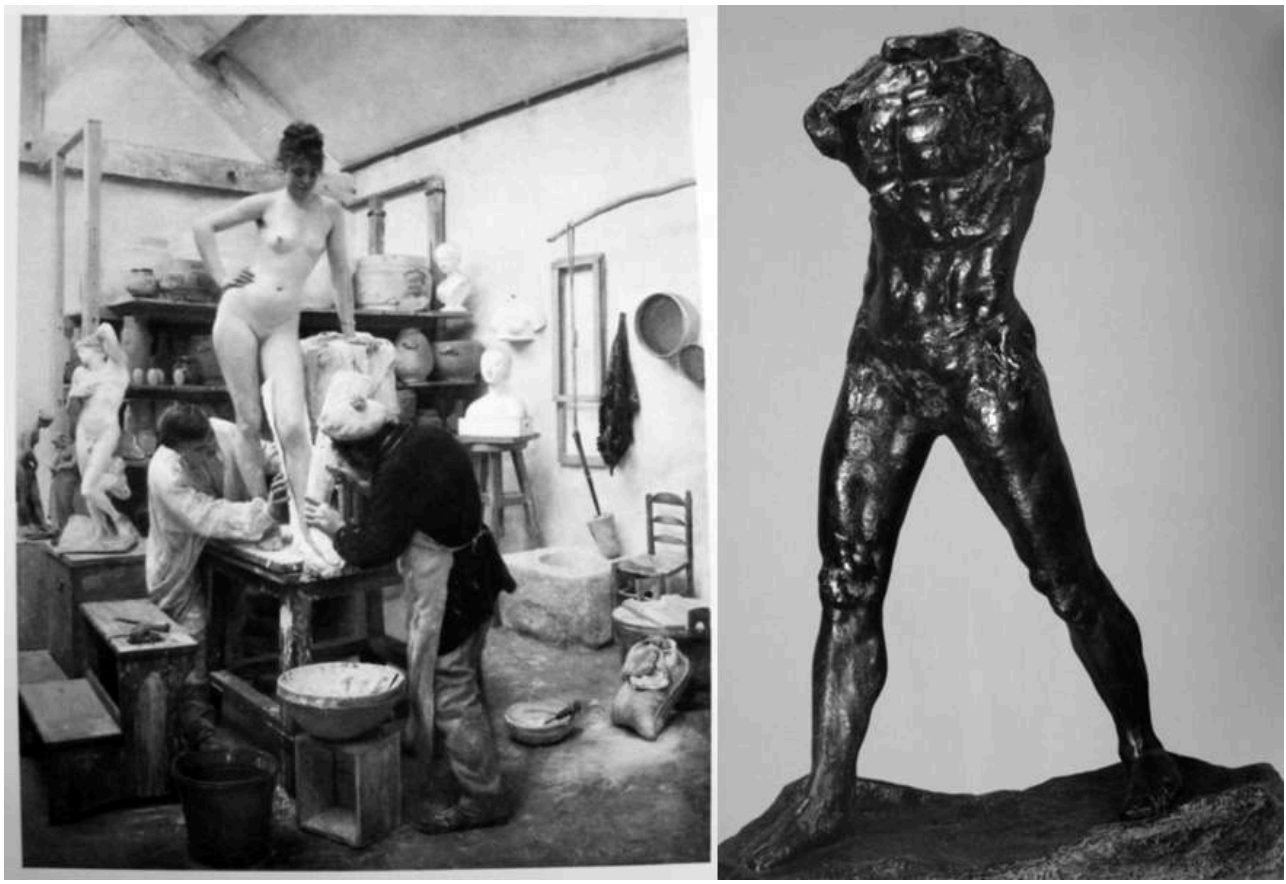

Dantan, Moulage sur nature, 1887, Konstmuseum, Göteborg ; August Rodin, Homme qui marche, 1877. Musée Rodin, Paris.

www.konstmuseum.gonteborg.se ; http://www.musee-rodin.fr/

Fig.19.
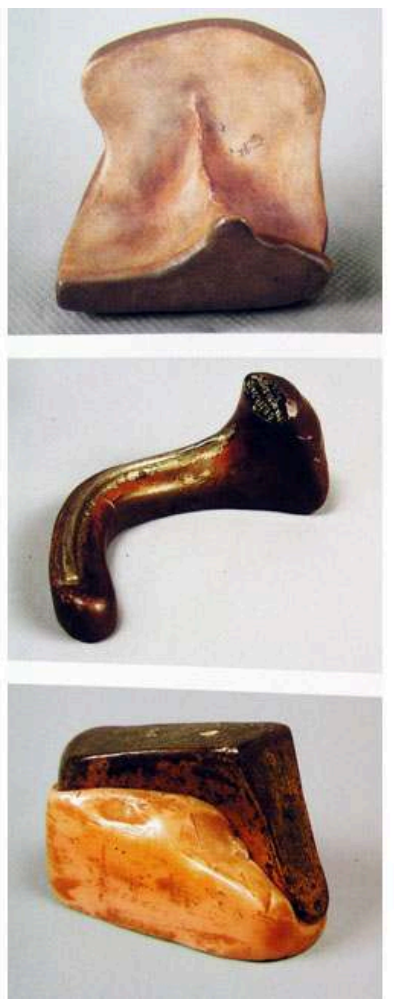

Marcel Duchamp, Feuille de vigne femelle ,1950, Objet-Dart,1951, Coin de chasteté, 1954. Dans HIRAYOSHI, Yukihiro, NAKAMURA Naoaki, YATSUYANAGI Sae, SAKAMOTO Kyoko, Mirrorical Returns, Marcel Duchamp and the 20th Century Art, National Museum of Osaka, 2004, p. 62-64. 
Fig.20.

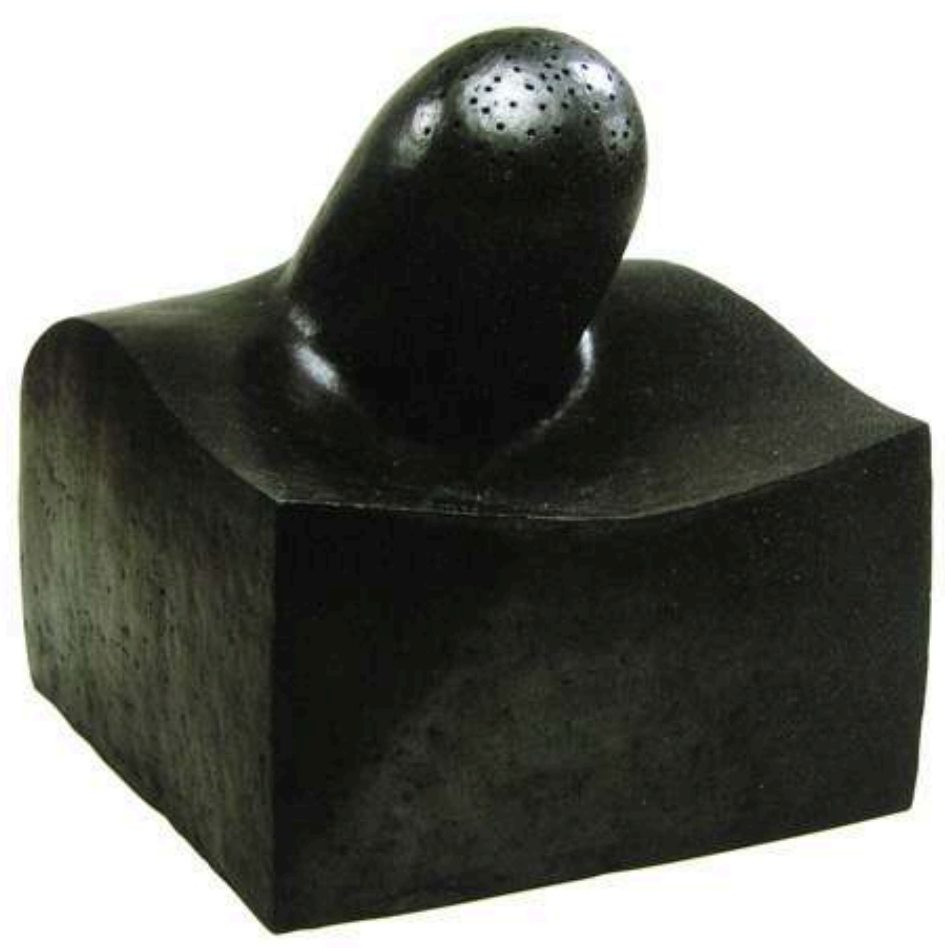

Yagi Kazuo, Black Ware, 1967. Dans Yagi 2004, p. 108.

Ce jeu en soi scandaleux du passif converti en actif semble être inspiré, ou au moins rétrospectivement rationalisé, par Marcel DUCHAMP (1887-1968), dont la « Feuille de vigne femelle » (en 1950) (fig.19) en haut est très évocatrice du « Vêtement »; une autre pièce jumelle de Yagi : «Faïence noire » (v. 1967: 108) (fig.20) annonce la «Marée montante sous la forme d'un melon" (1978: 287) (fig.20) qui correspond à s'y méprendre au fameux "Objet-Dart» (en 1951) [fig.24, milieu] duchampien, dont l'insinuation sexuelle, cachée dans le jeu de mot est encore plus explicite dans son " Coin de chasteté » (en 1950) (fig.19) en bas. Tout comme Duchamp, c'est en exhibant la partie secrète du corps que Yagi essaya de convertir la féminité essentielle du métier de poterie en des objets d'une masculinité avant-gardiste. 
Fig.21.

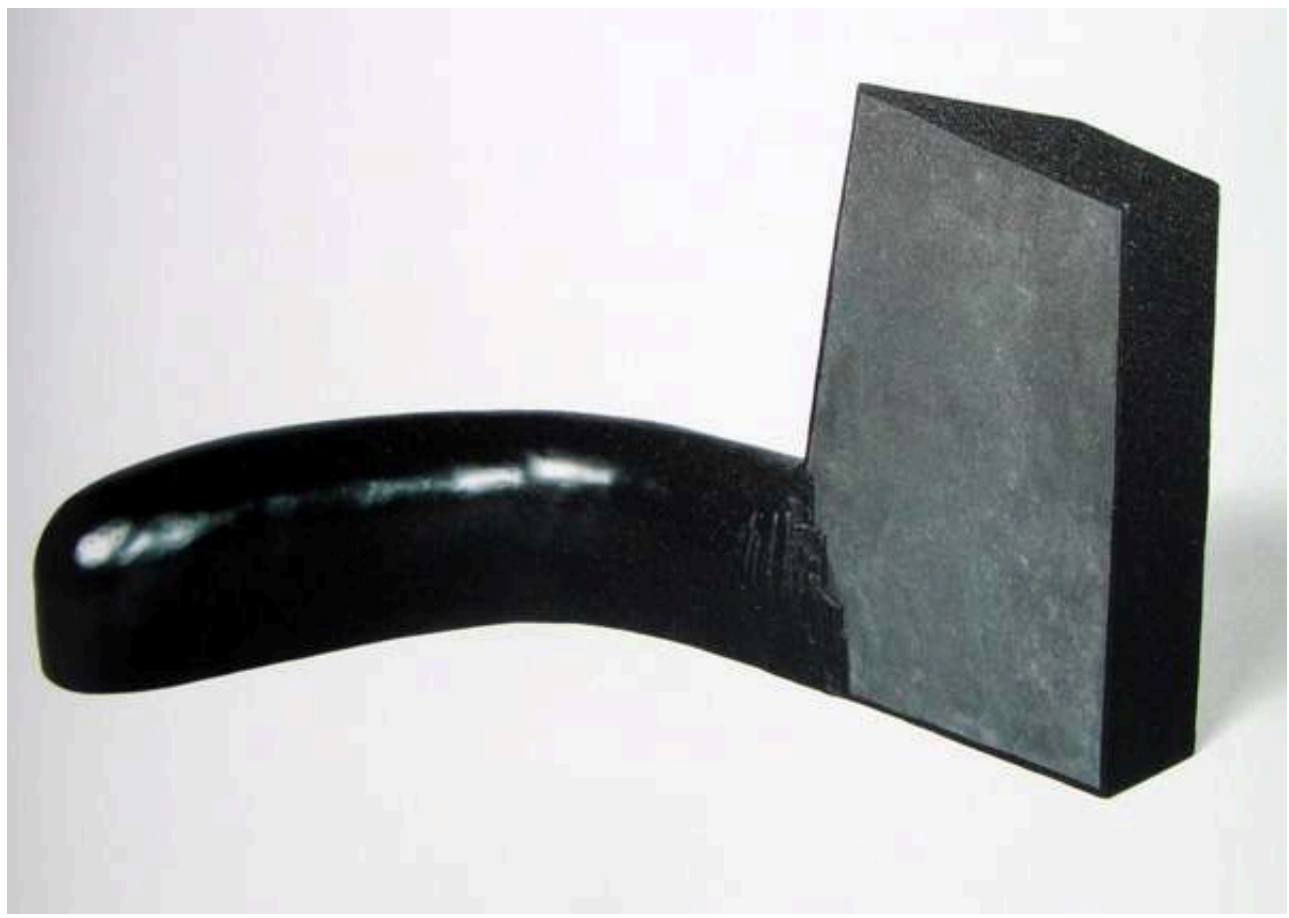

Yagi Kazuo, Tide Rising in the Shape of Melon, Black Ware, 1955. Dans Yagi 2004, p. 287.

D'autre part, le «Plâtre de Komachi » (1964:56) (fig.21) est en forme de coussin à dossier en cuire brun, nommé, on ne sait trop pourquoi, d'après la célèbre poétesse japonaise du VII siècle, Ono no Komachi. Le dossier gonflé a l'air d'être rempli de bourre et la peau est déchirée de plusieurs coups de couteau. Ces traces comme des cicatrices nous rappellent le "Concept de l'espace» (en 1961) (fig.23) de Lucio FONTANA (1899-1968) qui a exposé des toiles coupées par un couteau tranchant. Fontana endommage la surface plane d'une toile, condition sine qua non de la picturalité, afin d'ouvrir une autre dimension spatiale d'oeuvre d'art grâce au jeu de clair-obscur qu'accentue la lumière jetée sur la toile déchirée et ondoyante. Tout en se référant sans doute à cette tentative, en un sens destructive, de Fontana, Yagi, pour sa part, entaille le pot en terre cuite pour montrer que le plâtre cache un vide à l'intérieur de sa peau, rappelant qu'à l'origine c'est un vase-contenant. 
Fig.22.

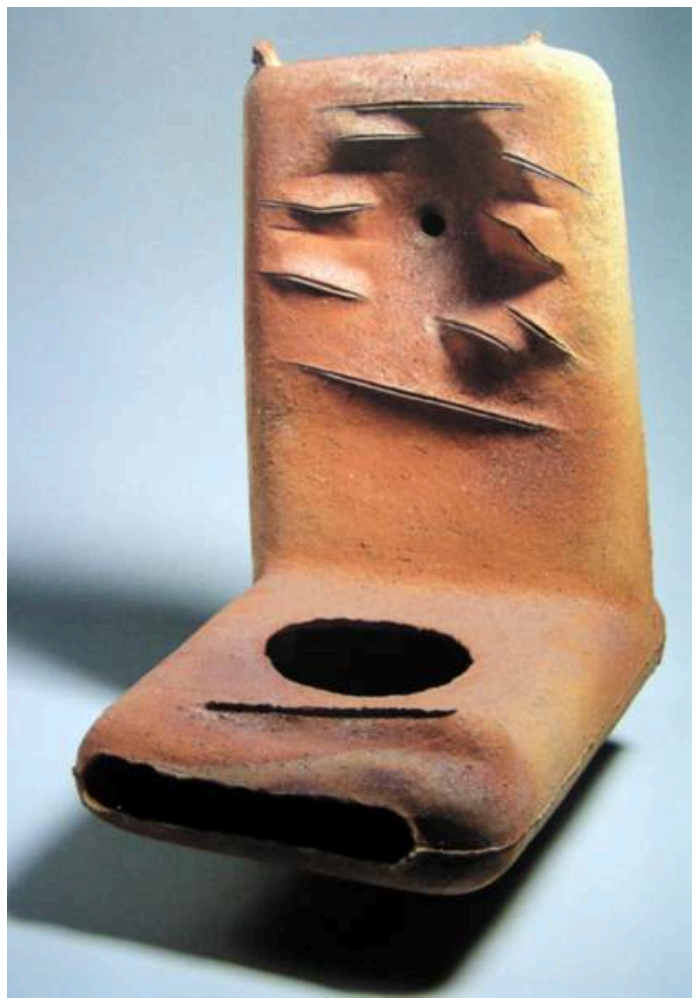

Yagi Kazuo, Kaomachi's Plaster, 1964. Dans Yagi 2004, p. 56.

Fig.23.

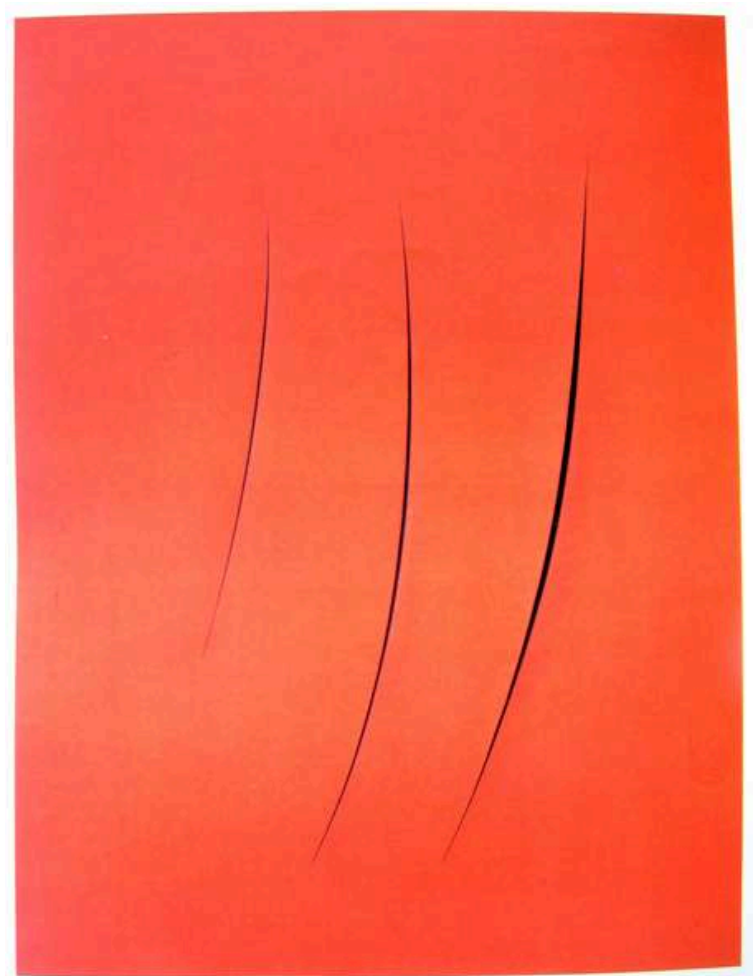

Lucio Fontana, Space Concept, 1961. Dans Asahi, No 76, vol. 8 : p. 161. 
Fig.24.

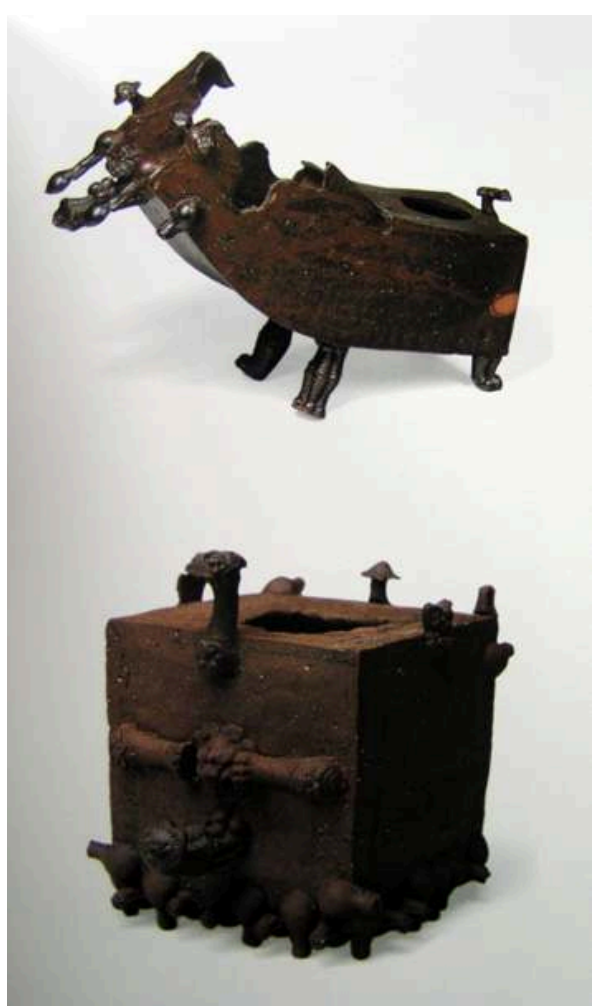

Yagi Kazuo, Dancing Incense Burner, 1965; Incense Burner, 1965. Dans Yagi 2004, pp. 77-78. 
Fig.25.
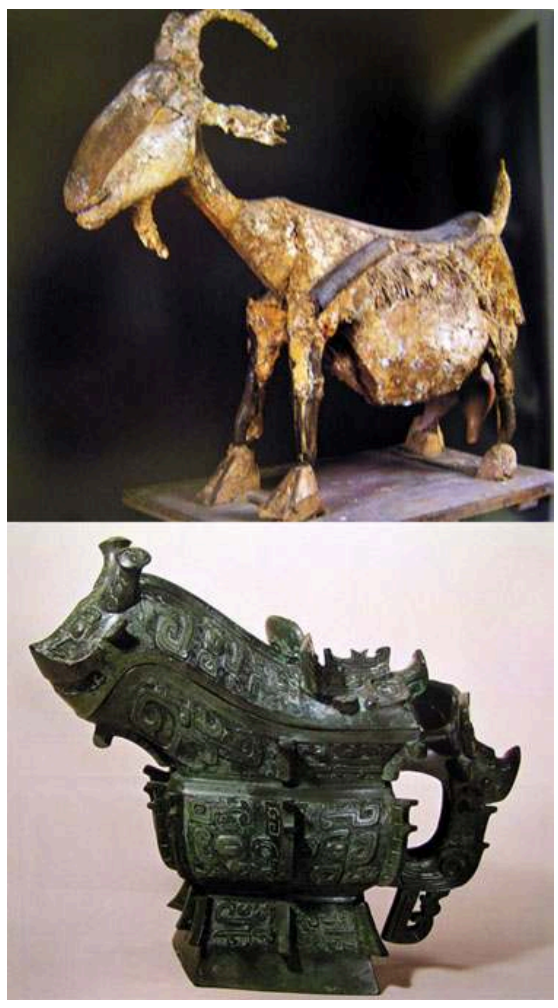

Pablo Picasso, Le Bouc,1950. Musée Picasso, Paris ; Vase rituel animalier en bronze de la Dynastie des Yin. Musée Idemitsu, Tokyo.

http://www.musee-picasso.fr/ ; http://www.idemitsu.co.jp/museum/english/index.html

La création yagienne de cette époque est marquée par la même ambiguïté, oscillant entre le vase-récipient et la forme sculptée. Le « Brûle-parfum dansant » (1965: 77) (fig. 24) en forme d'animal imaginaire et la « Boîte d'encens à motifs animaliers » (1965:78) trahissent l'attention que porte Yagi à la fois aux jouets en métal de Pablo Picasso (tels la «Chèvre » (en 1950)) (fig.25a) et aux bronzes animaliers de l'antiquité chinoise de la dynastie des Yin, des dynasties Shang et Zhou (?) (fig.25b), enjambant la création moderne avec l'origine historique du contenant. L'insistance de Yagi sur la cohésion interne que recèle l'objet, à l'insu et au mépris de son visage externe, s'intensifie davantage du fait de la concurrence avec TSUJI Shindô (1910-1981), sculpteur audacieux, et aussi son collègue à l'Université municipale des Beaux-Arts de Kyoto.

A ceci s'ajoute la révélation de la terre cuite préhistorique. Yagi se rappelle la sensation d'éveil qu'il a éprouvé lorsqu'il a vu les tuyaux de terre cuite, sans émail, renversés en désordre devant le four de cuisson chez un célèbre céramiste-artiste, KAWAI Kanjirô (1890-1966) (fig.26). 
Fig.26.

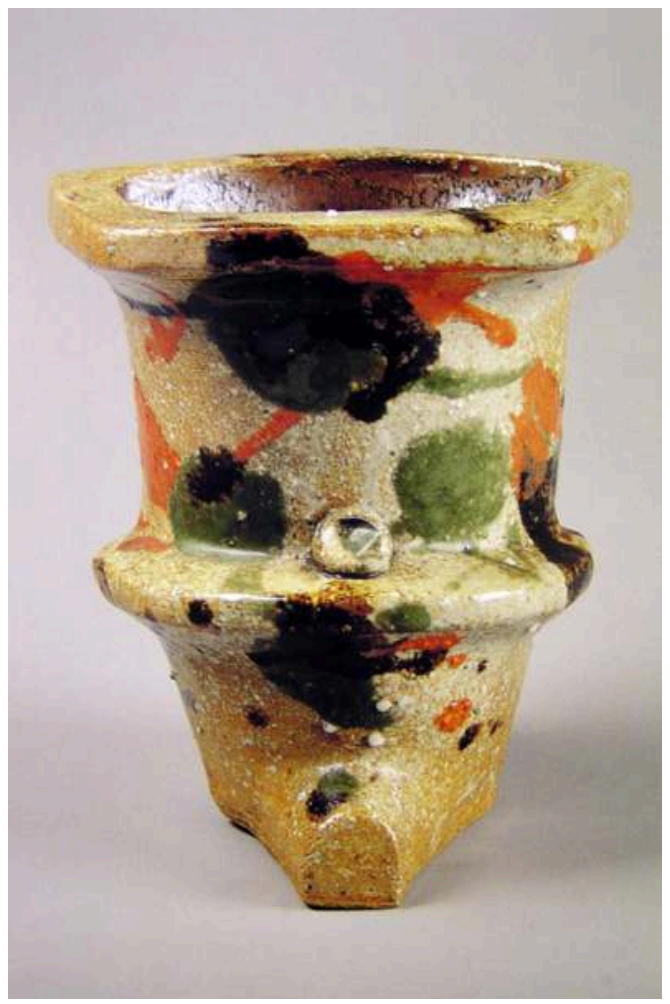

Kawai Kanjirô, Vase à trois couleurs en détrempe,1960. Musée Kawai Kanjirô, Kyoto. http://www.e-yakimono.net/html/kawaikanjiro.html

«Ces tuyaux de terre cuite étaient là, dit-il, tout nus et sans embellissement aucun, comme confectionnés pour les travaux d'une canalisation d'égout, brusques, laconiques et tellement dépourvus des sentiments propres à l'œuvre achevée du maître qu'il n'était possible d'en pressentir même la moindre odeur. Mais il y a là le visage nu, sans maquillage de la terre crue, qui attendait pourtant, et à coup sûr, quelque chose à venir » (« Visage nu »; Yagi :1999 : 227). 
Fig.27.

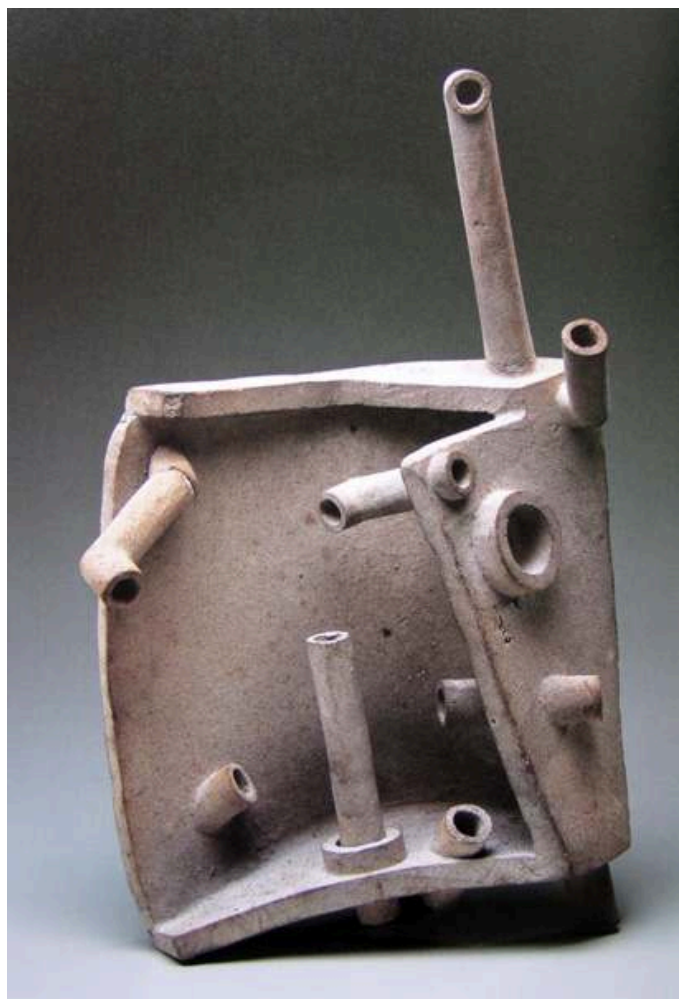

Yagi Kazuo, Clay Pipe, Directions of the Wind,1955. Dans Yagi 2004, p. 23.

25 La « Pipe en terre » (1955 : 23) (fig.27), oeuvre qui représente une boîte cassée munie de neuf tuyaux interrompus, aurait pu inspirer Tsuji Shindô pour sa série de boîtes ouvertes en guise de maison sans toiture (voir la photo sur la couverture de son livre, Deiko-an Zakki, 1992) (fig.28a-c). Le «Daruma-sa» (1956: 27) (fig.29), pour sa part, emprunte le nom d'un sage bouddhique populaire dont les membres ont rétréci à force d'ascèse. L'oeuvre consiste en un corps de personnage au ventre rebondi. D'innombrables tuyaux intestinaux ont tellement proliféré dans son ventre qu'une partie en déborde et le personnage n'est plus capable de se tenir debout, à cause de son abdomen dilaté. 
Fig. 28

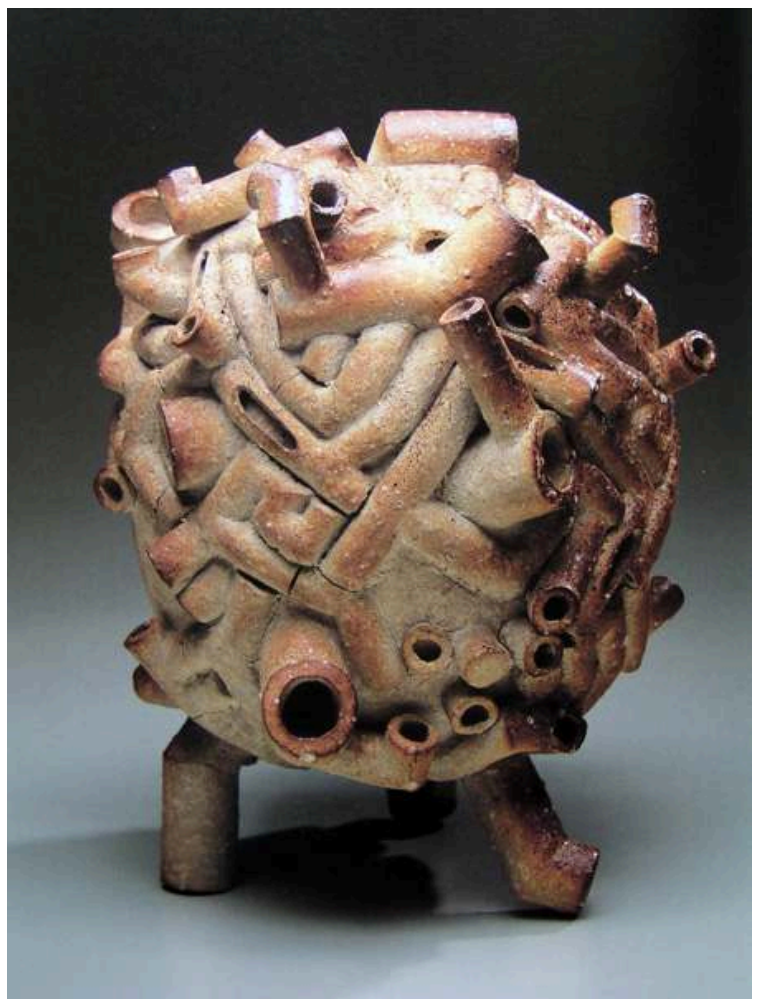

Yagi Kazuo, Sightless, 1955. Dans Yagi 2004, p. 24. 
Fig.29.

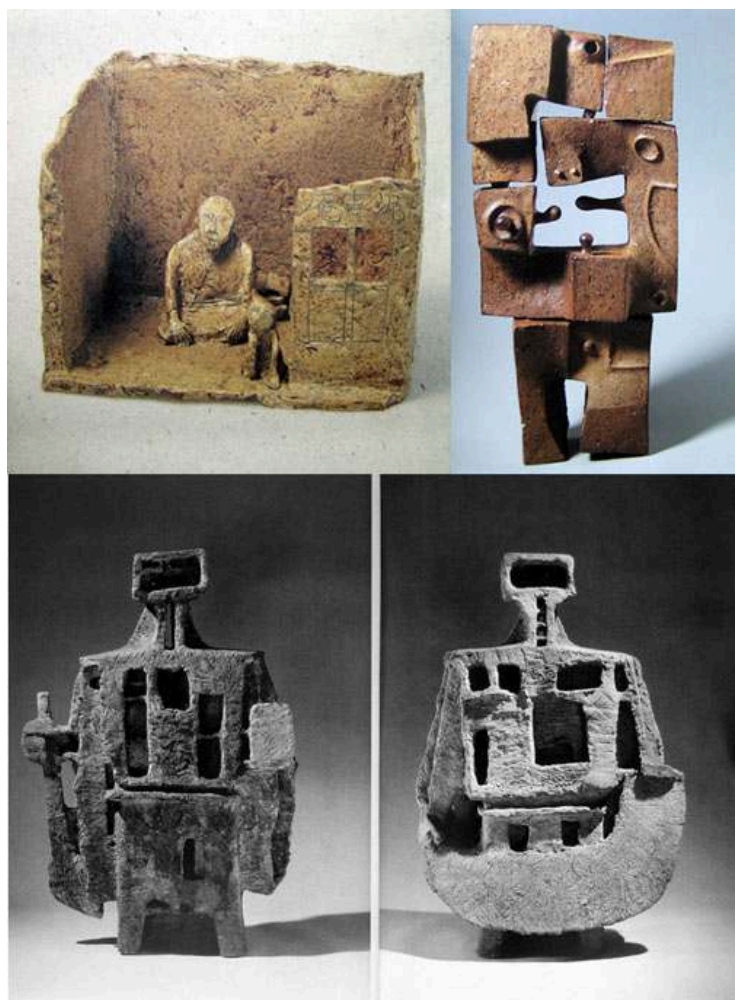

Tsuji Shindô, Deikoan, «La Hutte de Boue ». Dans TSUJI Shindô, Deikoan Zakki, Écrits épars de la "Hutte de Boue», Sansaisha,1992 ; Yagi Kazuo, Walk, 1957. Dans Yagi 2004, p. 29 ; Tusji Shindô, Kanzan et Jittoku, 1958. Dans TSUJI Shindô, ibid. 
Fig.30.

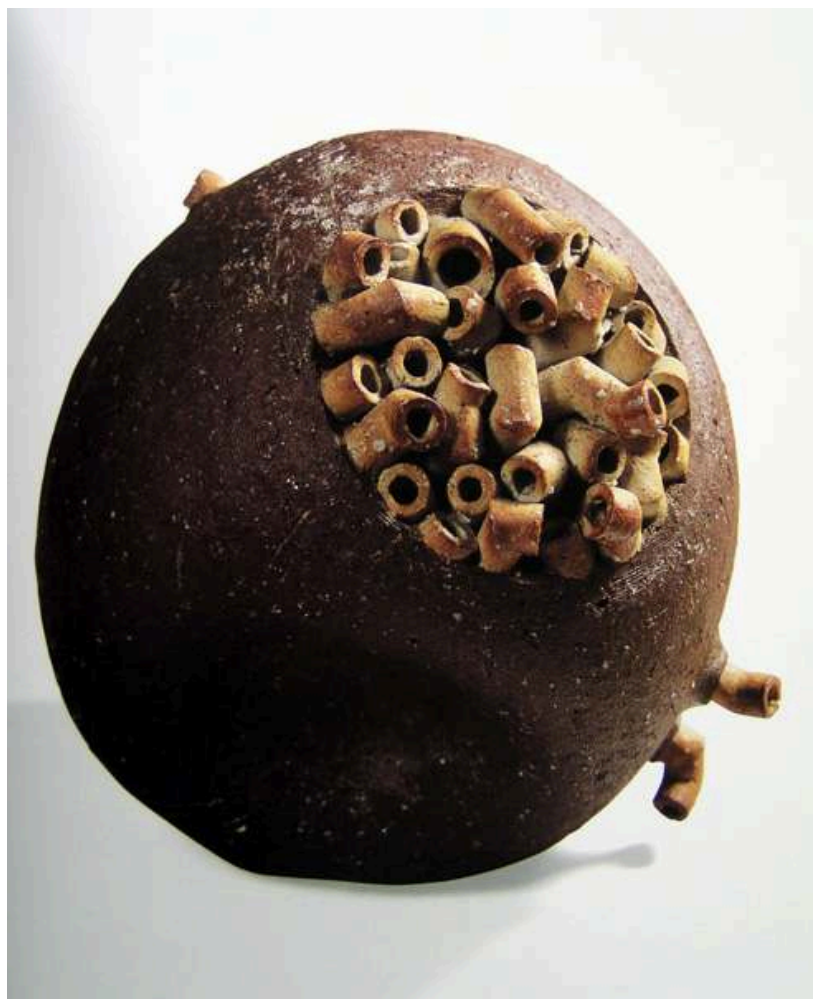

Yagi Kazuo, Daruma-san, 1956. Dans Yagi 2004, p. 27.

Yagi se rend compte que la prolifération excessive des tuyaux qui, en s'entravant l'un l'autre, recouvrent la surface entière du corps de terre cuite, aboutit à la "Cécité " (1955 : 22) (fig.30), où l'intérieur se confond avec l'extérieur, marquant la fin d'une problématique posée. Une fois épuisés tous les possibles ouverts par une problématique, Yagi se fait une habitude de vite plonger dans une autre. En ce sens une pièce dans la série « Maquillage en blanc brossé » est exceptionnelle (1964: 70) (fig.31). La forme de celle-ci laisse penser que le concept en fut largement «emprunté » à la sculpture de Constantin BRANCUSI (1866-1957): «Embrassement» (fig.32a et b). Pourtant le principe qui régit l'objet cuit de Yagi dévoile plutôt l'écart le séparant de son modèle roumain. Tandis que Brancusi sculpte la forme en taillant la pierre de l'extérieur, Yagi construit une forme semblable en modelant la terre glaise qui comporte une cavité en son intérieur. Pourtant, le jeu combinatoire dont Yagi a fait l'expérience avec cette pièce ne sera développé systématiquement que dans ses toutes dernières années. Avant de l'étudier, il faudrait d'abord examiner d'autres problématiques abordées. 
Fig.31.

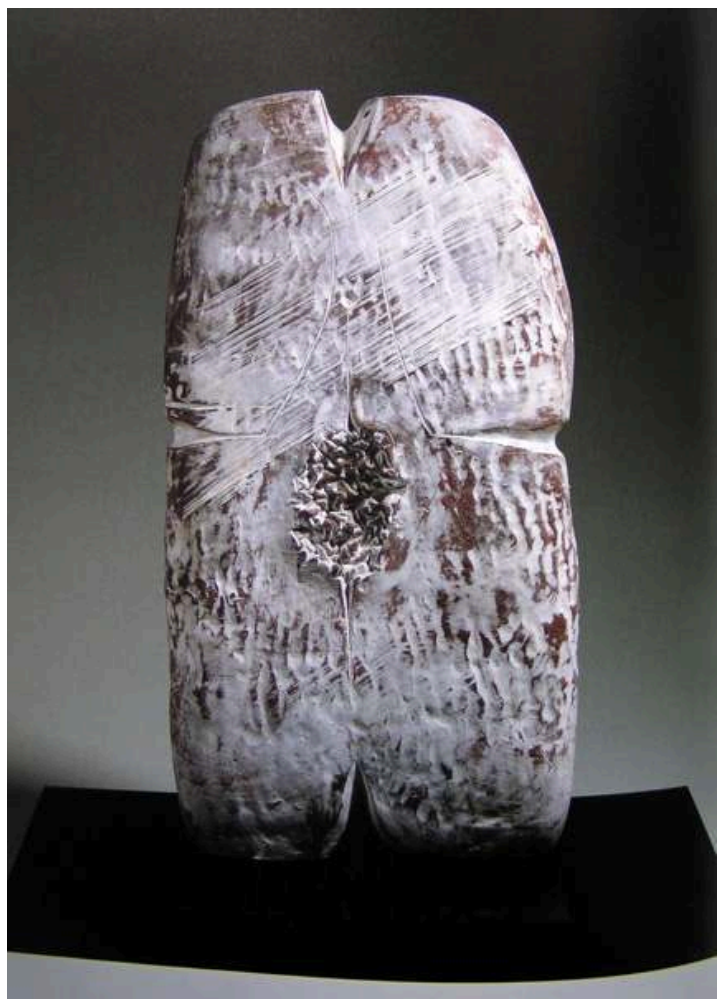

Yagi Kazuo, Work, White Brushmark Pattern, 1964. Dans Yagi 2004, p. 70.

Fig.32.

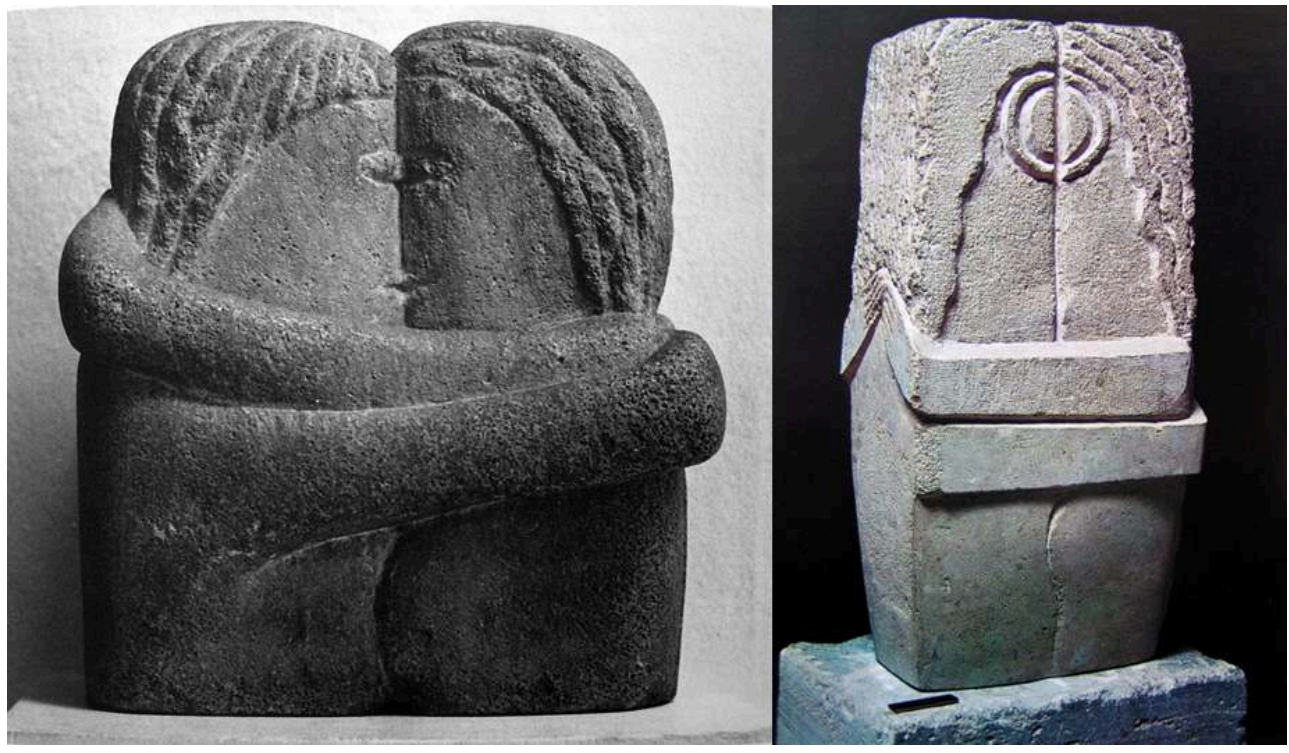

Constantin Brancusi, Embrassement, 1907-8. Musée National d'Art, Roumanie ; Constantin Brancusi, Embrassement, 1915. Centre Georges Pompidou, Paris. Dans Asahi No 74, vol. 8 : p. 94.

http://www.mnar.arts.ro/ ; http://www.centrepompidou.fr/Pompidou/Accueil.nsf/tunnel ?OpenForm 


\section{Le Trou et la porte}

\section{Fig.33.}

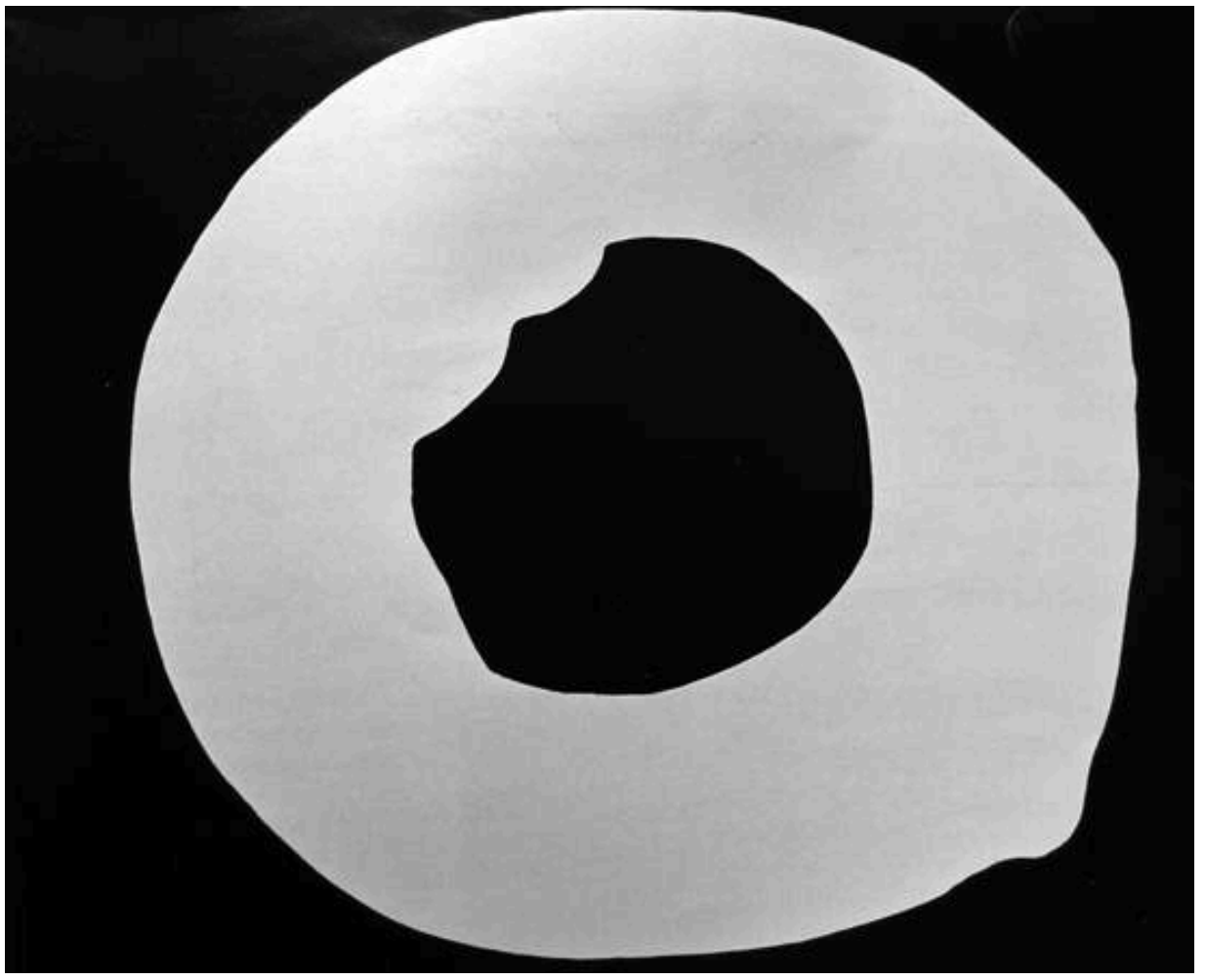

Yoshihara Jirô, Blanc sur noir, 1965. Musée National d'Art Moderne, Tokyo.

http://www.momat.go.jp/english/fr_museum/index.html 
Fig.34.

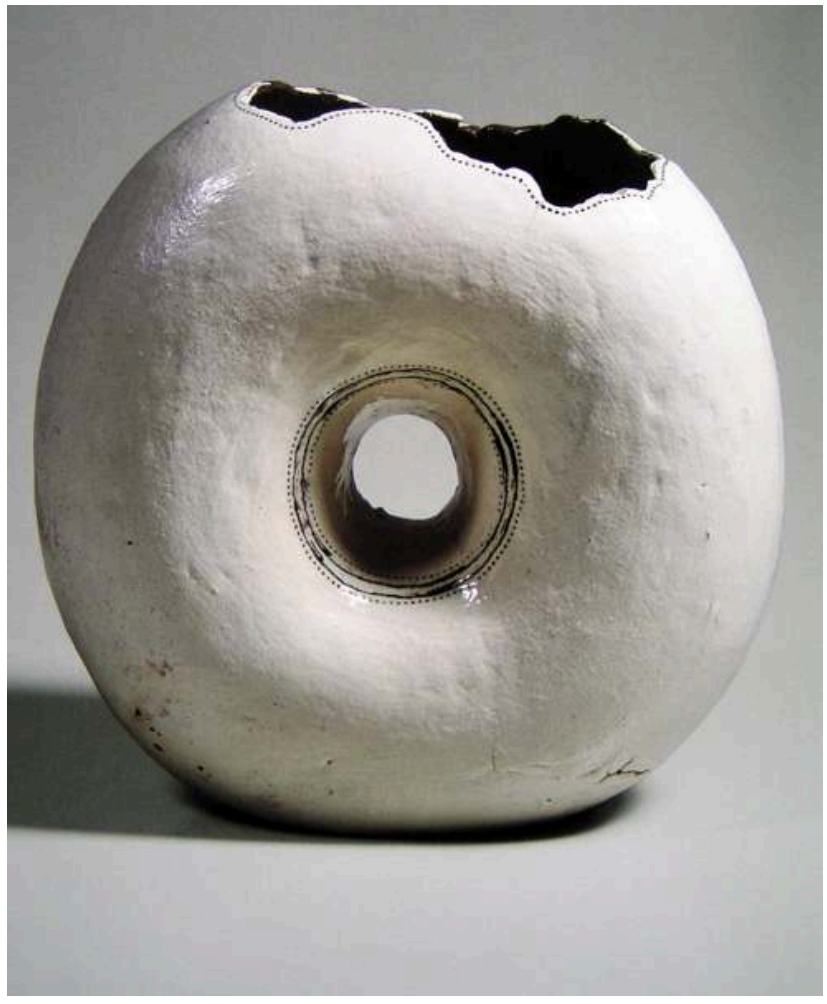

Yagi Kazuo, White Vase, 1966. Dans Yagi 2004, p. 91.

Fig.35.

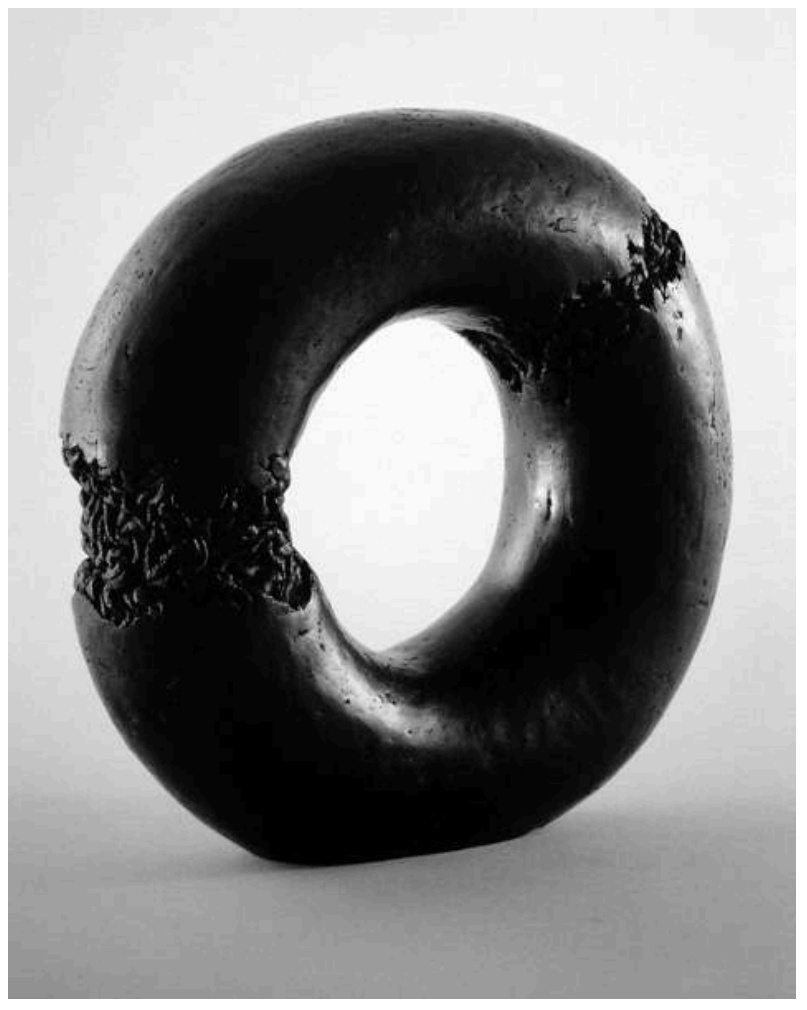

Yagi Kazuo, Circle, 1968. Dans Yagi 2004, p. 110. 
27 À partir de la deuxième moitié des années 60, c'est, plus qu'auparavant, dans la concurrence avec d'autres artistes et sculpteurs rivaux que Yagi cherche sa forme en céramique. Il faudrait d'abord le comparer avec YOSHIHARA Jirô (fig.33), fondateur du mouvement avant-gardiste de Gutai. Chez Yagi, on remarque une série de vases en forme de 'doughnut' circulaire et vertical avec un trou horizontal qui le traverse d'un bout à l'autre. Passant par le « Vase en cercle en émail jaune » (1966:90) et le « Vase en cercle blanc» (1966:9) (fig.34), qui conservent encore leur fonction pratique du vase à fleur en raison du trou qui s'ouvre au sommet, Yagi aboutit finalement à un cercle vertical qui n'a plus d'ouverture à l'extérieur avec le «Cercle en faïence noir » (1968 : 110) (fig.35).

Le cercle noir était la marque de fabrique de Yoshihara Jirô (1900-1972), qui dirigeait le groupe Gutai. Yagi n'a point hésité à transférer ce signe distinctif de Yoshihara, au départ en deux dimensions, dans un espace à trois dimensions. Dans cette apparente usurpation transparaît l'inébranlable confiance en soi de Yagi. Au centre de la composition circulaire et plane de Yoshihara, le vide demeurait sans signification. Mais il sera désormais doté d'un sens plastique inouï, une fois traduit et transplanté par Yagi dans un espace à trois dimensions. Il s'agit en effet d'ouvrir une porte au-delà de la limite de la surface plane de l'espace pictural. Grâce à la profondeur matérielle obtenue par le trou qui perce la pièce, on est invité maintenant à regarder l'au-delà du vide. Ce qui n'était pas du tout le cas avec le cercle peint de Yoshiwara Jirô.

À cela s'ajoute une autre dimension ontologique : l'anneau se compose d'une double structure de trous. C'est au moment où le trou à l'intérieur du tuyau se renferme sur lui-même que l'anneau se compose, et se faisant crée un autre trou par sa structure circulaire. Autrement dit, c'est au trou qui est maintenant serré dans le cercle en faïence que se superpose, dans l'axe diamétralement opposé, un autre trou qui le traverse. Une telle dialectique des trous que contient l'anneau ne peut se manifester que dans le monde à trois dimensions. 
Fig.36.

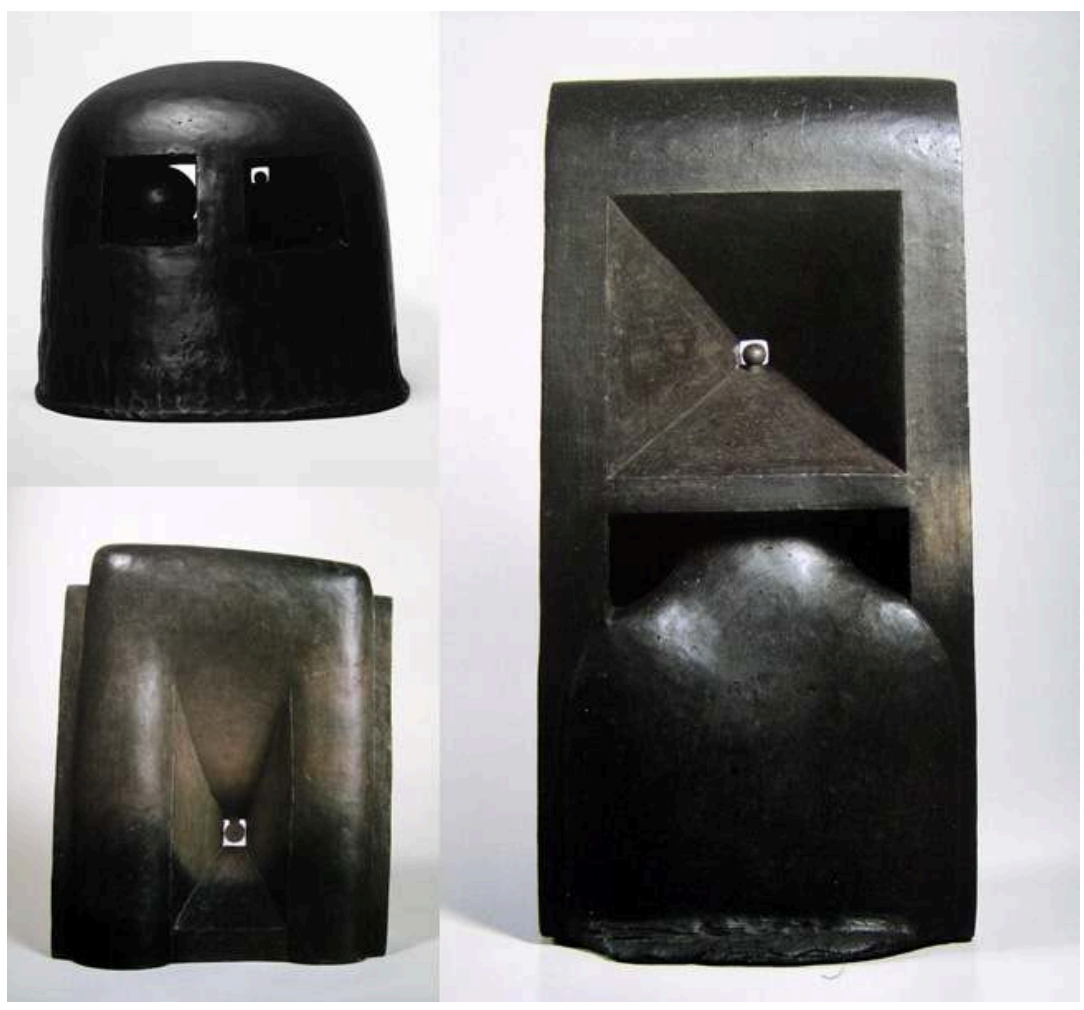

Yagi Kazuo, Information of Right Eye and Left Eye, 1968; Everything is Reversed,1968; The Head is Advancing ahead, Black Ware 1968. Dans Yagi 2004, p. 171-173.

Fig.37.
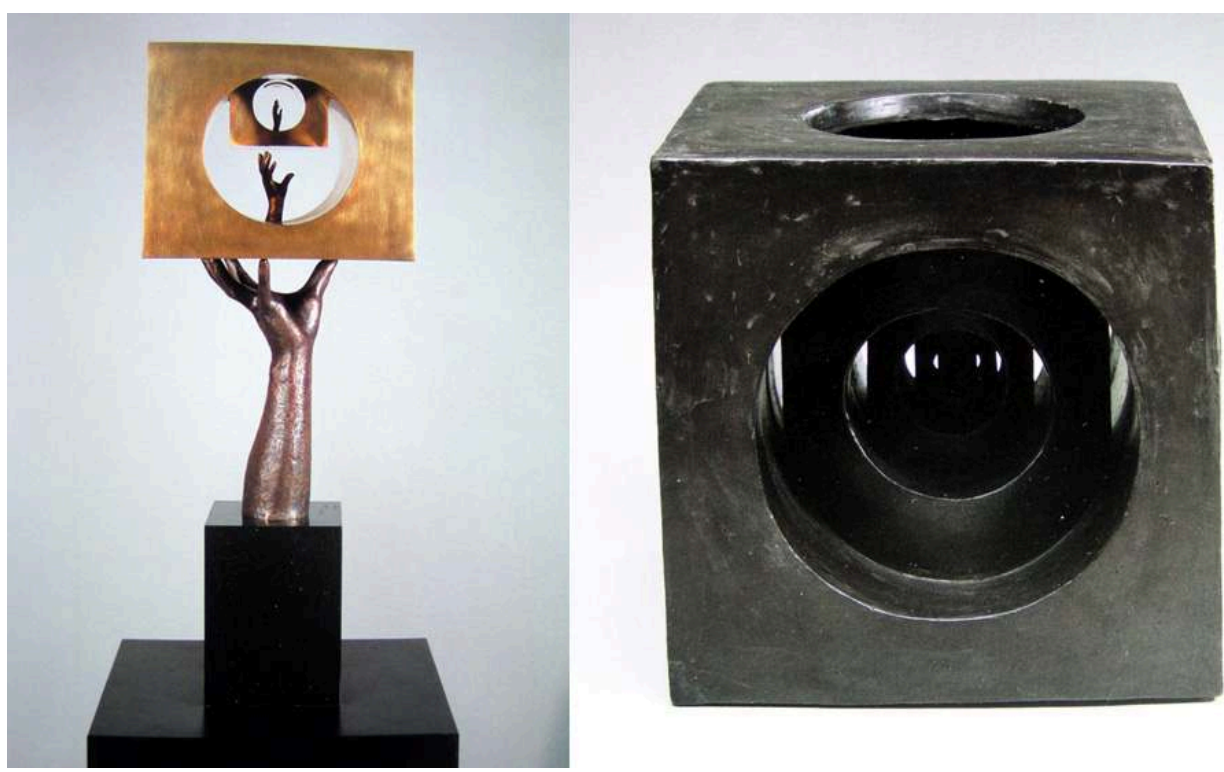

Horiuchi Masakazu, A Box Returning to the Sky, 1966. Dans NAGATO Saki et passim Eds., HORIUCHI Masakazu, The Yomiuri Shinbun, The Japan Association of Art Museums, 2003, p. 46; Yagi Kazuo, Hole Penetrating a Hole, 1969. Dans Yagi 2004, p. 127.

Vers la même époque commence une émulation intense avec HORIUCHI Masakazu (1911-2001), sculpteur à l'esprit extrêmement rationnel et lucide mais doté en même 
temps d'une sensibilité méditerranéenne non dénuée d'une sensualité sereine qu'il partage avec Yagi Kazuo. En apparence du moins, Yagi suit de près chaque nouvelle proposition faite par Horiuchi l'une après l'autre. C'est sans doute ce qui permet l'apparition d'oeuvres en faïence noire telles l'« Information d'un oeil droit et d'un oeil gauche » (1968: 111) (fig.36a), le " Tout est renversé » (1968: 120) (fig.36b) ou encore la» Tête avant» (1968: 113) (fig.36c). Autant d'exemples d'un esprit aussi ludique qu'espiègle réalisés moyennant un appareil d'illusions et de trompe-l'oeil qui étaient alors en vogue au Japon. Sont également mis en oeuvre des dispositifs tels que deux miroirs posés face à face ou un emboîtement se reculant jusqu'à l'infiniment petit dans sa multiplication auto-référentielle. En observant les oeuvres précédentes de Horiuchi, telles que « La Boîte qui retourne au ciel » (1966) (fig.37a), Yagi emprunte à son collègue ce dispositif intelligemment tautologique et les renferme dans les boîtes noires de ses propres oeuvres, sortes de 'chinese box', parmi lesquelles on peut citer, entre autres, le «Facteur primordial dans le facteur primordial» (1969:126), ou le «Trou qui passe dans le trou » (1969: 127) (fig.37b), titres en soi tautologiques.

Fig.38.

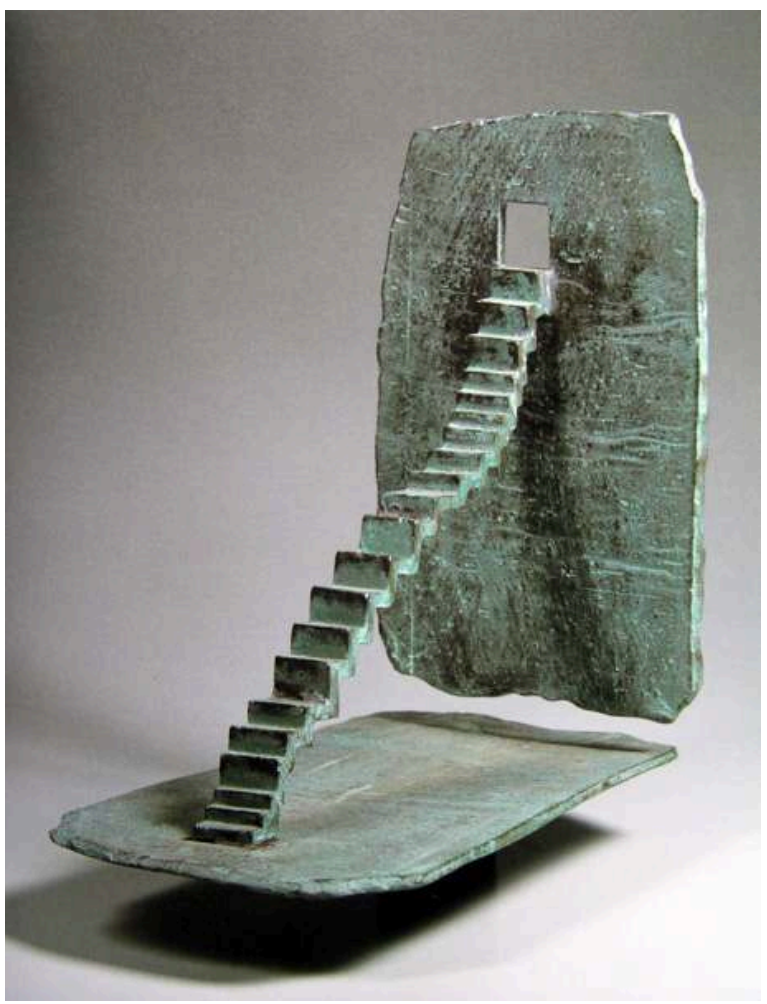

Yagi Kazuo, Distant Entrance, Bronze 1969. Dans Yagi 2004, p. 137.

31 Ces trous métaphysiques (dans la mesure où ces trous nous emmènent théoriquement à l'infini) se combinent à la fin des années 60 avec le cercle en trois dimensions (que nous venons d'analyser plus haut) pour désigner l'au-delà de la limite physique du monde. Tel est le cas de «L'Entrée lointaine » (1969: 137) (fig.38), du « Portrait d'un pécheur des perles » (1969: 138), ou d'« Aux alentours » (1969: 140), tous fabriqués en bronze. Dans le premier, le mur en suspens en air n'est soudé au terrain qu'à l'aide d'un escalier intermédiaire, et la porte en haut de l'escalier s'ouvre sur le vide. De telle sorte que l'escalier qui soutient la composition toute entière de l'oeuvre ne nous mène nulle part. 
Dans le dernier, c'est avec une sobriété extrême que l'artiste montre un seul cube noir qui est transpercé horizontalement par un trou hyperbolique.

Fig.39.

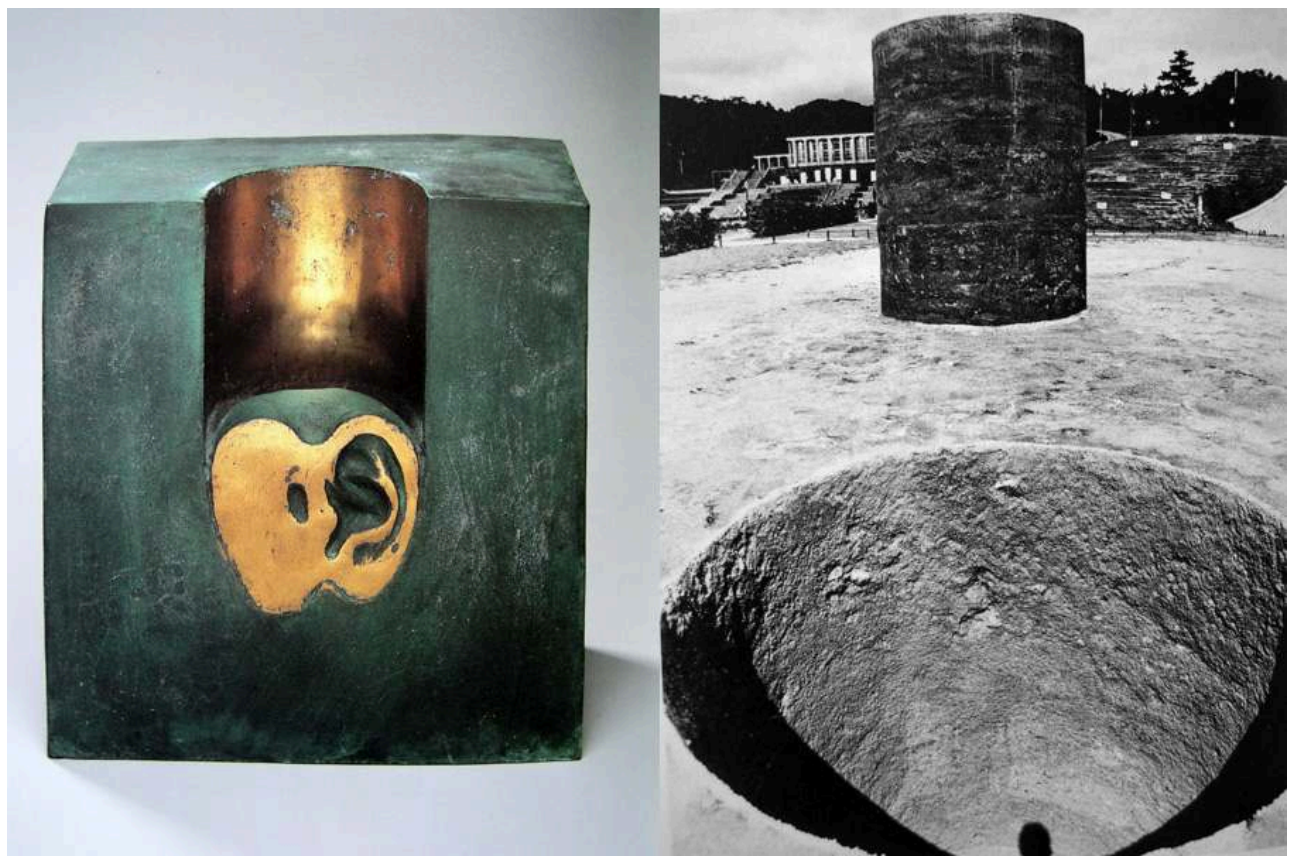

Yagi Kazuo, Newton's Ear, Bronze, 1969. Dans Yagi 2004, p. 143; Sekine Nobuo, Topology Earth, 1968. Dans Asahi No 139, vol. 14, p. 237. 
Fig.40.

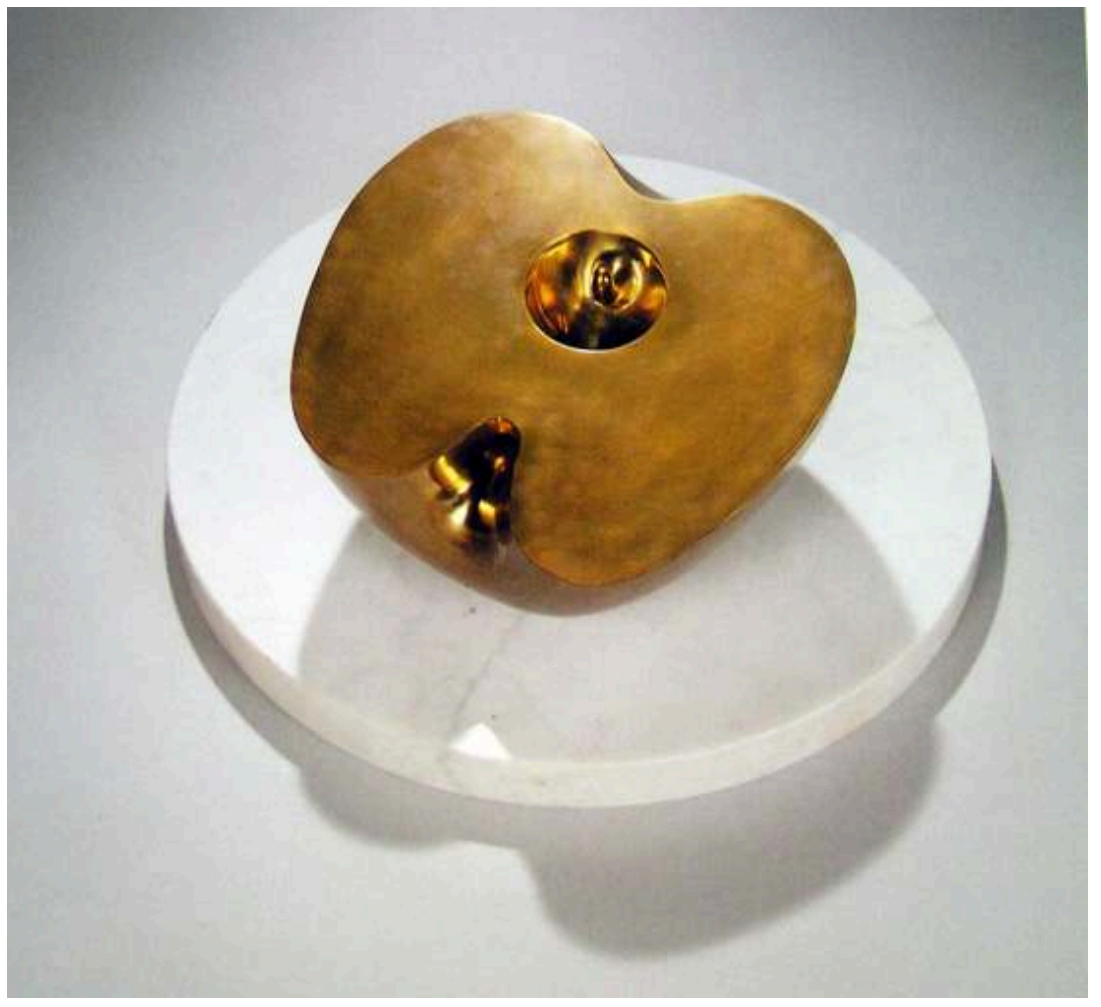

Horiuchi Masakazu, Large Apple from Eve, 1966. NAGATO Saki, et passim Eds., HORIUCHI Masakazu, The Yomiuri Shinbun, The Japan Association of Art Museums, 2003, p 45. 
Fig.41.
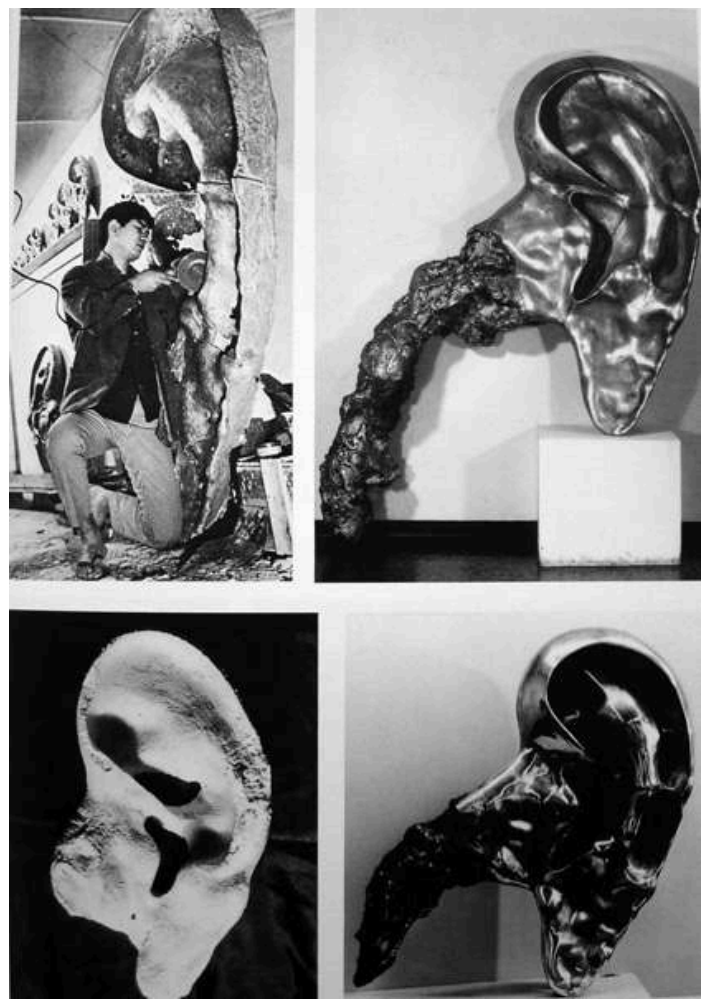

Miki Tomio, Ear,1965-72. Dans Le Japon des Avant-Garde 1910-1970, Centre Georges Pompidou, Paris, 1986.

L'aboutissement de cette série de trous est l'« Oreille de Newton » (1969: 143) (fig.39a). Le trou vertical est sans aucun doute une référence quasi-explicite à une oeuvre monumentale de SEKINE Nobuo (1942-), «Topologie-Terre» (fig.39b), qui avait fait sensation l'année précédente (1968). Pourquoi alors la pomme s'enfonce-elle au fond du trou? La pomme de Newton, bien entendu, suggérant la loi de gravitation. Il faut évoquer aussi la "Grande Pomme donnée par Ève» (1966) (fig.40) de Horiuchi Masakazu, pièce subtilement érotique : elle est pourvue d'un vagin et d'un pénis. Et pourquoi encore l'oreille qui s'insinue dans la coupe verticale de la pomme? Il ne serait guère plus difficile de nous rappeler l'« Oreille » de MIKI Tomio (1937-1978) (fig.41). Ce que Yagi entend insinuer est tout à fait limpide. En somme, il s'agit ici d'une sorte de synthèse de la scène d'Avant-garde contemporaine qui se résume et se présente en une section longitudinale. Le côté facétieux du goût et du talent de Yagi Kazuo pour l'assemblage se manifeste sans pudeur dans cette tranche de la vie artistique japonaise. Loin d'être un simple pastiche, ce profil témoigne de la portée considérable de la problématique du trou qui s'élaborait dans la création yagienne. 
Fig.42.

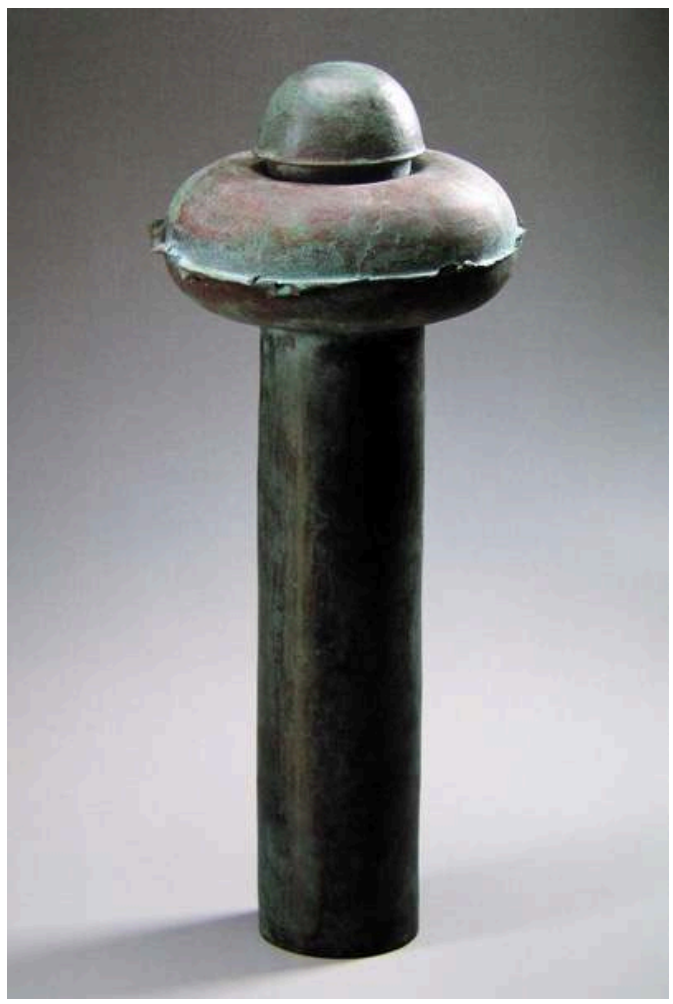

Yagi Kazuo, Warrior, bronze, 1969. Dans Yagi 2004, p. 131.

Fig.43.

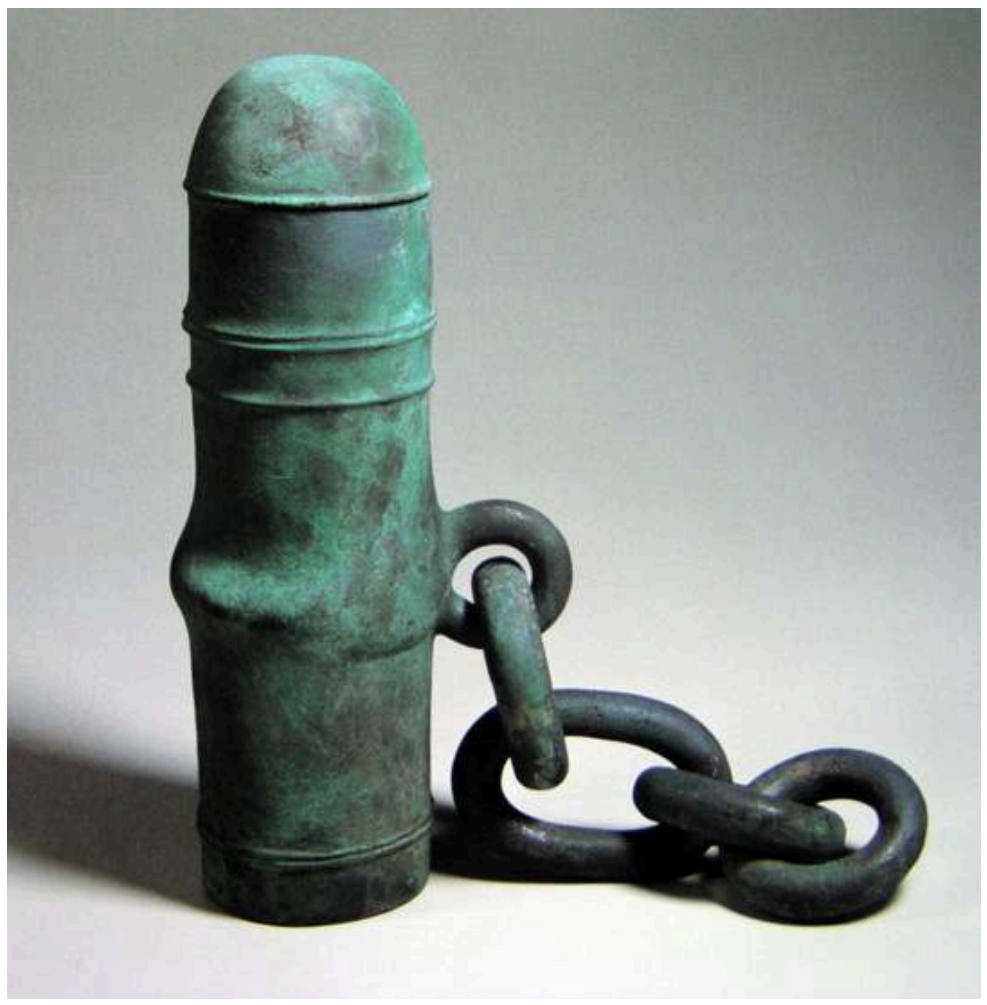

Yagi Kazuo, Chained Vessel, bronze, 1969. Dans Yagi 2004, p. 132. 
La fin des années 60 voit la création en bronze de pièces telles que «La Matinée qui s'allonge » (1969: 129) ou le "Guerrier» (1969: 131) (fig.42) où l'anneau réapparaît sous la forme d'une ceinture de natation qui se combine avec une sorte de marmite par l'intermédiaire d'une colonne tantôt verticale, tantôt courbée. L'artiste y accole un titre aussi contradictoire que la "Séparation vers une fusion» $(1969: 130)$ et ose attacher à la colonne les anneaux d'une chaîne, faisant allusion à l'esclavage ( « La Vase attachée » (1969: 132) (fig.43)). Il n'est pas difficile d'y détecter une métaphore de la révolte étudiante qui s'est développée sur le plan mondial, si on pense au casque des étudiants militants et aux nombreuses scissions et factions qui ne cessaient de se produire, malgré leur volonté de fusionner leurs mouvements révolutionnaires. Et on peut enfin évoquer l'arrestation massive des étudiants extrémistes dans leur débâcle. Chose symptomatique, on peut remarquer la présence solitaire d'une forme semblable à une tête de tortue qui caractérise toute une série en bronze de cette période.

Fig.44.

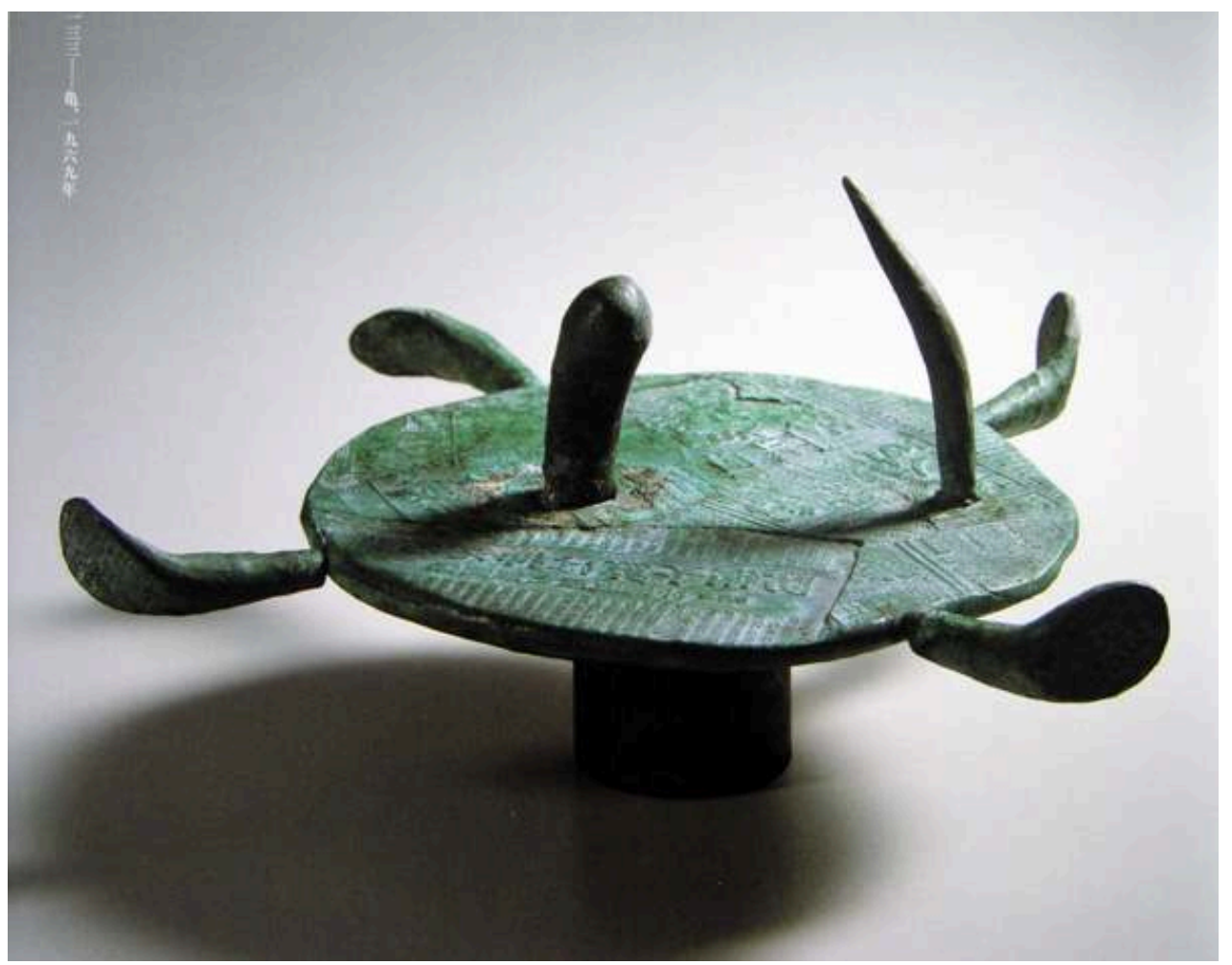

Yagi Kazuo, Turtlebronze, 1969. Dans Yagi 2004, p. 133. 
Fig.45.

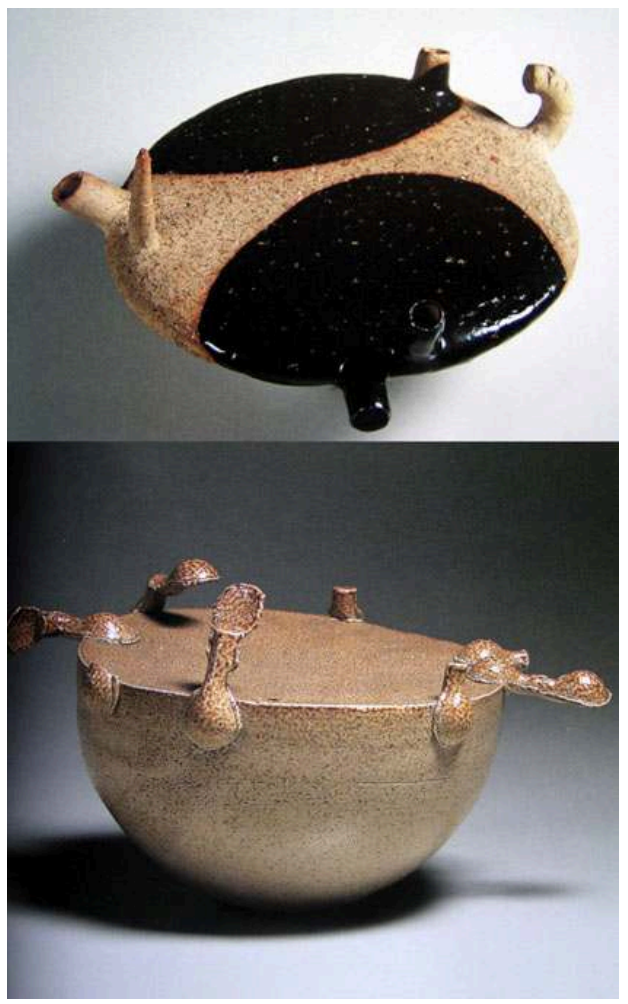

Yagi Kazuo, Moon, 1954 et Tortoise, 1973.. Dans Dans Yagi 2004, p. 20, 189.

Ce ne serait donc pas un hasard que Yagi fabrique vers la même époque la tortue marine remuant en vain les membres en l'air («La Tortue»1968: 133) (fig.44). Le disque pourvu de bras et de pieds se retrouve déjà à l'origine d'une filiation qui passe par la «Promenade de M. Samsa», et qui comprend «La Lune» (1954:20) (fig.45a). Quelques années plus tard, le même concept sera développé dans une autre "Tortue " (1973 : 189) (fig.45b) terrestre, dont le corps grossi en un hémisphère est tellement lourd que l'animal renversé ne parait pas capable de se retourner sur son ventre pour marcher normalement sur ses quatre pattes. Il serait trop facile d'y voir un dysfonctionnement du principe masculin, étant donné que le gland ou la tête du pénis est nommée en japonais "la tête de tortue ». Néanmoins, cet objet absurde, qui ne servirait, au mieux, que de presse-papiers ou de bibelot, peut être interprété comme une allégorie ironique du créateur lui-même, autoportrait d'un artisan résigné à son métier artisanal, tellement il est conscient de son incapacité de s'émanciper dans une création autonome. En un mot, la désillusion face à l'avortement de la révolte d'étudiants se répercute chez Yagi sur cette figuration caricaturalement pessimiste et défaitiste, laissant entrevoir son impuissance subconsciente à travers la métaphore sexuelle d'une tête de tortue assujettie.

\section{Au-delà du refus et du néant}


Fig.46.

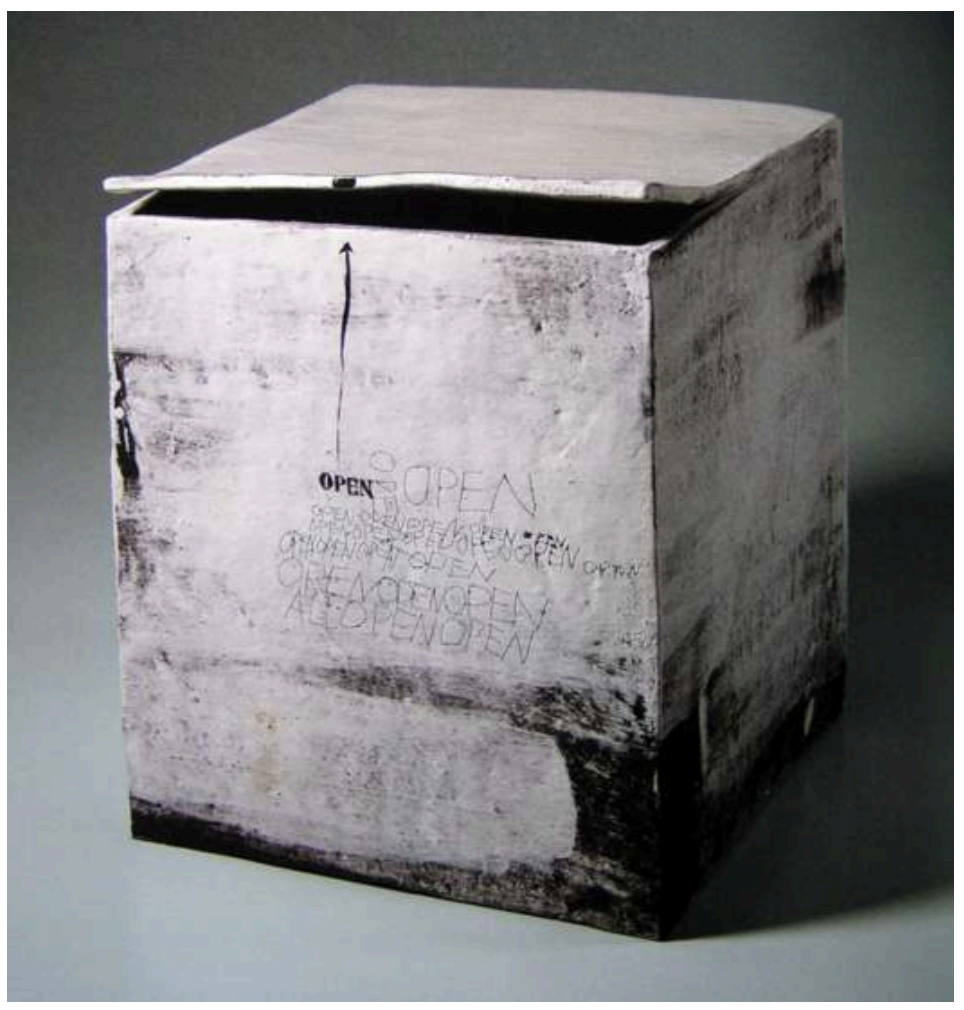

Yagi Kazuo, White Box, Open Open, OPEN OPEN 1971. Dans Yagi, p. 161.

$\mathrm{Au}$ début des années 70 , Yagi dans sa pleine maturité montre une compétence spontanée et une facilité pleine d'humour à jongler avec le concept orientaliste du zen, en maquillant en blanc des vases et des pots à motifs minimalistes gravés en fer, ou calligraphiés à l'encre de chine. "L'Île au soleil levant» (1970-5: 149) ou le «Jeter la pierre» (1970: 140) en sont des exemples typiques. La tendance conceptualiste s'accentue davantage dans la série des boîtes cubiques. Partant du " Pot dessiné au fer » (1969-70 : 146) figurant le rond, le triangle et le carrée du goût zen bouddhiste, la série débouche sur la « Boîte blanche » (1971 : 160) ou la « Boîte blanche OPEN OPEN » (1971 : 161) (fig.46). Les planches en terre dont se compose la boîte sont grattées par les gribouillages, tantôt en style cursif comme des graffiti, tantôt en écriture moulée imitant l'inscription stylisée mais avec une maladresse voulue. Le couvercle entr'ouvert suscite la tentation irrésistible de scruter l'intérieur ténébreux dans lequel se cacherait un secret invisible. 
Fig.47.

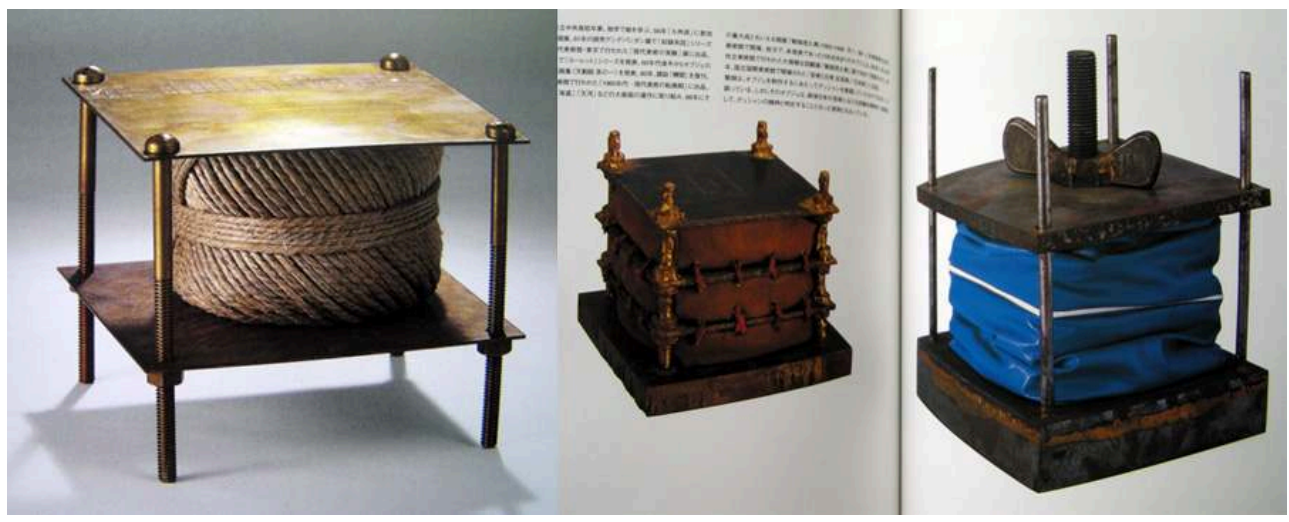

Marcel Duchamp, With Hidden Noise, 1916/1964; Kikuhata Mokuma, Closing Plan, 1969; Swan No.1, 1968. Dans HIRAYOSHI, Yukihiro et passim, Mirrorical Returns, Marcel Duchamp and the 20th Century Art, National Museum of Osaka, 2004, p. 26, 93.

Fig.48.

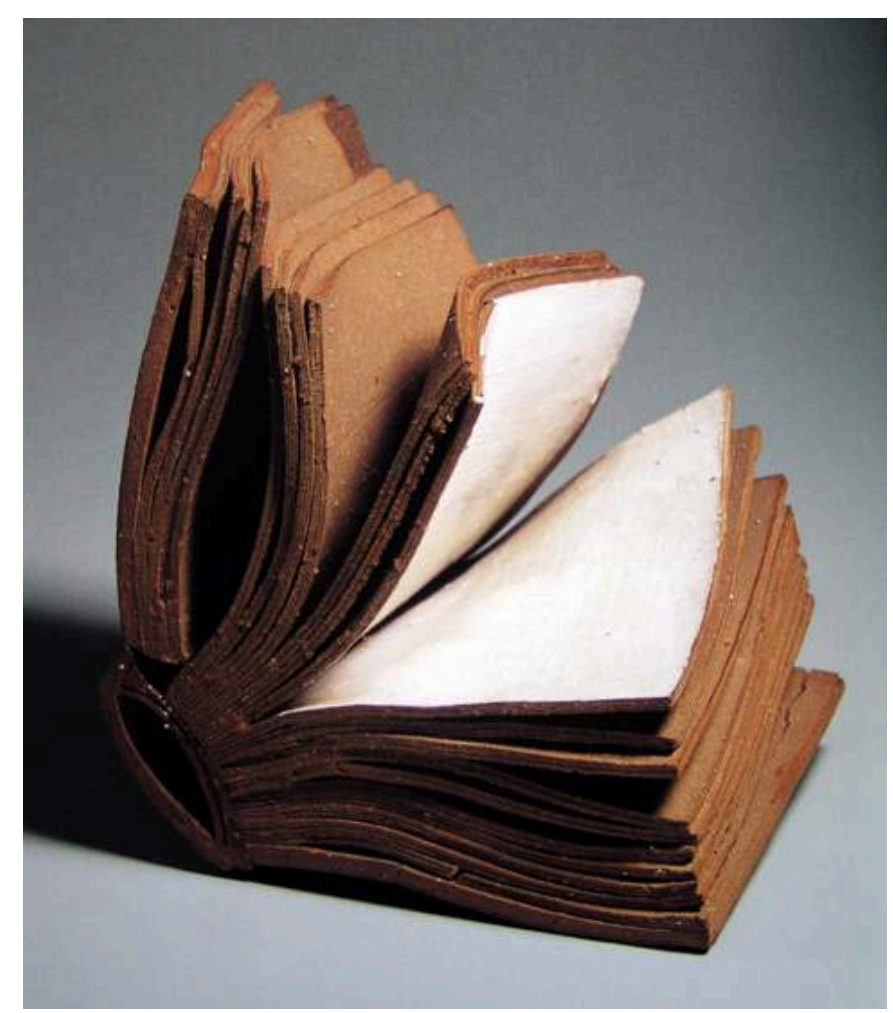

Yagi Kazuo, Ruffling Pages, 1972. Dans Yagi 2004, p. 164.

Cette tactique de mystification, qui consiste à suggérer la présence d'un élément inaccessible caché à l'intérieur d'une boîte, nous rappelle «À bruit secret » de Marcel Duchamp (1887-1968) (fig.47a), la pièce qui venait d'être recopiée par KIKUHATA Mokuma (1935-) en 1968-9 (fig.47b). La même tactique se poursuit encore dans la série des livres qui commence en 1972 (fig.48), mais ceci sur un ton expressément nihiliste : alors que le livre est sensé renfermer le savoir et préserver l'information, les céramiques imitant la forme du livre ne contiennent rien, à moins qu'elles ne cachent du vide en leur intérieur impénétrable. C'est donc le néant sémiotique qui est contenu 
dans la vacuité de la terre cuite. Anéantissant l'illusion de la connaissance accumulée, ces faux-livres illisibles, faits de kaolin, ironisent sur la destinée du contenant utilitaire subrepticement déguisé en oeuvre d'art. Marquée par le désintéressement selon la tradition kantienne, l'oeuvre d'art est supposée être dotée d'un message spirituel. Et pourtant, cette spiritualité, censée être condensée à l'intérieur d'une oeuvre d'art, y échappe, laissant un vide dépourvu de toute la signification.

Fig.49.

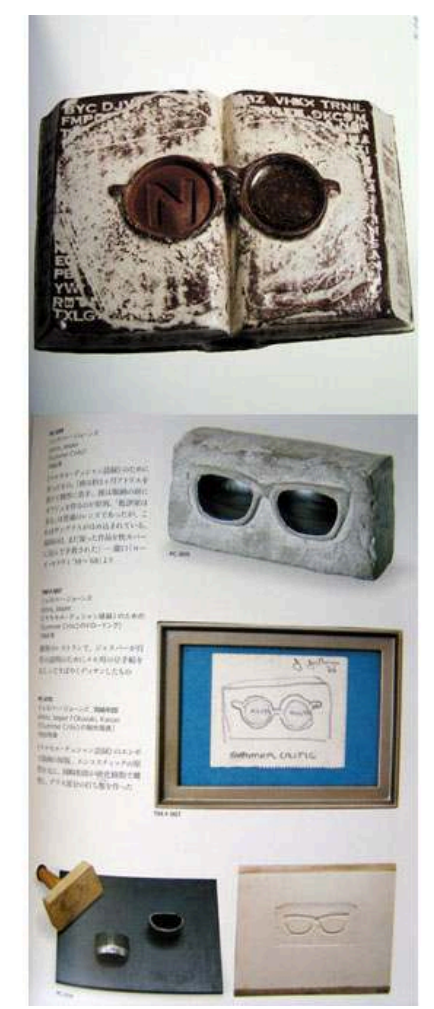

Yagi Kazuo, No, 1972. Dans Yagi 2004, p. 180; Jasper Jones, Summer Critic, 1966. Dans Drifting Objects of Dreams, The Collection of Shuzo Takiguchi, Setagaya Art Museum, p. 114.

Ce refus symbolique du statut anticipé à l'oeuvre d'art se déclare encore plus explicitement dans le «NO» (1970: 180) (fig.49a), une paire de lunettes incrustées sur un livre ouvert. Le céramiste japonais doit ce concept apparemment à Jasper JONES (1930- ) (fig.49b), qui, lui, a été inspiré par Marcel Duchamp. Le mimétisme du livre est poussé maintenant à l'absurdité absolue, car ce livre, ou plutôt ce semblant de livre, est réduit ici à une table plate, support sans signification sur laquelle se posent des lunettes. Mais ces lunettes, ou plus précisément, ces formes qui ne sont qu'un semblant de lunettes sont marquées par le «NO " et se refusent donc à servir de lentilles oculaires. De fait, on ne peut rien voir à travers la terre opaque et imperméable. Aussi, Yagi, tout en se référant à l'artiste américain, pousse-t-il encore plus loin la possibilité conceptuelle des lunettes dans sa négativité. Car il a ôté aux lunettes leur fonction première d'appareil optique. Submergés par la matière de la céramique, les lunettes inspirées par Jones deviennent littéralement aveugles. La cécité ainsi obtenue de ces fausses lunettes se superpose à l'illisibilité matérialisée du faux-livre, et dédouble le refus de la pénétrabilité sémantique. 


\section{L' Opera opérationnelle et la main retrouvée}

Fig.50.
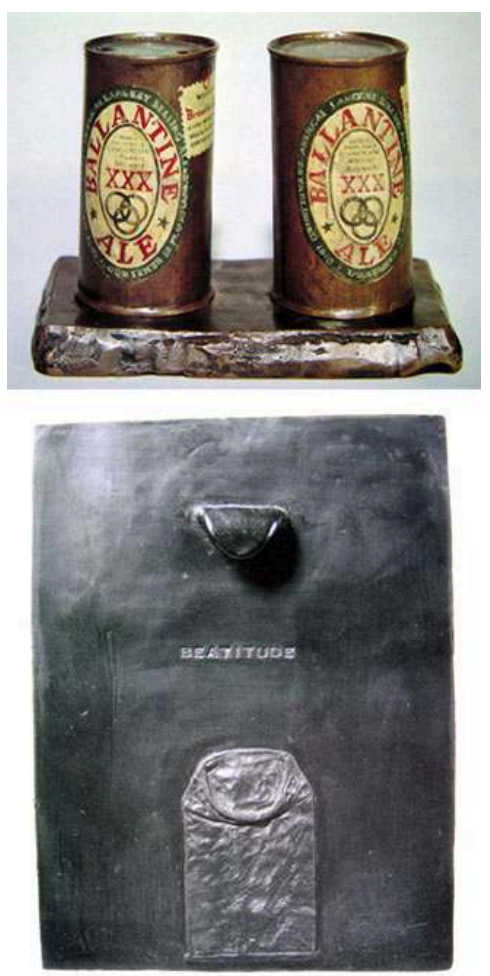

Jasper Jones, Painted Bronze, 1960. Dans Asahi No 74, vol. 8, p. 109; Yagi Kazuo, Bliss, Black Ware, 1975. Dans Yagi 2004, p. 207.

Fig.51.

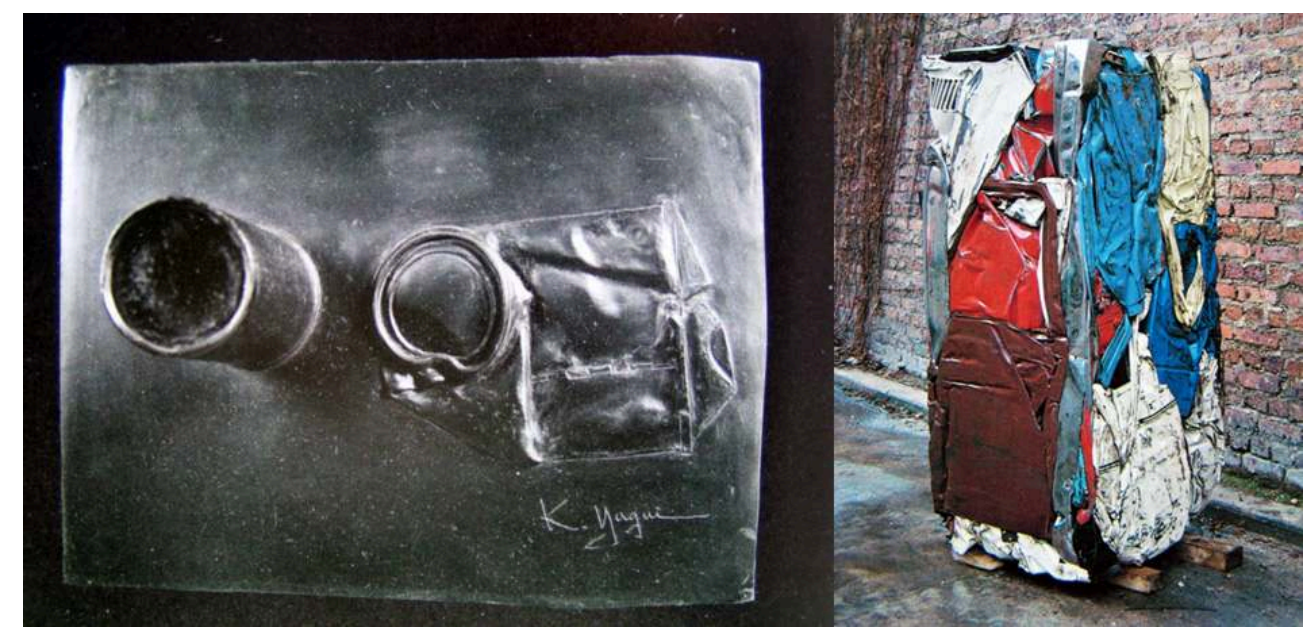

Yagi Kazuo, Plaque, Black Ware, 1975. Dans Yagi 2004, p. 208 ;César, Compression, 1960. Dans Asahi No 74 , vol. 8, p. 110.

38 Ici s'annonce une autre problématique, à savoir, l'oeuvre d'art anéantie et réduite à un support passif et dépourvu de signification : l'inversion logique entre l'oeuvre et son support sera développée dans la série des cannes. Ici encore, tout en se référant à 
Jasper Jones dont on connaît le «Bronze peint " (en 1960) (fig.50a), Yagi en détourne délibérément l'orientation. Dans le cas de la « Physionomie d'une canne » (1975: 206), un cylindre métallique noir, posé sur une table de la même couleur, commence à s'y fondre. Son identité est presque perdue dans « L'Exil » $(1974: 205)$ et finalement la série atteint le stade de «Béatitude » (1975 : 207) (fig.50b) où l'on ne voit plus que le résidu écrasé à plat de ce qui a été jadis la canne. Dans le cas du «Plat de faïence noire » (1975 : 208) (fig.51a), le céramiste met en scène par phases successives le processus de compression d'une canne opérée sur une table d'exécution. Tout se passe comme s'il imitait, en argile malléable, la compression exercée par un CÉSAR (1921-1998) à l'aide de marteau-pilon (fig.51b).

Fig.52.

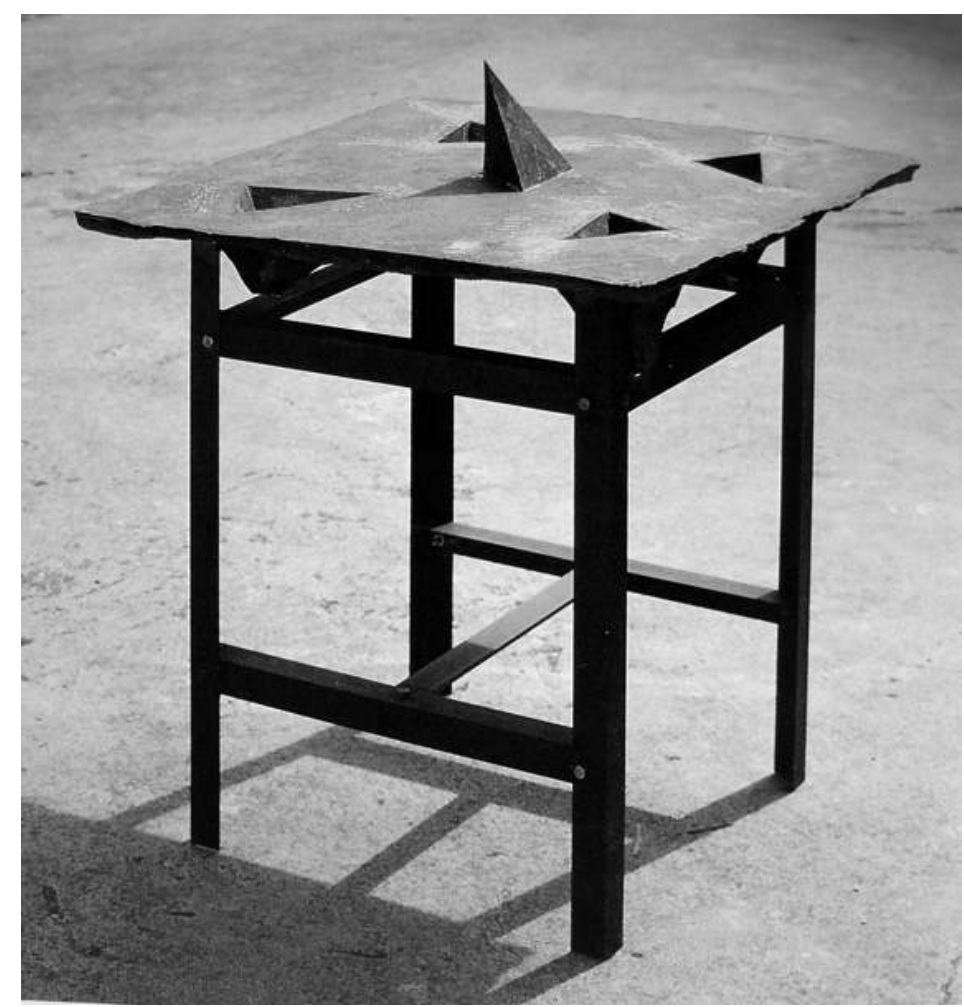

Koshimizu Susumu, Tetrahedron, 1974/1992. MINEMURA Toshiaki, OKADA Kiyoshi, KOSHIMIZU Susumu, Sculptor of Today, The Museum of Fine Arts, Gifu, p. 1.

C'est précisément vers la même époque que KOSHIMIZU Susumu (1944-) commence à s'intéresser à la «Table d'opération» (1974-) (fig.52). Il ne s'agit pas d'y faire une oeuvre d'art, et encore moins d'en faire une oeuvre d'art, mais au contraire de réfléchir sur la nature et le modus operandi d'un outil de travail, hors de l'oeuvre par définition et parergon par excellence. Au lieu de l'écarter et l'abandonner, comme d'habitude, après le parachèvement $d^{\prime}$ opus operatum, une fois qu'un travail est accompli, il fallait au contraire le récupérer dans son mode d'opération. 
Fig.53.

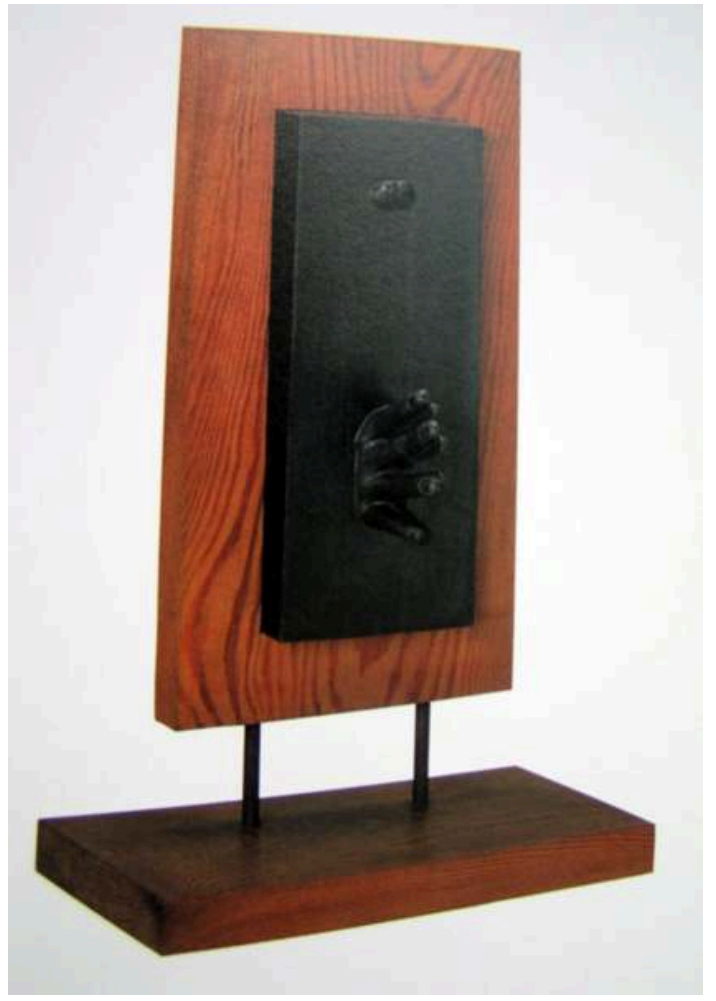

Yagi Kazuo, Leader, Black Ware, 1974. Dans Yagi 2004, p. 197.

40 L'attention portée à l'outil de travail au même titre qu'à l'oeuvre achevée, et l'importance accordée à leur interdépendance : ces deux facteurs seraient sans doute responsables de l'apparition des «Mains » dans la création de Yagi Kazuo à partir de 1974. Rétrospectivement parlant, la série de trous creusés dans le vase invita le céramiste à explorer l'au-delà de ceux-ci, et la table d'opération finit par absorber les oeuvres qui attendent d'être créées sur elle. D'un bout à l'autre, l'oeuvre en soi n'était que le prétexte et le résidu d'une problématique créatrice qui était en cause. A l'issue de ce processus, toutes les matières sont absorbées dans une table plate et noire, comme si tout était anéanti. De ce néant, représenté par le tableau tout noir, émergent vers nous, donc en sens inverse, les mains moulées et dédoublées de l'artiste, comme dans le "Führer» (1974: 197) (fig.53) avec les pouces écartés suggérant, selon le philosophe UMEHARA Takeshi (1926-), la solitude de ceux qui dirigent, ou bien dans le « Départ » (1974: 198), annonçant un retour à l'ici-bas. Revenant des pays invisibles cachés à l'intérieur insondable du fond noir, ces mains scrutent comme des tentacules le monde d'en deçà qui semble leur rester inconnu. 
Fig.54.

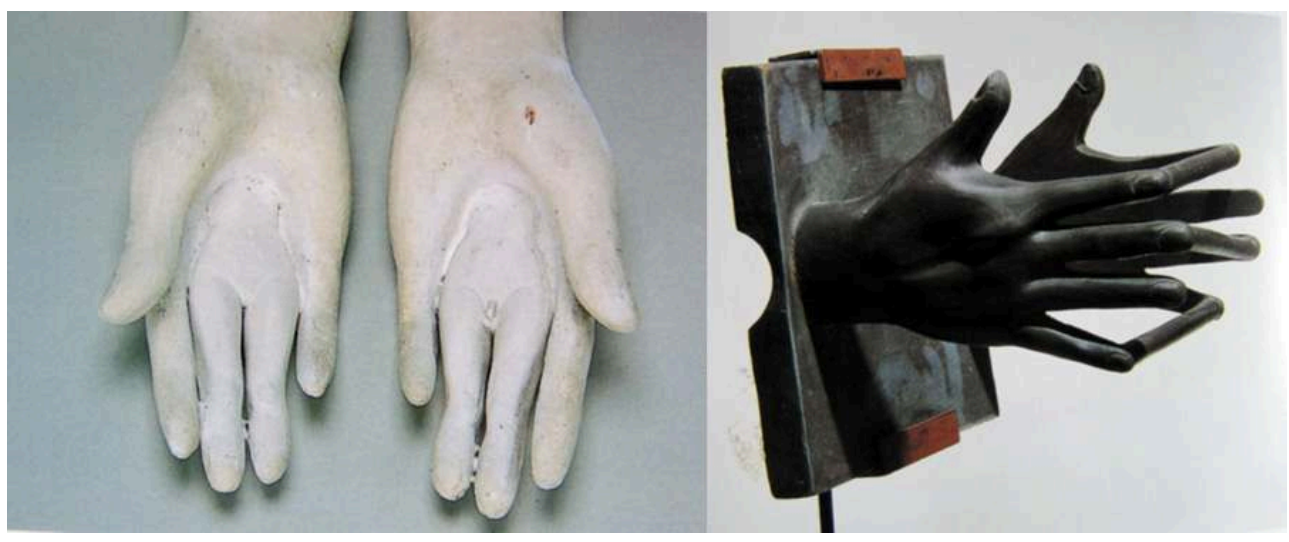

Horiuchi Masakazu, Androgynos (détail), 1969. Dans NAGATO Saki et passim Eds., HORIUCHI Masakazu, The Yomiuri Shinbun, , 2003, p. 53 ; Yagi Kazuo, Indication, 1974. Dans Yagi 2004, p. 203.

Fig. 55.

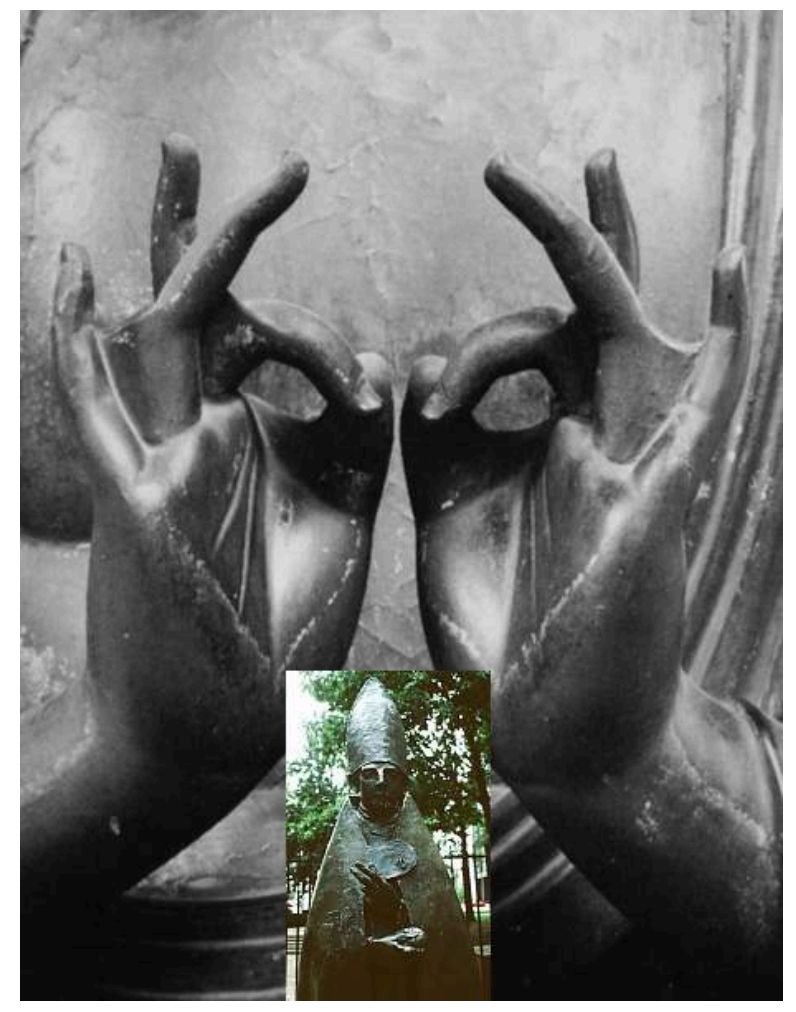

Amida Nyorai (Amitâbha), 1196. Raigô-ji Temple, Shiga Prefecture, Japan ; Giacomo Manzu, Cardinale, 1954. Columbus Museum of Art, Ohio, USA.

41 Ici encore, l'inspiration semble venir directement de son collègue, Horiuchi, qui avait crée une paire de mains nommées « Androgynes » (1969 : 53) (fig.54a), dont la paume dissimule secrètement un couple, un corps féminin et un masculin. Cependant, Yagi n'a pas cette fois-ci recours à l'insinuation délibérément sexuelle de Horiuchi, mais s'intéresse davantage à la fusion des mains droite et gauche, comme en témoignent la « Distance d'une adhérence » (1974:197) ou l'« Oeuvre» (1974:204) dans laquelle les médius d'une paire de mains se soudent, partageant le même ongle. Comme le montrent explicitement les titres, tels que la «Présentation» (1974:202) ou 
l'«Indication » (1974 : 203) (fig.54b), ces mains en paires, au lieu de se retirer dans le monde d'au-delà, s'étendent vers les spectateurs afin de leur faire signe en leur offrant ce qu'elles soutiennent entre les doigts. Parmi les précédents pertinents, on pourrait noter l'expressivité des mains sur laquelle travailla Giacomo MANZU (1908-1991) dans sa série de "Cardinale » (fig.55a). Yagi a dû être aussi familier avec les signes gestuels de l'iconographie bouddhique d'Amithaba qui tend ses mains pour sauver des âmes (fig. 55b). Ce n'est pas seulement sur la quête de l'éternité à sens unique, mais sur le retour au monde d'ici-bas qui suit l'éveil spirituel, que le bouddhisme du grand véhicule met l'accent. Reliant ainsi la sculpture occidentale contemporaine et la spiritualité orientale, Yagi montre aussi son itinéraire d'aller-retour dans la quête plastique. Et ce faisant, le dédoublement de ses propres mains (ici encore quelques oeuvres de Horiuchi servent de référence) marque clairement son insistance invariable sur le métier du potier : c'est maintenant un vase invisible que tiennent ses mains entre la «Distance » (1974 : 204) qui sépare les paumes droite et gauche.

\section{Cuisson et Refroidissement}

Fig. 56.

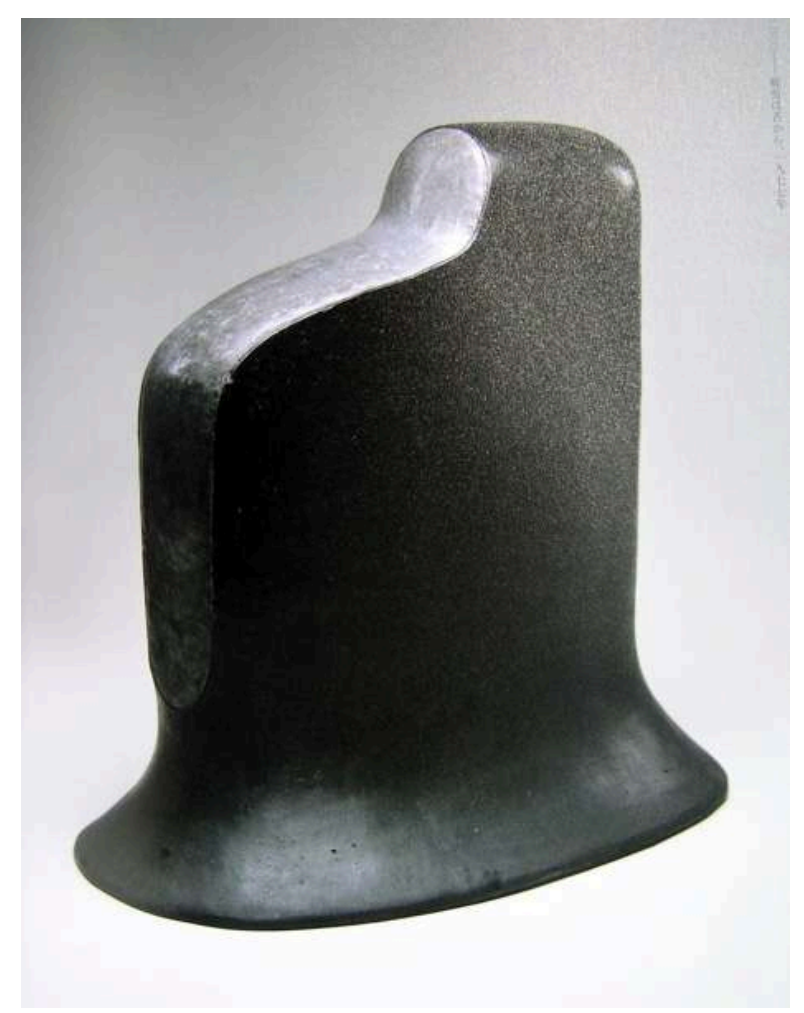

Yagi Kazuo, Fatigue Comes from the Tongue, Black Ware, 1977. Dans Yagi 2004, p. 233.

42 À la fin des années 70, Yagi change de direction et se concentre sur deux aspects spécifiques. D'une part il poursuit une recherche sur le sens tactile du ruissellement, aspect peu apprécié dans la tradition visuelle occidentale. Il réfléchit d'autre part sur la possibilité de composition en groupe, problématique qui restait encore peu explorée dans ses recherches précédentes. D'abord, un texte intitulé « L'École de Limpa vue par un potier» (en 1974) atteste son intérêt pour la fluidité du noir de l'encre de chine 
appliquée en ruissellement ('dripping'). Les pièces comme «La Forme se déshabillant petit à petit » (1979: 134), « La Lumière se glisse sur la joue » ou « La Fatigue commence par la langue » (1977 : 233) (fig.56) traduisent l'effet d'un écoulement lent d'un fluide terne et extrêmement visqueux, au moyen de l'application du plomb aplati sur la faïence noire. L'« Aspect d'une germination» (1977: 240) fort évocateur du linga hindou, symbole phallique de Siva, concrétise, pour sa part, un bourgeonnement graduel vers le haut. C'est surtout le mouvement figé qui est recherché tout au long de cette poursuite de la liquidité.

Fig. 57.

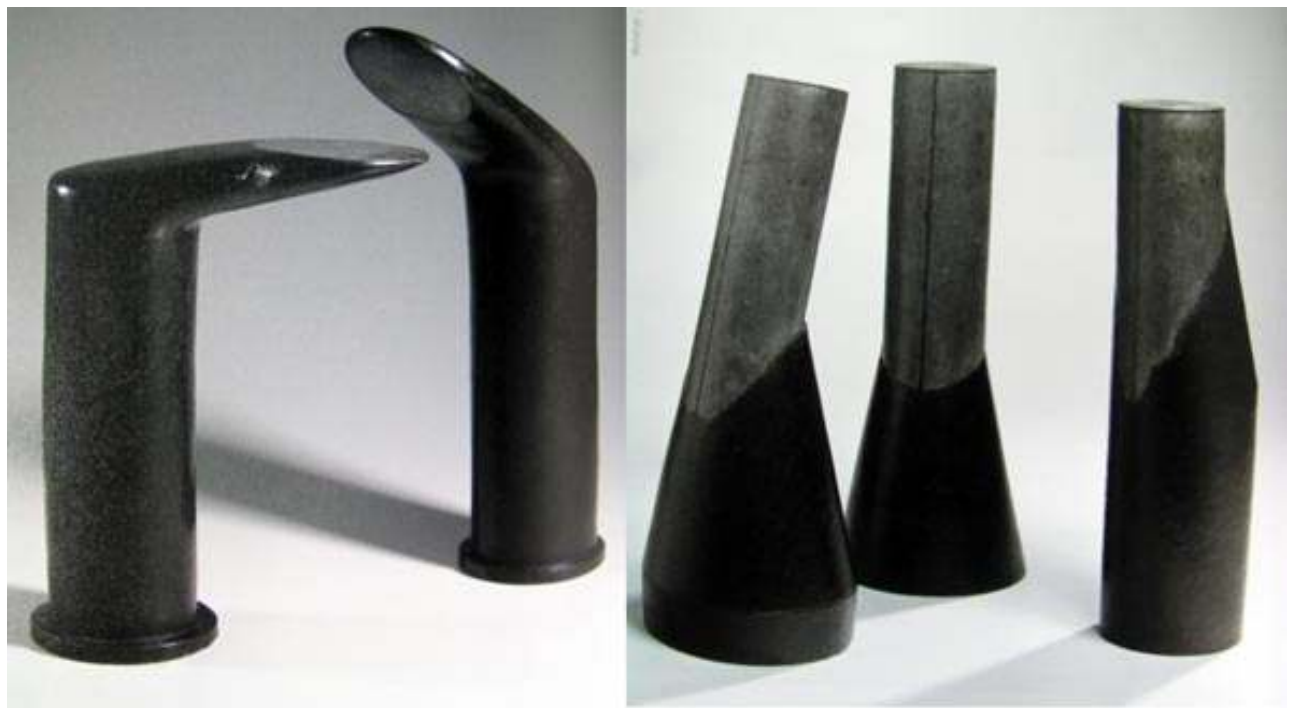

Yagi Kazuo, Form of Greeting, Black Ware, 1977. Dans Yagi 2004, p. 237 ;

Yagi Kazuo, Sanshi Sansei, 1977. Dans Yagi 2004, p. 242.

La présentation des objets en groupe peut être par ailleurs considérée comme un prolongement de sa série des mains en paires. Le «Salut mis en forme est...» (1977 : 237) (fig.57a) peut être vu comme l'abstraction d'une paire de mains posées à proximité l'une de l'autre. «Ce que comprendre veut dire » $(1977: 239)$ montre plus explicitement encore la négociation des deux colonnes qui manquent de se toucher l'une l'autre. «Trois pensées, trois réflexions» (1977: 242) (fig.57b), titre tiré d'un dicton chinois, montre trois cylindres de formes irrégulières qui se penchent vers le centre de leur configuration, mettant en relief ce centre vide. Mais on s'aperçoit vite que c'est la vacuité centrale qui soutient l'indépendance mutuelle de ses trois piliers tout en entretenant leur dialogue à trois. Une autre variante de la dialectique entre le vide du milieu et la substance qui l'entoure. 
Fig. 58.

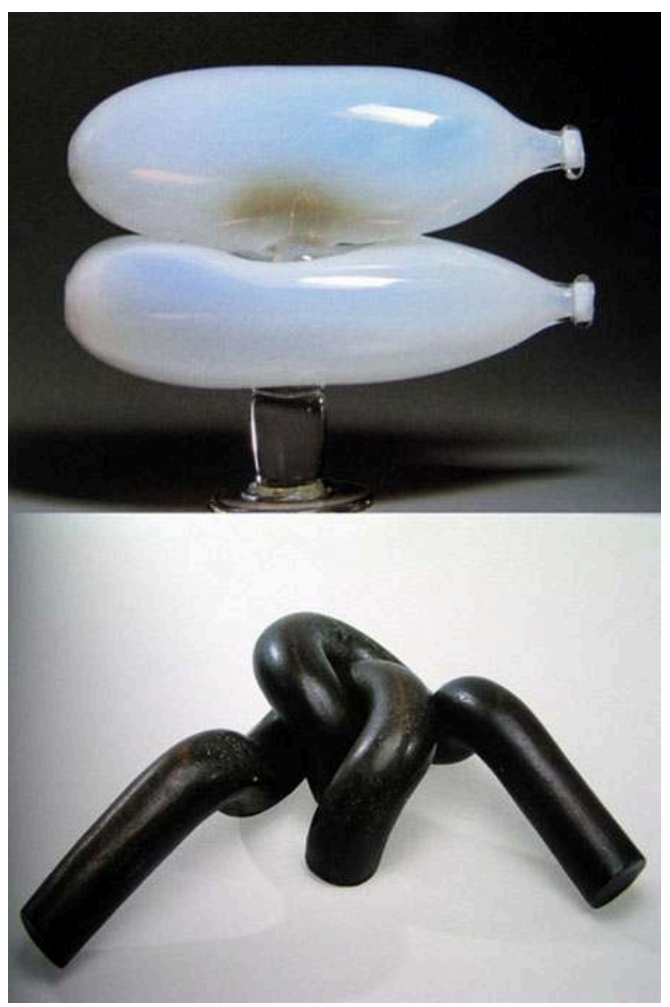

Yagi Kazuo, Glass, 1967. Dans Yagi 2004, p. 106; Yagi Kazuo, Puzzle Ring, bronze, 1969. Dans Yagi 2004, p. 139

La combinaison des formes suscite facilement une image sexuelle. L'«appareil empoisonnant A » $(1977: 251)$ consiste en une forme étendant l'injecteur et d'une autre voisinant qui le reçoit, allusion indéniable au coït. Auparavant, Yagi avait superposé deux bouteilles de verre opaque («L'oeuvre en verre " 1969: 105) (fig.58a) qui se pénètrent par une paire d'appareils femelle et mâle comme deux poissons en copulation, ou les "anneaux magiques" (1969: 139) (fig.58b) symétriques, qui se croisent comme en un embrassement amoureux. L'allusion par trop voyante au rapport sexuel des premiers essais prend de plus en plus une forme géographique et décharnée, au fur et à mesure que la peau des objets se débarrasse graduellement de la sensation organique d'épiderme. 
Fig. 59.

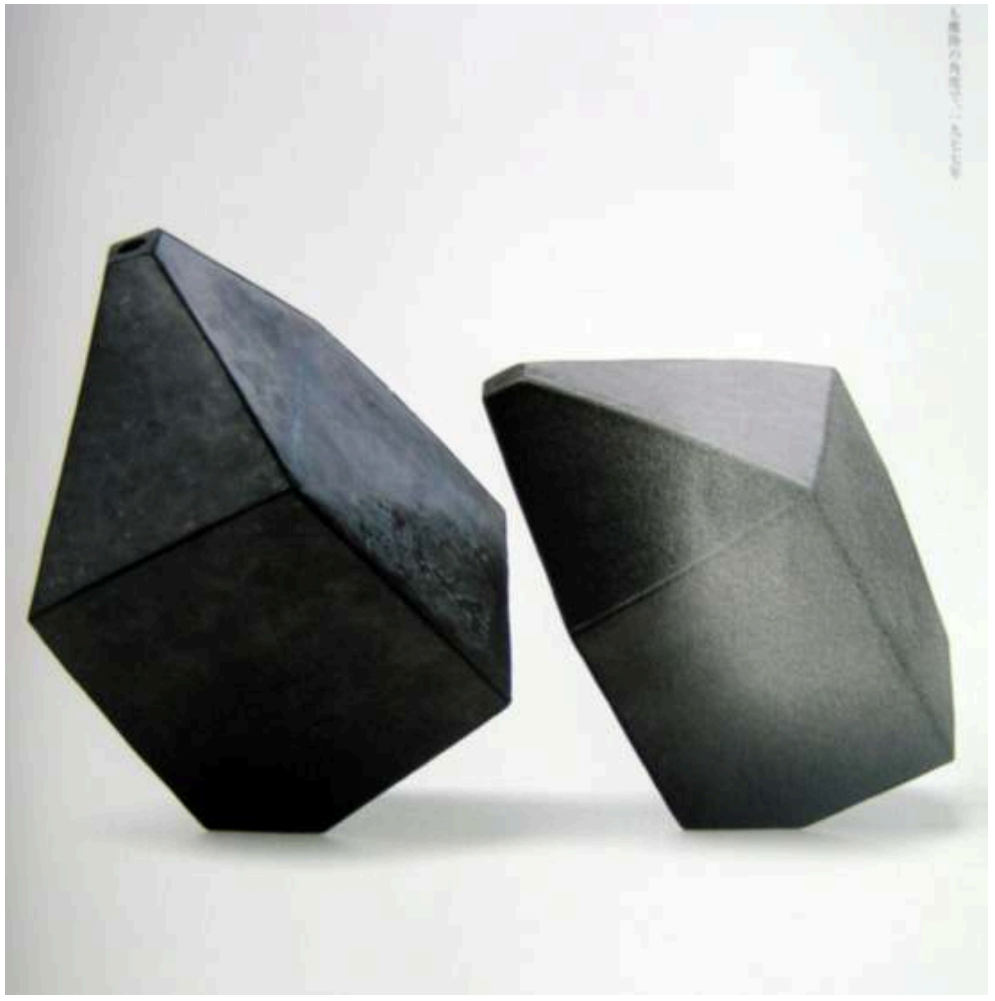

Yagi Kazuo, Keeping an Angle Ready to Leave Black Ware, 1977. Dans Yagi 2004, p. 256.

À quoi s'ajoute un troisième facteur: c'est l'intérêt porté par le céramiste à l'objet penché qui est mis en jeu. Le moment dynamique de l'inclinaison se manifeste dans des pièces telles que « Le Pigeon qui prend un bain du soleil » $(1978: 273)$, la « Hache à main en céramique » $(1978: 274)$, ou la « Direction du vent » $(1978: 280)$. Ces trois facteurs, à savoir (i) la surface ternie de plomb qui coule, (ii) les objets assemblés en groupe, et (iii) le dynamisme de l'inclinaison se combinent finalement dans le groupe nommé «Prenant toujours l'angle prêt au décollage » (1977: 256) (fig.59). Les polyèdres de forme irrégulière font penser, dit-on, au cercueil en pierre, la couleur noire, à la mort, et le " décollage » dans le titre, au détachement de l'esprit vers le monde de l'au-delà, c'est-à-dire la séparation de l'existence terrestre. S'agissait-il de la préparation à un prochain décollage vers l'avenir, ou au contraire le chant du cygne annonçant l'adieux?

L'année suivante, en 1978, Yagi, à l'âge de 60 ans, qui marque le retour au commencement dans le calendrier chinois, expose, à côté de ses oeuvres anciennes, six oeuvres nouvelles ayant les mêmes titres, déjà historiques, à savoir la «Promenade de M. Samsa », la " Mémoire d'un nuage ", la « Tortue aveugle », etc. Ce n'est que quelques mois plus tard, le 28 février 1979, que sa mort survient subitement suite à une crise cardiaque, nous laissant s'imaginer ce qu'aurait pu être, avec ce retour, sa deuxième vie créatrice. 
Fig. 60.

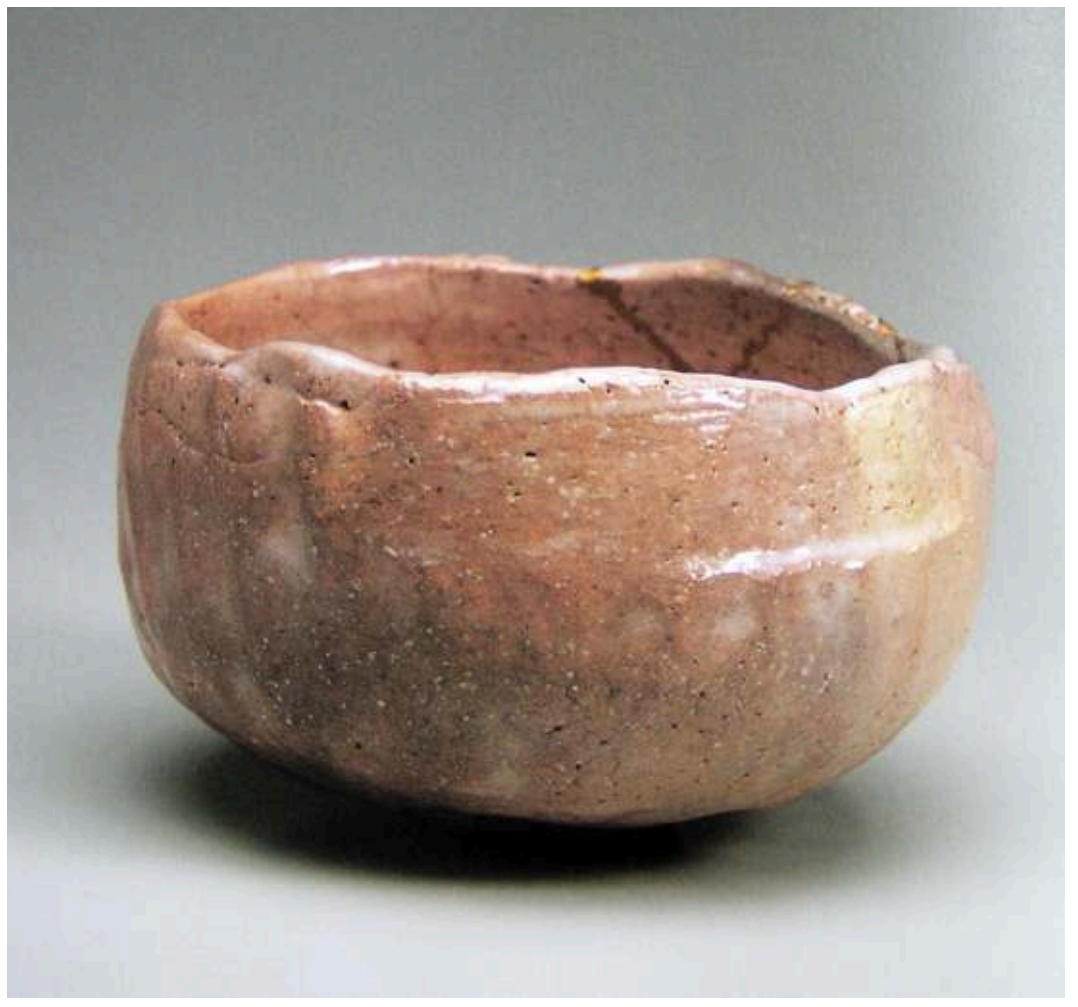

Yagi Kazuo, Tea Bowl, 'Suetsumuhana' Raku Ware, 1977. Dans Yagi 2004, p. 224.

Fig. 61.

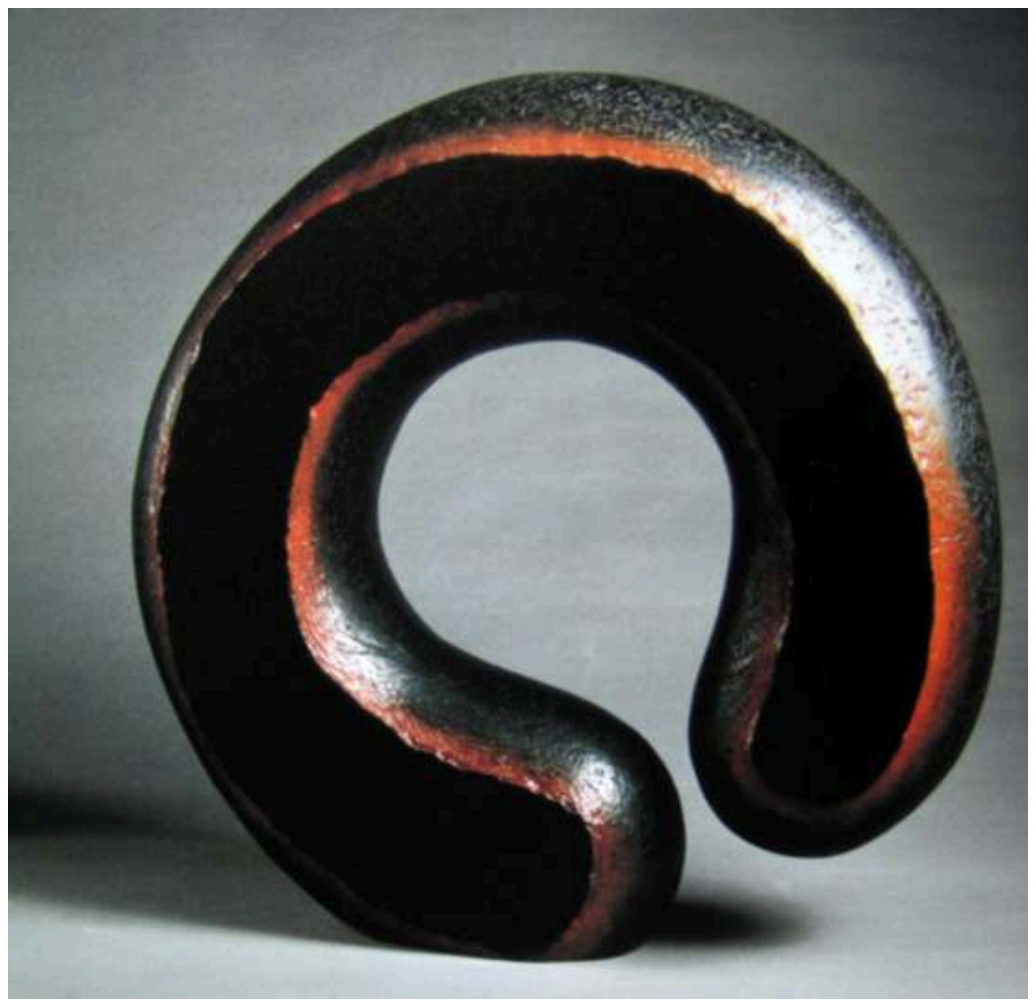

Yagi Kazuo, Circle, 1978. Dans Yagi 2004, p. 271. 
Un texte qu'il a rédigé en 1969, intitulé « Refroidissement » (pp. 114-5), est en ce sens révélateur. Yagi y explique comment le noir caractéristique de la poterie Raku apparaît (fig.60). C'est au moment où l'on fait sortir le bol incandescent du four de cuisson pour l'immerger dans l'eau que la couleur change tout d'un coup grâce au refroidissement brutal. «Suivant les conditions, dit Yagi, la physionomie du bol change brusquement, déterminant la vie ou la mort pour l'éternité ». La leçon qu'il y a puisée, c'était que «le refroidissement fait bien partie de la cuisson ». Yagi, qui venait de mener une vie en cuisson constante a eu l'impression alors de se faire réprimander par le bol. Le noir qu'il a cherché à la fin de sa vie est-il l'expression de cette quête du refroidissement (fig.61)?

Fig. 62.

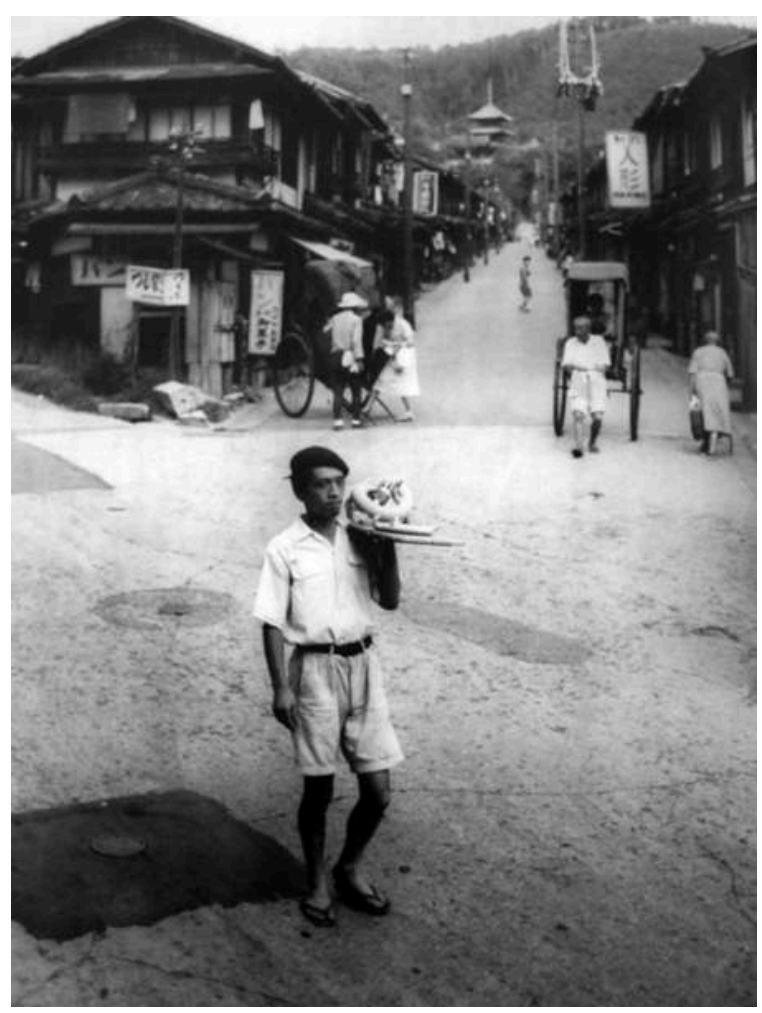

Photo de Yagi Kazuo portant sur l'épaule The Walk of Mr. Samsa. Tiré du Journal Mainichi, 5 sep. 1954, dans Yagi 2004, p. 25.

Quelques années avant sa mort, Yagi effectua un voyage en Iran. Il laisse un poème racontant son impression de la route de Karachi où il remarque «une lumière semblable à la vieille plaie $»^{6}$. Comment Yagi aurait-il pu regarder de près le lustre inquiétant des cicatrices, traces ineffaçables des blessures qu'il n'a cessé de subir au cours de sa création? Création comme blessure qui s'enfonce aux confins du domaine de la sculpture et du territoire de la poterie. Sonder le terrain en profondeur de sa création pour y détecter la lésion mentale et physique et ceci en fonction de son " goût sadique ou masochiste», comme il le disait («Le Patient de Dali» 1964 : p. 47). Telle sera la tâche à accomplir dans une future recherche sur la vie d'un céramiste d'avantgarde. Le terrain défriché et le chemin tracé par Yagi Kazuo sont jonchés d'images d'une nouveauté inattendue et surprenante. Ses inventions diverses sont autant de 
plaies qu'a laissées la rencontre du Japon et de l'Europe dans la poursuite de la modernité artistique à l'échelle du monde (fig.62)7 .

\section{NOTES}

1. Le texte en français est une traduction libre de mon texte rédigé en japonais, publié comme «Furukizu ni yadoru Hikari » (La Lumière qui demeure dans la vieille plaie), dans le mensuel Aida, $n^{\circ}$ 109, 20 janvier 2005. Une autre version abrégée est lue dans le colloque tenu en Alsace 8-10 Décembre, 2005 sur le thème de «La rencontre du Japon et de l'Europe : images d'une découverte ». Un texte légèrement différent est publié dans le Japan Review, International Research Center for Japanese Studies $\mathrm{N}^{\circ} 18$ (2007). Nous présentons ici une version modifiée pour convenir à la publication dans un périodique scientifique en langue française.

2. Les textes de Yagi, sauf indication contraire, sont tous tirés et cités de Yagi Kazuo, Objet Yaki (Objet cuit), Yagi Akira ed., Kôdansha Bungei Bunko, 1999. Les numéros entre parenthèses indiquent l'année de fabrication de l'oeuvre et la pagination.

3. Les titres et numéros de référence (entre guillemets et entre parenthèses) des oeuvres de Yagi Kazuo renvoient au catalogue d'exposition, Yagi Kazuo, A Retrospective, The Kyoto National Museum of Modern Art, Kyoto, 2004. De même dans les légendes, l'abréviation utilisée pour citer cet ouvrage est : Yagi 2004.

4. Isabelle Charrier, "Yagi Kazuo's art beyond tradition and modernity ", communication faite lors d'un colloque international sur "Traditional Japanese Arts and Crafts in the 21st Century » que j'ai organisé à l'International Research Center for Japanese Studies, du 8 au 12 novembre 2005. Les actes de ce colloque vont paraître prochainement. L'appellation française de «céramiste-artiste » nous rappelle rétrospectivement que l'art céramique ne faisait pas partie intégrante du système académique des Beaux-Arts (même au moment de l'Exposition universelle de Paris en 1900). La notion de «sculpture » est elle, devenue caduque après l'effondrement du système des Beaux-Arts. Au Japon, comme dans la plupart des aires culturelles non occidentales, les arts se développèrent en dehors de la hiérarchie de classification à l'occidentale. Et l'art céramique tôgei) avait un statut social à part entière (et parfois auto-suffisant) sans être repoussé dans la catégorie inférieure des " arts appliqués ». Aussi, la question de savoir si Yagi Kazuo est un sculpteur ou un artiste céramiste ne se pose-t-elle pas au Japon, aux embarras des classificateurs occidentaux. Cette insouciance japonaise me paraît avoir contribué au peu d'attention que l'on a porté sur le cas Yagi Kazuo (parmi bien d'autres) dans le contexte de l'art dit contemporain en Occident. Le manque d'équivalent du ' tôgei' dans le bagage théorique et classificateur de l'Occident constitue ainsi structurellement un point aveugle. Ni «maitre fabricant des arts appliqués ", ni « sculpteur moderne " Yagi, malgré lui, indique la fissure entre les deux taxinomies hétérogènes et incompatibles de l'ordre des choses qui sépare l'Occident du Japon ; telle est l'autre dimension d'une «blessure symbolique » que le présent article essaie de dévoiler.

5. L'auto-appellation de ' chawan-ya ' est encore une fois intentionnellement péjorative. Etymologiquement le ' chawan ' veut dire 'bol à thé', et Yagi en a beaucoup fabriqué notamment à la fin de sa vie, en partie parce qu'il a dû satisfaire le besoin du marché domestique pressant. Pourtant le terme ' chawan ' ne s'applique pas aux pièces dont on se sert dans la cérémonie du thé. Bien que le célèbre «Ido-jawan » soit l'appellation d'une pièce historique distinguée, le 
terme de ' jawan ', évoque pourtant ici son origine modeste. Dans le langage courant et quotidien, ' chawan ' veut dire 'bol à riz' d'usage ordinaire. En se référant comme ' chawan-ya ', Yagi s'identifie avec auto-dérision à un fabricant d'outils médiocres et sans distinction.

6. Le poème de Yagi est cité dans Shiba Ryôtarô, Bikô no nakano Uchû L'Univers dans la pénombre), Chûkô bunko, 1991, p.203.

7. Je tiens à remercier M. Matthias Hayek et Mme Emmanuelle Simon pour la relecture du texte ci-dessus. Mes remerciements vont aussi à Eric Janicot, et à Christophe Marquet, qui m'ont apporté des précisions précieuses. En dernier lieu, je tiens aussi à remercier Noémie Hosoi pour son apport éditorial.

\section{RÉSUMÉS}

Un des pionniers de la poterie avant-gardiste au Japon, Yagi Kazuo (1918-1979) traça un chemin sans précédent en se détournant de la tradition de la poterie nippone. Si Yagi ne paraît pas encore jouir d'une légitimité d'artiste au sens occidental du terme, nous voudrions jeter une nouvelle lumière sur son activité de créateur. Nous comparerons son parcours avec celui de sculpteurs et de peintres contemporains, tant Occidentaux qu'Orientaux, afin de faire ressortir les spécificités de son œuvre. S'opposant à la fois à la notion de l'art et à celle des "arts et métiers ", sa pensée plastique scrute et synthétise la marge qui sépare Europe et Japon. Notre but sera de sonder le secret de sa création qui se traduirait par la cicatrice due à la confrontation entre la vocation d'un art conceptuel et autonome à venir, et la conception passéiste d'un récipient utilitaire.

\section{INDEX}

Index géographique : Japon

Mots-clés : avant-garde, œuvre d'art, poterie, sculpture, tradition

Thèmes : arts plastiques, céramique

Index chronologique : XXe siècle

\section{AUTEUR}

\section{SHIGEMI INAGA}

Shigemi Inaga est professeur au Centre de recherche internationale sur les études japonaises et à l'Ecole doctorale des études avancées de Kyoto. 